\title{
Synthesis of and initial biological evaluation of carborane-containing prostate specific membrane antigen inhibitors for therapy of prostate cancer using boron neutron capture therapy
}

Sinan Wang, Charles Blaha, Raquel Santos, Tony Huynh, Thomas R. Hayes, Denis R. Beckford-Vera, Joseph E. Blecha, Andrew S. Hong, Miko Fogarty, Thomas A. Hope, David R. Raleigh, David M. Wilson, Michael J. Evans, Henry F. VanBrocklin, Tomoko Ozawa, Robert R. Flavell

Table of contents

1. General S2

2. Procedures for the synthesis of compound 1a S2

3. Procedures for the synthesis of compound $1 \mathrm{~b}$ S2

4. Procedures for the synthesis of compound 1c S3

5. Procedures for the synthesis of compound 1d S4

6. Procedures for the synthesis of compound 1e S5

7. Procedures for the synthesis of compound if S7

8. Procedures for the synthesis of compound $1 \mathrm{~g}$ S8

9. Procedures for the synthesis of compound $1 \mathrm{~h}$ S9

10. Table S1. $\mathrm{IC}_{50}$ of compounds $1 \mathrm{a}, 1 \mathrm{~d}$ and $1 \mathrm{f}$ on $22 \mathrm{Rv} 1$ and LNCap

11. Table S2. Serum protein binding

12. Table S3. Cell toxicity test

13. Figure S1. Cell toxicity analysis for compound 1a, $1 \mathrm{~d}$ and $1 \mathrm{f}$

14. Table S4. Acute toxicity test

15. Table S5. Region of interest analysis of \% ID/cc on tumor for the micro PET/CT images

16. Table S6. Region of interest analysis of SUV on tumor for the micro PET/CT images

17. Table S7. ${ }^{68}$ Ga-PSMA-11 biodistribution analysis data

18. Table S8. In vivo boron biodistribution analysis data ( $\mu \mathrm{g} / \mathrm{gram}$ tissue)

19. Table S9. In vivo boron biodistribution analysis data (ID\%/gram tissue)

20. Figure S2. In vivo boron biodistribution analysis data (ID\%/gram tissue)

21. References

22. ${ }^{1} \mathrm{H}$ and ${ }^{13} \mathrm{C}$ NMR spectra data 


\section{General}

Unless otherwise noted, all reagents were obtained commercially and used without further purification. Unless otherwise specified, all other reagents were purchased from Sigma Aldrich or TCI and used without further purification. ${ }^{1} \mathrm{H}$ NMR spectra were recorded at $400 \mathrm{MHz},{ }^{13} \mathrm{C}$ NMR spectra were recorded at $100 \mathrm{MHz}$. Chemical shifts were reported in parts per million (ppm, $\delta$ ). Proton coupling patterns are described as singlet $(\mathrm{s})$, doublet $(\mathrm{d})$, triplet $(\mathrm{t})$, quartet $(\mathrm{q})$, multiplet $(\mathrm{m})$, and broad (br).

\section{Procedures for the synthesis of compound 1 a.}

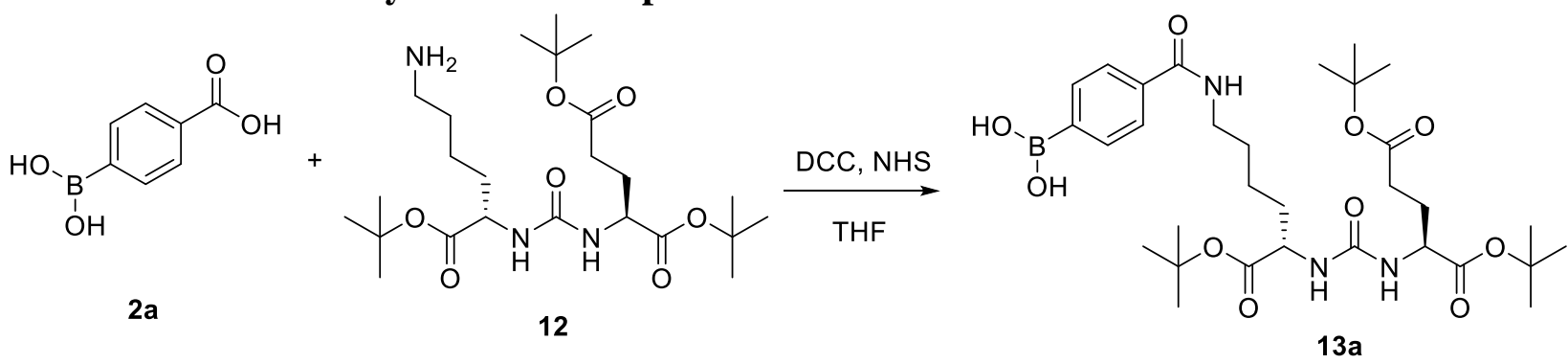

(4-((6-(tert-Butoxy)-5-(3-((S)-1,5-di-tert-butoxy-1,5-dioxopentan-2-yl)ureido)-6-oxohexyl)carbamoyl) phenyl)boronic acid (13a).

To a solution of compound 2a (332 mg, $2 \mathrm{mmol}$ ) in anhydrous THF was added DCC (618 $\mathrm{mg}, 3 \mathrm{mmol}$ ) and NHS ( $345 \mathrm{mg}, 3 \mathrm{mmol})$. The reaction was stirred at room temperature overnight. The mixture was filtered to remove the insoluble material and compound $\mathbf{1 2}(974 \mathrm{mg}, 2 \mathrm{mmol})$ was added to the solution. The reaction was stirred at room temperature overnight. The solvent was removed under reduced pressure. The mixture was purified by a flash column chromatography ( $\mathrm{DCM} / \mathrm{MeOH}=20: 1$ to 10:1) to afford compound 13a as a white solid (914 mg, $72 \%$ yield). ${ }^{1} \mathrm{H}$ NMR $\left(400 \mathrm{MHz}, \mathrm{CD}_{3} \mathrm{OD}\right): \delta 7.84(\mathrm{~d}, 2 \mathrm{H}$, $J=8.4 \mathrm{~Hz}), 7.78(\mathrm{~d}, 2 \mathrm{H}, J=8.0 \mathrm{~Hz}), 6.31-6.27(\mathrm{~m}, 2 \mathrm{H}), 4.06-3.97(\mathrm{~m}, 2 \mathrm{H}), 3.26-3.23(\mathrm{~m}, 2 \mathrm{H}), 2.26-$ $2.19(\mathrm{~m}, 2 \mathrm{H}), 1.69-1.64(\mathrm{~m}, 2 \mathrm{H}), 1.55-1.52(\mathrm{~m}, 4 \mathrm{H}), 1.40-1.37(\mathrm{~m}, 27 \mathrm{H}), 1.33-1.31(\mathrm{~m}, 2 \mathrm{H}) .{ }^{13} \mathrm{C} \mathrm{NMR}$ (100 MHz, CD $\left.\mathrm{CD}_{3} \mathrm{OD}\right): \delta 172.70,172.34,171.88,166.65,157.56,136.36,134.32,129.19,126.46,81.05$, $80.74,80.20,53.52,52.61,39.76,39.55,32.29,31.34,29.27,28.19,28.09,26.02,23.03$. HRMS (ESI) $\mathrm{m} / \mathrm{z}$ calcd for $\mathrm{C}_{31} \mathrm{H}_{51} \mathrm{BN}_{3} \mathrm{O}_{10}(\mathrm{M}+\mathrm{H})^{+}$636.3662, found 636.3679 .<smiles>CC(C)(C)OC(=O)CCC(NC(=O)N[C@@H](CCCCNC(=O)c1ccc(B(O)O)cc1)C(=O)OC(C)(C)C)C(=O)OC(C)(C)C</smiles>

((5-(4-Boronobenzamido)-1-carboxypentyl)carbamoyl)- $L$-glutamic acid (1a)

To a solution of compound 13a $(635 \mathrm{mg}, 1.0 \mathrm{mmol})$ in $3 \mathrm{~mL}$ DCM was added $3 \mathrm{~mL}$ TFA, the reaction mixture was stirred at room temperature for 16 hours. The solvent was removed under reduced pressure. The residue was dissolved in $\mathrm{H}_{2} \mathrm{O}$ and evaporated again to remove the remaining TFA. The residue was dissolved in $\mathrm{CHCl}_{3}$ and evaporated until white solid formed (467 mg, 100\% yield). ${ }^{1} \mathrm{H}$ NMR $(400 \mathrm{MHz}$, $\left.\mathrm{CD}_{3} \mathrm{OD}\right): \delta 8.45(\mathrm{~s}, 1 \mathrm{H}), 7.85(\mathrm{~d}, 2 \mathrm{H}, J=8.0 \mathrm{~Hz}), 7.79(\mathrm{~d}, 2 \mathrm{H}, J=8.4 \mathrm{~Hz}), 6.35-6.31(\mathrm{~m}, 2 \mathrm{H}), 4.12-4.07$ $(\mathrm{m}, 2 \mathrm{H}), 3.27-3.22(\mathrm{~m}, 2 \mathrm{H}), 2.28-2.24(\mathrm{~m}, 2 \mathrm{H}), 1.96-1.91(\mathrm{~m}, 1 \mathrm{H}), 1.76-1.72(\mathrm{~m}, 2 \mathrm{H}), 1.68-1.49(\mathrm{~m}, 3 \mathrm{H})$, 1.39-1.33 (m, 2H). ${ }^{13} \mathrm{C}$ NMR (100 MHz, $\left.\mathrm{CD}_{3} \mathrm{OD}\right): \delta 175.00,174.64,174.19,166.71,157.77,136.39$, 134.34, 129.18, 126.48, 52.77, 52.11, 39.26, 32.27, 30.35, 29.31, 26.00, 23.16. HRMS (ESI) m/z calcd for $\mathrm{C}_{19} \mathrm{H}_{25} \mathrm{BN}_{3} \mathrm{O}_{10}(\mathrm{M}-\mathrm{H})^{-} 466.1638$, found 466.1621 .

\section{Procedures for the synthesis of compound $1 b$.}


<smiles>CC(C)(C)OC(=O)CC[C@H](NC(=O)N[C@@H](CCCCNC(=O)c1ccc(B2OC(C)(C)C(C)(C)O2)cc1)C(=O)OC(C)(C)C)C(=O)OC(C)(C)C</smiles>

Di-tert-butyl ((1-(tert-butoxy)-1-oxo-6-(4-(4,4,5,5-tetramethyl-1,3,2-dioxaborolan-2-yl)benzamido) hexan-2-yl)carbamoyl)-L-glutamate (13b).

The title compound was prepared from $\mathbf{2 b}$ and compound 12, using a similar method described for preparing compound 13a. It was purified by a flash column chromatography (hexane/ethyl acetate $=4: 1$ to $1: 1$ ) to afford compound $\mathbf{1 3 b}$ as a white solid in $58 \%$ yield. ${ }^{1} \mathrm{H} \mathrm{NMR}\left(400 \mathrm{MHz}, \mathrm{CDCl}_{3}\right): \delta 7.87$ (d, $2 \mathrm{H}, J=8.0 \mathrm{~Hz}), 7.82(\mathrm{~d}, 2 \mathrm{H}, J=8.4 \mathrm{~Hz}), 6.69(\mathrm{~s}, 1 \mathrm{H}), 5.25-5.21(\mathrm{~m}, 2 \mathrm{H}), 4.36-4.28(\mathrm{~m}, 2 \mathrm{H}), 3.48-3.45$ $(\mathrm{m}, 2 \mathrm{H}), 2.35-2.29(\mathrm{~m}, 2 \mathrm{H}), 1.88-1.82(\mathrm{~m}, 2 \mathrm{H}), 1.69-1.63(\mathrm{~m}, 6 \mathrm{H}), 1.47-1.45(\mathrm{~m}, 27 \mathrm{H}), 1.37(\mathrm{~s}, 9 \mathrm{H})$, $1.26(\mathrm{~s}, 3 \mathrm{H}) .{ }^{13} \mathrm{C}$ NMR $\left(100 \mathrm{MHz}, \mathrm{CDCl}_{3}\right): \delta 173.06,172.50,172.24,167.77,157.35,136.87,134.70$, $129.41,126.38,83.98,82.15,81.50,80.47,53.39,52.91,39.86,32.52,31.57,28.91,28.04,27.97,27.92$, 24.86, 24.83, 24.81, 22.93. HRMS (ESI) $\mathrm{m} / \mathrm{z}$ calcd for $\mathrm{C}_{37} \mathrm{H}_{61} \mathrm{BN}_{3} \mathrm{O}_{10}(\mathrm{M}+\mathrm{H})^{+}$718.4445, found 718.4451.<smiles>CC1(C)OB(c2ccc(C(=O)NCCCC[C@H](NC(=O)N[C@@H](CCC(=O)O)C(=O)O)C(=O)O)cc2)OC1(C)C</smiles>

((1-Carboxy-5-(4-(4,4,5,5-tetramethyl-1,3,2-dioxaborolan-2-yl)benzamido)pentyl)carbamoyl)- $L$ glutamic acid (1b).

The title compound was prepared from $\mathbf{1 3 b}$, using a similar method described for preparing compound 1a, to generate $\mathbf{1 b}$ as a white solid in $100 \%$ yield. ${ }^{1} \mathrm{H}$ NMR $\left(400 \mathrm{MHz}, \mathrm{CD}_{3} \mathrm{OD}\right): \delta 8.54-8.51(\mathrm{~m}, 1 \mathrm{H})$, $7.84(\mathrm{~d}, 2 \mathrm{H}, J=8.4 \mathrm{~Hz}), 7.74(\mathrm{~d}, 2 \mathrm{H}, J=8.0 \mathrm{~Hz}), 6.34-6.32(\mathrm{~m}, 2 \mathrm{H}), 4.10-4.08(\mathrm{~m}, 3 \mathrm{H}), 3.25-3.24(\mathrm{~m}$, $2 \mathrm{H}), 2.28-2.22(\mathrm{~m}, 2 \mathrm{H}), 1.96-1.90(\mathrm{~m}, 1 \mathrm{H}), 1.72-1.67(\mathrm{~m}, 2 \mathrm{H}), 1.57-1.51(\mathrm{~m}, 3 \mathrm{H}), 1.39-1.36(\mathrm{~m}, 2 \mathrm{H})$, $1.31(\mathrm{~s}, 12 \mathrm{H}) .{ }^{13} \mathrm{C}$ NMR $\left(100 \mathrm{MHz}, \mathrm{CD}_{3} \mathrm{OD}\right): \delta 174.99,174.63,174.18,166.33,157.75,137.59,134.70$, 130.36, 126.97, 84.37, 52.75, 52.10, 32.29, 30.35, 29.26, 27.99, 25.14, 23.17. HRMS (ESI) m/z calcd for $\mathrm{C}_{25} \mathrm{H}_{35} \mathrm{BN}_{3} \mathrm{O}_{10}(\mathrm{M}-\mathrm{H})^{-} 548.2421$, found 548.2385.

\section{Procedures for the synthesis of compound 1c.}

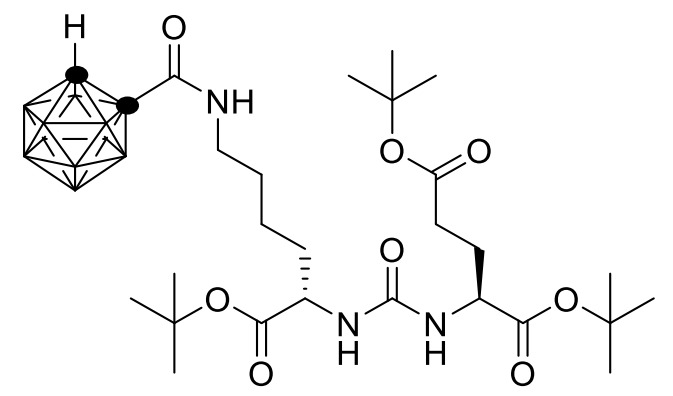

Di-tert-butyl (((S)-1-(tert-butoxy)-6-(((1,2-dicarba-closo-dodecarboranyl)carbonyl)amino)-1-oxohexan2-yl)carbamoyl)-L-glutamate (13c). 
The title compound was prepared from 2c and compound 12, using a similar method described for preparing compound 13a. It was purified by a flash column chromatography (hexane/ethyl acetate $=4: 1$ to $2: 1$ ) to afford compound $9 \mathrm{c}$ as a white solid in $18 \%$ yield. ${ }^{1} \mathrm{H}$ NMR (400 $\mathrm{MHz}, \mathrm{CDCl}_{3}$ ): $\delta 6.57-6.54$ $(\mathrm{m}, 1 \mathrm{H}), 5.28(\mathrm{~d}, 1 \mathrm{H}, J=8.0 \mathrm{~Hz}), 5.19(\mathrm{~d}, 1 \mathrm{H}, J=8.0 \mathrm{~Hz}), 4.38-4.33(\mathrm{~m}, 3 \mathrm{H}), 3.30-3.26(\mathrm{~m}, 2 \mathrm{H}), 3.10-$ 1.76 (br, carborane H), 2,36-2.33 (m, 2H), 2.29-2.11 (m, 1H), 1.89-1.75 (m, 3H), 1.64-1.56 (m, 2H), 1.49-1.48 (m, 18H), 1.46 (s, 9H), 1.39-1.37 (m, 2H). $\left.{ }^{13} \mathrm{C} \mathrm{NMR} \mathrm{(100} \mathrm{MHz,} \mathrm{CDCl}_{3}\right): \delta 172.43,172.27$, $159.70,156.87,82.30,81.97,80.63,72.00,57.10,53.19,53.10,40.95,32.62,31.57,28.39,28.27,28.09$, 28.03, 22.23 .

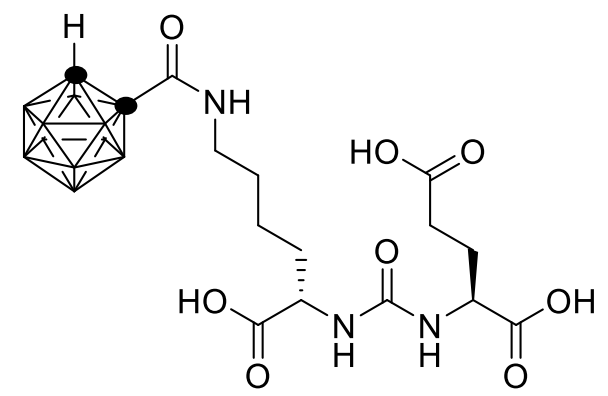

(((S)-1-carboxy-5-(((1,2-dicarba-closo-dodecarboranyl)carbonyl)amino)pentyl)carbamoyl)- $L$-glutamic acid (1c).

The title compound was prepared from 13c, using a published method. ${ }^{1}$

\section{Procedures for the synthesis of compound $1 \mathrm{~d}$.}

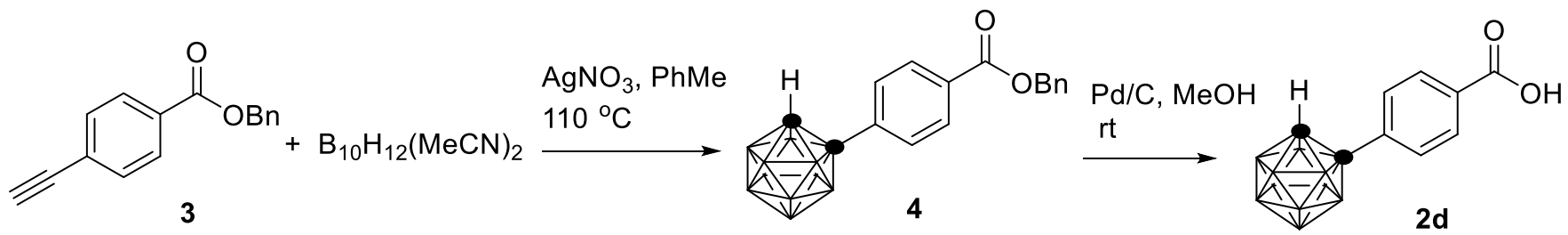

4-(1,2-Dicarba-closo-dodecarboranyl) benzoic acid (2d).

To a solution of compound $3(1.18 \mathrm{~g}, 5 \mathrm{mmol})$ in $10 \mathrm{~mL}$ anhydrous toluene was added $\mathrm{B}_{10} \mathrm{H}_{12}(\mathrm{MeCN})_{2}$ $(1.21 \mathrm{~g}, 6 \mathrm{mmol})$ and $\mathrm{AgNO}_{3}(85 \mathrm{mg}, 0.5 \mathrm{mmol})$. The reaction mixture was stirred at $110{ }^{\circ} \mathrm{C}$ for 4 hours. After TLC showed the starting materials were completely consumed, the solvent was removed under reduced pressure. The mixture was purified by a flash column chromatography (hexane/ethyl acetate $=$ 20:1) to afford a white solid compound 4. Compound 4 was dissolved in $10 \mathrm{~mL} \mathrm{MeOH}$ and $118 \mathrm{mg} 10 \%$ $\mathrm{Pd} / \mathrm{C}$ was added to the solution. The resulting mixture was stirred under hydrogen atmosphere at room temperature for $2 \mathrm{~h}$. After TLC showed the starting materials were completely consumed, the reaction mixture was filtered and evaporated in vacuo to afford compound $\mathbf{2 d}$ as a white solid (692 $\mathrm{mg}, 52 \%$ yield). ${ }^{1} \mathrm{H} \mathrm{NMR}\left(400 \mathrm{MHz}, \mathrm{CDCl}_{3}\right): \delta 8.07(\mathrm{~d}, 2 \mathrm{H}, J=8.4 \mathrm{~Hz}), 7.59$ (d, 2H, $\left.J=8.8 \mathrm{~Hz}\right), 7.51(\mathrm{br}, 1 \mathrm{H})$, 4.07 (s, 1H), 3.14-1.76 (br, 10H, carborane H). ${ }^{13} \mathrm{C}$ NMR (100 MHz, $\left.\mathrm{CDCl}_{3}\right): \delta 170.14,138.45,131.16$, 130.52, 127.63, 75.34, 59.72. HRMS (ESI) m/z calcd for $\mathrm{C}_{9} \mathrm{H}_{15} \mathrm{~B}_{10} \mathrm{O}_{2}(\mathrm{M}-\mathrm{H})^{-}$265.2008, found 265.2038.<smiles>CC(C)(C)OC(=O)CC[C@H](NC(=O)N[C@@H](CCCCNC(=O)c1ccc(C2C3C4CC5C4C2[C@H]53)cc1)C(=O)OC(C)(C)C)C(=O)OC(C)(C)C</smiles>

(S)-2-(1-((S)-1-tert-Butylcarboxy-5-(4-(1,2-dicarba-closo-dodecarboranyl)benzamide)pentyl)ureido) ditert-butyl pentanedioic acid (13d). 
The title compound was prepared from $\mathbf{2 d}$ and compound 12, using a similar method described for preparing compound 13a. It was purified by a flash column chromatography (hexane/ethyl acetate $=2: 1$ to $1: 1)$ to afford compound $\mathbf{1 3 d}$ as a white solid $\left(809 \mathrm{mg}, 55 \%\right.$ yield). ${ }^{1} \mathrm{H} \mathrm{NMR}\left(400 \mathrm{MHz}, \mathrm{CDCl}_{3}\right): \delta$ 7.96-7.94 (m, 3H), $7.56(\mathrm{~d}, 2 \mathrm{H}, J=8.8 \mathrm{~Hz}), 6.01(\mathrm{~d}, 2 \mathrm{H}, J=8.4 \mathrm{~Hz}), 5.58(\mathrm{~d}, 2 \mathrm{H}, J=7.6 \mathrm{~Hz}), 4.33(\mathrm{~s}$, $1 \mathrm{H})$, 4.24-4.14 (m, 2H), 3.58-3.55 (m, 1H), 3.33-3.30 (m, 1H), 3.14-1.76 (br, carborane H), 2.32-2.29 (m, $2 \mathrm{H}), 1.74-1.52(\mathrm{~m}, 6 \mathrm{H}), 1.43-1.42(\mathrm{~m}, 18 \mathrm{H}), 1.34(\mathrm{~s}, 9 \mathrm{H}), 1.29-1.24(\mathrm{~m}, 2 \mathrm{H}) .{ }^{13} \mathrm{C} \mathrm{NMR}(100 \mathrm{MHz}$, $\left.\mathrm{CDCl}_{3}\right): \delta 174.10,172.36,172.04,166.16,157.68,136.21,135.73,128.01,127.32,82.75,81.55,80.90$, 75.80, 59.79, 53.90, 52.92, 39.90, 32.36, 31.23, 29.02, 28.05, 27.97, 27.84, 27.74, 23.78. HRMS (ESI) $\mathrm{m} / \mathrm{z}$ calcd for $\mathrm{C}_{33} \mathrm{H}_{58} \mathrm{~B}_{10} \mathrm{~N}_{3} \mathrm{O}_{8}(\mathrm{M}-\mathrm{H})^{-} 734.5160$, found 734.5110 .

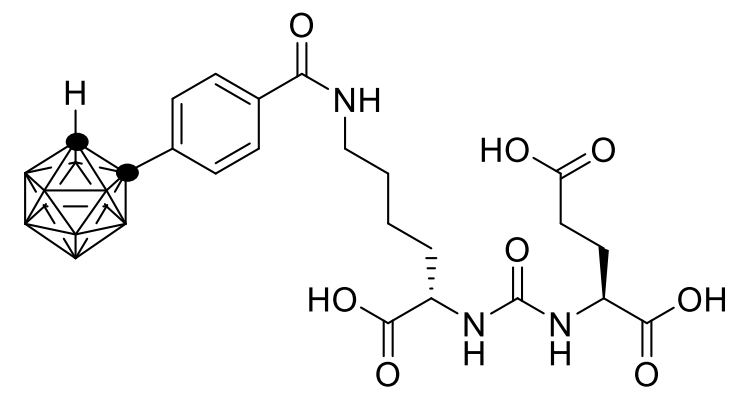

(S)-2-(1-((S)-1-Carboxy-5-(4-(1,2-dicarba-closo-dodecarboranyl)benzamide)pentyl)ureido) pentanedioic acid (1d).

The title compound was prepared from 13d, using a similar method described for preparing compound 1a, to generate 1d as a white solid in $100 \%$ yield. ${ }^{1} \mathrm{H}$ NMR $\left(400 \mathrm{MHz}, \mathrm{CD}_{3} \mathrm{OD}\right): \delta 7.82(\mathrm{~d}, 2 \mathrm{H}, J=8.4$ $\mathrm{Hz}), 7.67(\mathrm{~d}, 2 \mathrm{H}, J=8.4 \mathrm{~Hz}), 5.20(\mathrm{~s}, 1 \mathrm{H}), 4.34-4.29(\mathrm{~m}, 2 \mathrm{H}), 3.42-3.32(\mathrm{~m}, 2 \mathrm{H}), 3.14-1.76(\mathrm{br}$, carborane H), 2.45-2.40 (m, 2H), 1.90-1.85 (m, 2H), 1.74-1.65 (m, 4H), 1.52-1.47 (m, 2H). ${ }^{13} \mathrm{C}$ NMR (100 MHz, $\left.\mathrm{CD}_{3} \mathrm{OD}\right): \delta 175.07,175.01,174.46,167.47,158.74,136.69,135.69,127.37,127.23,75.90$, $60.25,52.55,52.10,39.44,31.82,29.69,28.48,27.47,22.61$. HRMS (ESI) $\mathrm{m} / \mathrm{z}$ calcd for $\mathrm{C}_{21} \mathrm{H}_{34} \mathrm{~B}_{10} \mathrm{~N}_{3} \mathrm{O}_{8}$ $(\mathrm{M}-\mathrm{H})^{-}$566.3282, found 566.3267 .

\section{Procedures for the synthesis of compound $1 \mathrm{e}$.}

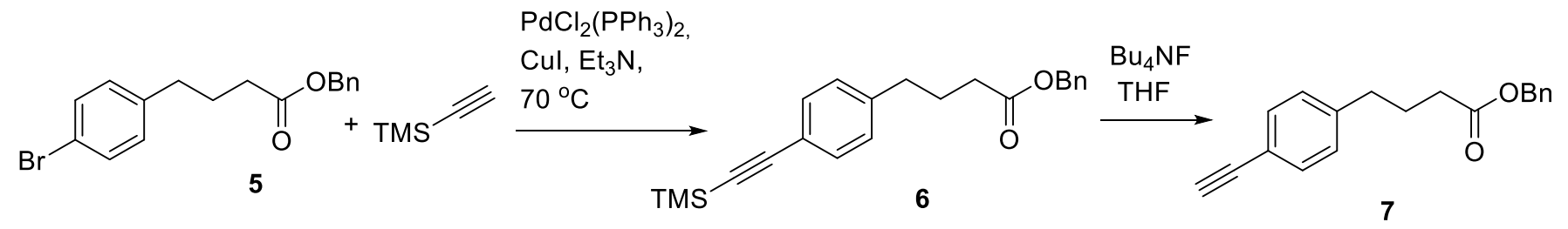

Benzyl 4-(4-ethynylphenyl)butanoate (7).

Compound 5 (3.2 g, $10 \mathrm{mmol}$ ) was dissolved in $20 \mathrm{~mL} \mathrm{Et}_{3} \mathrm{~N}$, then (trimethylsilyl) acetylene (1.18 g, 12 mmol), $\mathrm{Pd}\left(\mathrm{PPh}_{3}\right)_{2} \mathrm{Cl}_{2}$ (702 mg, $\left.1.0 \mathrm{mmol}\right)$, and $\mathrm{CuI}(19 \mathrm{mg}, 0.1 \mathrm{mmol})$ were added. The resulting mixture was heated under Ar protection at $70{ }^{\circ} \mathrm{C}$ for 12 hours. After TLC showed the starting materials were completely consumed, the solvent was removed under reduced pressure, and the residue was purified by a flash column chromatography (hexane/ethyl acetate $=20 / 1$ ) to give compound 6 . Compound 6 was dissolved in $10 \mathrm{~mL}$ THF and $16 \mathrm{~mL} 1 \mathrm{M} \mathrm{Bu} \mathrm{BF}_{4}$ was added. The reaction mixture was stirred at room temperature for 30 minutes. The solvent was removed under reduced pressure, and the residue was purified by a flash column chromatography (hexane/ethyl acetate $=20 / 1$ ) to yield compound 7 as white solid $(2.22 \mathrm{~g}, 80 \%$ yield $) .{ }^{1} \mathrm{H} \mathrm{NMR}\left(400 \mathrm{MHz}, \mathrm{CDCl}_{3}\right): \delta 7.45-7.36(\mathrm{~m}, 7 \mathrm{H}), 7.14(\mathrm{~d}, 2 \mathrm{H}, J=$ $8.4 \mathrm{~Hz}), 5.15(\mathrm{~s}, 2 \mathrm{H}), 3.07(\mathrm{~s}, 1 \mathrm{H}), 2.67(\mathrm{t}, 2 \mathrm{H}, J=7.6 \mathrm{~Hz}), 2.40(\mathrm{t}, 2 \mathrm{H}, J=7.6 \mathrm{~Hz}), 2.03-1.96(\mathrm{~m}, 2 \mathrm{H})$. ${ }^{13} \mathrm{C}$ NMR (100 MHz, $\left.\mathrm{CDCl}_{3}\right): \delta 173.13,142.34,135.99,132.20,128.60,128.52,128.28,119.74,83.70$, 66.25, 34.99, 33.51, 26.25. HRMS (ESI) m/z calcd for $\mathrm{C}_{19} \mathrm{H}_{19} \mathrm{O}_{2}(\mathrm{M}+\mathrm{H})^{+} 279.1380$, found 279.1340. 


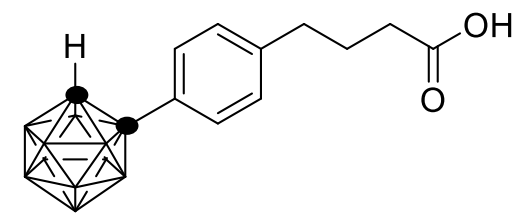

4-(4-(1,2-Dicarba-closo-dodecarboranyl)phenyl)butanoic acid (2e).

The title compound was prepared from compound 7 and $\mathrm{B}_{10} \mathrm{H}_{12}(\mathrm{MeCN})_{2}$, using a similar method described for preparing compound $\mathbf{2 d}$, to generate $\mathbf{2 e}$ as a white solid in $48 \%$ yield. ${ }^{1} \mathrm{H} \mathrm{NMR}(400 \mathrm{MHz}$, $\left.\mathrm{CDCl}_{3}\right): \delta 7.41(\mathrm{~d}, 2 \mathrm{H}, J=8.0 \mathrm{~Hz}), 7.14(\mathrm{~d}, 2 \mathrm{H}, J=8.4 \mathrm{~Hz}), 3.96,(\mathrm{~s}, 1 \mathrm{H}), 3.14-1.76($ br, carborane H), $2.67(\mathrm{t}, 2 \mathrm{H}, J=7.6 \mathrm{~Hz}), 2.40(\mathrm{t}, 2 \mathrm{H}, J=7.6 \mathrm{~Hz}), 2.02-1.95(\mathrm{~m}, 2 \mathrm{H}) .{ }^{13} \mathrm{C} \mathrm{NMR}\left(100 \mathrm{MHz}, \mathrm{CDCl}_{3}\right): \delta$ 173.00, 143.57, 131.23, 128.91, 127.69, 76.57, 60.34, 34.46, 33.49, 26.12. HRMS (ESI) m/z calcd for $\mathrm{C}_{12} \mathrm{H}_{21} \mathrm{~B}_{10} \mathrm{O}_{2}(\mathrm{M}-\mathrm{H})^{-}$307.2478, found 307.2440.

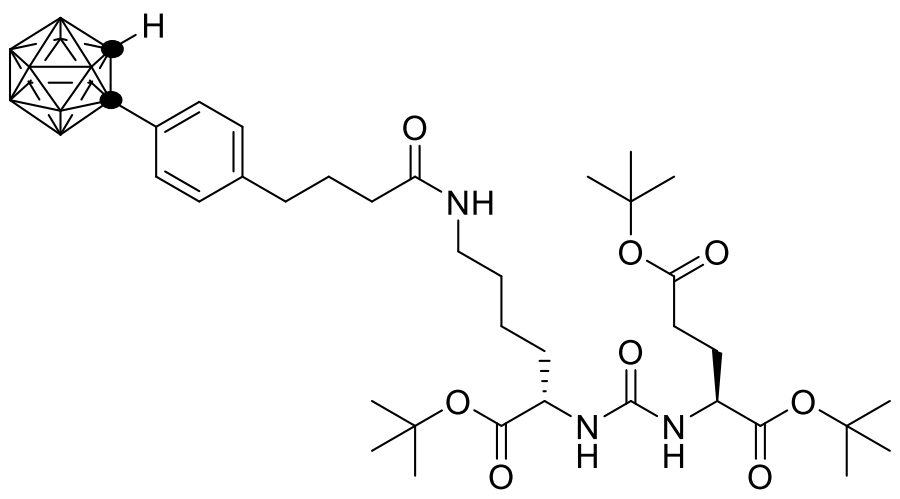

Di-tert-butyl (((S)-1-(tert-butoxy)-6-(4-(4-(1,2-dicarba-closo-dodecarboranyl)phenyl)butanamido) -1oxohexan-2-yl)carbamoyl)- $L$-glutamate (13e).

The title compound was prepared from $\mathbf{2 e}$ and compound 12, using a similar method described for preparing compound 13a. It was purified by a flash column chromatography (hexane/ethyl acetate $=1: 1$ to pure ethyl acetate) to afford compound 9e as a white solid in $56 \%$ yield. ${ }^{1} \mathrm{H} \mathrm{NMR}\left(400 \mathrm{MHz}, \mathrm{CDCl}_{3}\right)$ : $\delta 7.35(\mathrm{~d}, 2 \mathrm{H}, J=8.8 \mathrm{~Hz}), 7.10(\mathrm{~d}, 2 \mathrm{H}, J=8.8 \mathrm{~Hz}), 6.84(\mathrm{br}, 1 \mathrm{H}), 5.95(\mathrm{~d}, 2 \mathrm{H}, J=8.0 \mathrm{~Hz}), 5.67(\mathrm{~d}, 2 \mathrm{H}$, $J=7.6 \mathrm{~Hz}), 4.28(\mathrm{t}, 1 \mathrm{H}, J=4.4 \mathrm{~Hz}), 4.15(\mathrm{t}, 1 \mathrm{H}, J=4.0 \mathrm{~Hz}), 3.22-3.11(\mathrm{~m}, 2 \mathrm{H}), 3.14-1.76(\mathrm{br}$, carborane $\mathrm{H}), 2.61-2.57(\mathrm{~m}, 2 \mathrm{H}), 2.28-2.18(\mathrm{~m}, 4 \mathrm{H}), 2.03-2.01(\mathrm{~m}, 2 \mathrm{H}), 1.91-1.79(\mathrm{~m}, 2 \mathrm{H}), 1.67-1.53(\mathrm{~m}$, $2 \mathrm{H}), 1.46-1.41(\mathrm{~m}, 2 \mathrm{H}), 1.39-1.38(\mathrm{~m}, 27 \mathrm{H}), 1.29-1.25(\mathrm{~m}, 2 \mathrm{H}) .{ }^{13} \mathrm{C} \mathrm{NMR}\left(100 \mathrm{MHz}, \mathrm{CDCl}_{3}\right): \delta 173.48$, 172.95, 172.38, 172.07, 157.49, 143.94, 131.01, 128.81, 127.47, 82.39, 81.39, 80.59, 76.65, 60.31, 53.56, 52.93, 39.03, 35.62, 34.68, 32.40, 31.53, 28.91, 28.09, 28.01, 27.95, 26.93, 23.04. HRMS (ESI) m/z calcd for $\mathrm{C}_{36} \mathrm{H}_{64} \mathrm{~B}_{10} \mathrm{~N}_{3} \mathrm{O}_{8}(\mathrm{M}-\mathrm{H})^{-} 776.5629$, found 777.5678 .

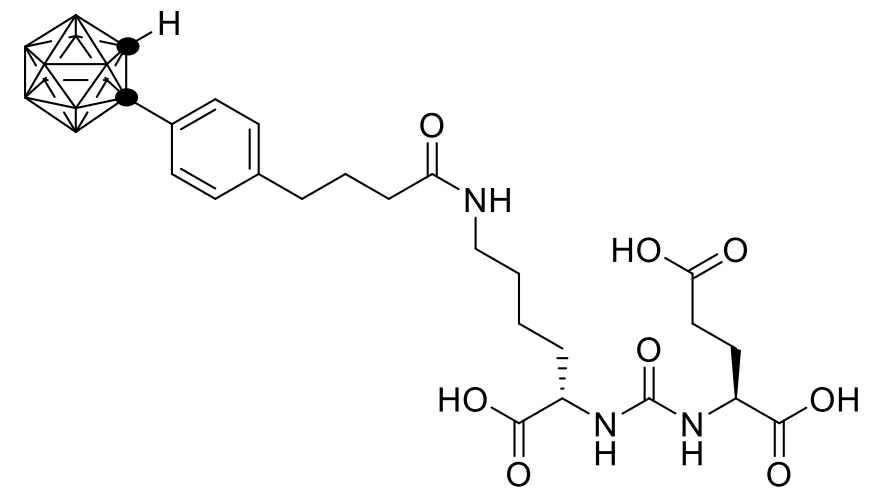

(((S)-1-carboxy-5-(4-(4-(1,2-dicarba-closo-dodecarboranyl)phenyl)butanamido)pentyl) carbamoyl)- $L$ glutamic acid (1e).

The title compound was prepared from 13e, using a similar method described for preparing compound 13a, to generate 1e as a white solid in $100 \%$ yield. ${ }^{1} \mathrm{H} \mathrm{NMR}\left(400 \mathrm{MHz}, \mathrm{CD}_{3} \mathrm{OD}\right): \delta 7.47(\mathrm{~d}, 2 \mathrm{H}, J=8.4$ $\mathrm{Hz}), 7.20(\mathrm{~d}, 2 \mathrm{H}, J=8.0 \mathrm{~Hz}), 4.98(\mathrm{~s}, 1 \mathrm{H}), 4.35-4.26(\mathrm{~m}, 2 \mathrm{H}), 3.18(\mathrm{t}, 2 \mathrm{H}, J=6.8 \mathrm{~Hz}), 3.14-1.76(\mathrm{br}$, 
carborane H), $2.64(\mathrm{t}, 2 \mathrm{H}, J=7.6 \mathrm{~Hz}), 2.45-2.41(\mathrm{~m}, 2 \mathrm{H}), 2.23-2.19(\mathrm{~m}, 2 \mathrm{H}), 1.92-1.89(\mathrm{~m}, 4 \mathrm{H}), 1.74-$ $1.67(\mathrm{~m}, 2 \mathrm{H}), 1.54-1.43(\mathrm{~m}, 4 \mathrm{H}) .{ }^{13} \mathrm{C}$ NMR (100 MHz, CD $\left.{ }_{3} \mathrm{OD}\right): \delta 175.18,175.12,174.53,174.41$, $158.75,143.74,131.43,128.60,127.16,76.84,60.53,52.63,52.17,38.79,35.03,34.22,31.76,29.75$, 28.49, 27.48, 27.00, 22.58. HRMS (ESI) $\mathrm{m} / \mathrm{z}$ calcd for $\mathrm{C}_{24} \mathrm{H}_{40} \mathrm{~B}_{10} \mathrm{~N}_{3} \mathrm{O}_{8}(\mathrm{M}-\mathrm{H})^{-}$608.3751, found 608.3800 .

\section{Procedures for the synthesis of compound 1f}

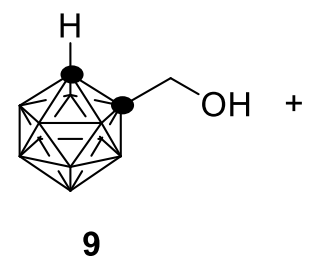<smiles>O=C(Cl)Oc1ccc([N+](=O)[O-])cc1</smiles>

9

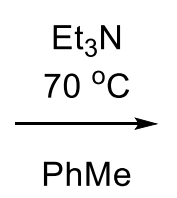

$\mathrm{PhMe}$

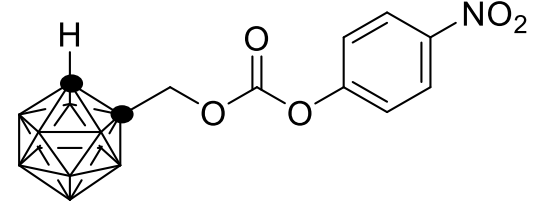

10

1,2-Dicarba-closo-dodecarboranyl (4-nitrophenyl) carbonate (10).

To a solution of compound $9(1.74 \mathrm{~g}, 10 \mathrm{mmol})$ in $30 \mathrm{~mL}$ anhydrous toluene was added $\mathrm{Et}_{3} \mathrm{~N}(1.52 \mathrm{~g}, 15$ mmol) and 4-nitrophenyl chloroformate $(3.02 \mathrm{~g}, 15 \mathrm{mmol})$. The reaction mixture was stirred at $70{ }^{\circ} \mathrm{C}$ for 16 hours. After TLC showed the starting materials were completely consumed, the solvent was removed under reduced pressure. The mixture was purified by a flash column chromatography (hexane/ethyl acetate $=8: 1$ to $4: 1)$ to afford compound 10 as a yellow solid $\left(2.05 \mathrm{~g}, 60 \%\right.$ yield). ${ }^{1} \mathrm{H} \mathrm{NMR}(400 \mathrm{MHz}$, $\left.\mathrm{CDCl}_{3}\right): \delta 8.33(\mathrm{~d}, 2 \mathrm{H}, J=9.2 \mathrm{~Hz}), 7.41(\mathrm{~d}, 2 \mathrm{H}, J=9.2 \mathrm{~Hz}), 4.75(\mathrm{~s}, 2 \mathrm{H}), 3.91(\mathrm{~s}, 1 \mathrm{H}), 2.88-1.60(\mathrm{br}$, $10 \mathrm{H}$, carborane $\mathrm{H}) .{ }^{13} \mathrm{C}$ NMR $\left(100 \mathrm{MHz}, \mathrm{CDCl}_{3}\right): \delta 154.88,151.72,145.81,125.50,121.66,70.67$, 68.63, 59.31. HRMS was tested but could not be obtained due to its lability.

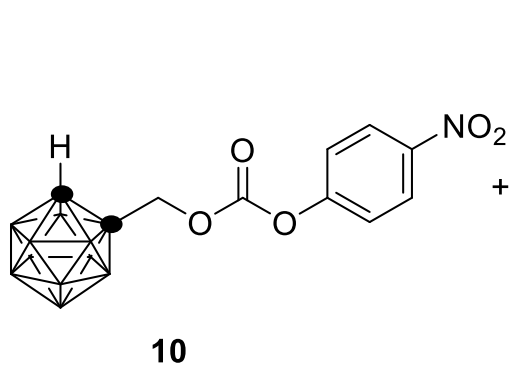

10

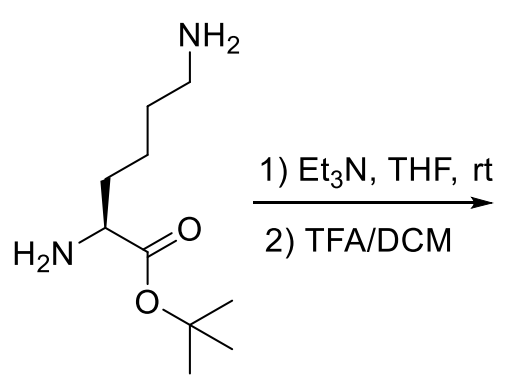

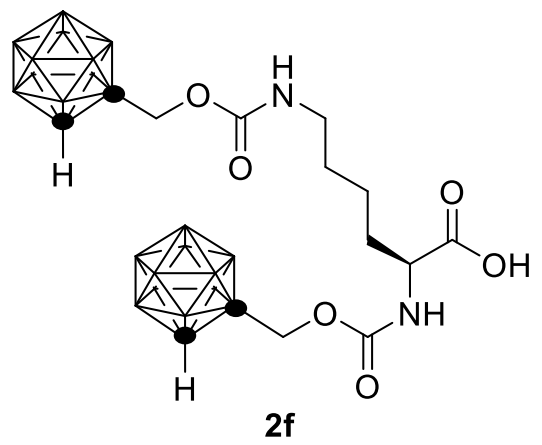

$2 f$

$N^{2}, N^{6}$-Bis((-(1,2-dicarba-closo-dodecarboranyl)methoxy)carbonyl)-L-lysine (2f).

To a solution of compound $\mathbf{1 0}(1.36 \mathrm{~g}, 4 \mathrm{mmol})$ in $10 \mathrm{~mL}$ anhydrous toluene was added $\mathrm{Et}_{3} \mathrm{~N}$ (404 mg, 4 mmol) and $L$-lysine tert-butyl ester $(404 \mathrm{mg}, 2 \mathrm{mmol})$. The reaction mixture was stirred at room temperature for 16 hours. After TLC showed the starting materials were completely consumed, the solvent was removed under reduced pressure. Ethyl acetate was added and the mixture was washed by saturated $\mathrm{Na}_{2} \mathrm{CO}_{3}$ twice. The organic layer was evaporated under reduced pressure and was purified by a flash column chromatography (hexane/ethyl acetate $=4: 1$ to $2: 1$ ) to afford a yellow solid. This yellow solid was dissolved in $5 \mathrm{~mL}$ DCM and $5 \mathrm{~mL}$ TFA was added to the solution. The reaction mixture was stirred at room temperature for 16 hours. The solvent was removed under reduced pressure. The residue was dissolved in $\mathrm{H}_{2} \mathrm{O}$ and evaporated again to remove the remaining TFA. The residue was dissolved in $\mathrm{CHCl}_{3}$ and evaporated until white solid formed (396 mg, 36\% yield). $\left.{ }^{1} \mathrm{H} \mathrm{NMR} \mathrm{(400} \mathrm{MHz,} \mathrm{CDCl}_{3}\right): \delta$ $5.51(\mathrm{~d}, 1 \mathrm{H}, J=8.0 \mathrm{~Hz}), 4.96(\mathrm{~s}, 1 \mathrm{H}), 4.55-4.54(\mathrm{~m}, 4 \mathrm{H}), 4.19(\mathrm{t}, 1 \mathrm{H}, J=8.0 \mathrm{~Hz}), 3.92(\mathrm{~s}, 2 \mathrm{H}), 3.23-$ $3.18(\mathrm{~m}, 2 \mathrm{H}), 3.14-1.76(\mathrm{br}$, carborane $\mathrm{H}), 1.86-1.83(\mathrm{~m}, 1 \mathrm{H}), 1.72-1.68(\mathrm{~m}, 1 \mathrm{H}), 1.60-1.56(\mathrm{~m}, 2 \mathrm{H})$, 1.42-1.34 (m, 2H). $\left.{ }^{13} \mathrm{C} \mathrm{NMR} \mathrm{(100} \mathrm{MHz,} \mathrm{CDCl}_{3}\right): \delta 170.86,155.04,154.55,73.01,72.75,65.31,65.17$, 59.55, 59.39, 54.32, 40.90, 32.07, 29.21, 22.14. HRMS (ESI) m/z calcd for $\mathrm{C}_{14} \mathrm{H}_{37} \mathrm{~B}_{20} \mathrm{~N}_{2} \mathrm{O}_{6}(\mathrm{M}-\mathrm{H})^{-}$ 549.4518 , found 549.4506 . 


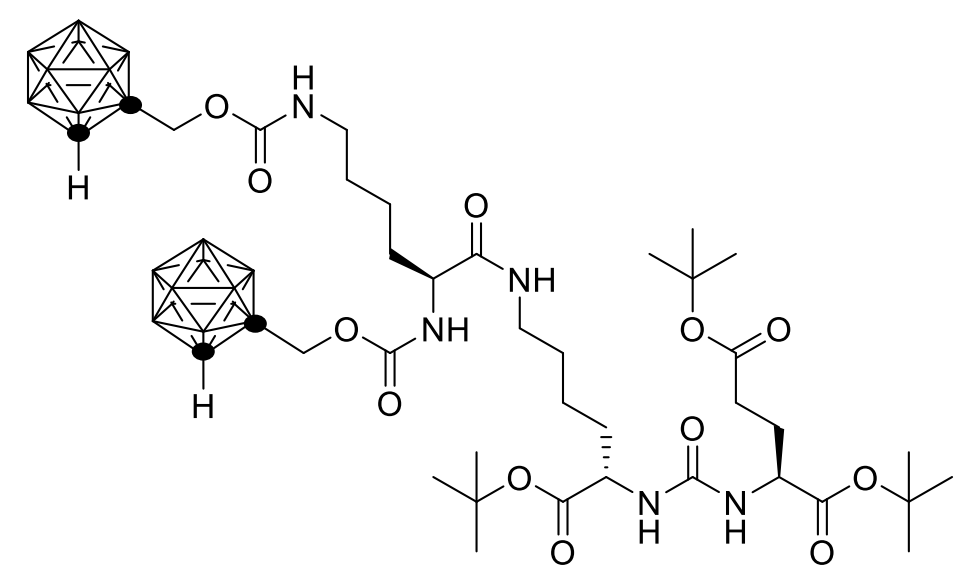

Tri-tert-butyl

(9S,16S,20S)-1-(1,2-dicarba-closo-dodecarboranyl)-9-((((1,2-dicarba-closododecarboranyl)methoxy)carbonyl)amino)-3,10,18-trioxo-2-oxa-4,11,17,19-tetraazadocosane-16, 20,22tricarboxylate (13f).

The title compound was prepared from $\mathbf{2 f}$ and compound 12, using a similar method described for preparing compound 13a. It was purified by a flash column chromatography (hexane/ethyl acetate $=2: 1$ to $1: 1)$ to afford compound $\mathbf{1 f}$ as a white solid in $46 \%$ yield. ${ }^{1} \mathrm{H}$ NMR $\left(400 \mathrm{MHz}, \mathrm{CDCl}_{3}\right): \delta 7.38(\mathrm{~s}, 1 \mathrm{H})$, $7.01(\mathrm{~s}, 1 \mathrm{H}), 6.29-6.27(\mathrm{~m}, 1 \mathrm{H}), 5.79-5.77(\mathrm{~m}, 1 \mathrm{H}), 5.41-5.39(\mathrm{~m}, 1 \mathrm{H}), 4.65-4.62(\mathrm{~m}, 1 \mathrm{H}), 4.50(\mathrm{~s}, 2 \mathrm{H})$, 4.46-4.43 (m, 1H), 4.32-4.25 (m, 3H), $4.07(\mathrm{~s}, 1 \mathrm{H}), 3.95(\mathrm{~s}, 1 \mathrm{H}), 3.18-3.13(\mathrm{~m}, 4 \mathrm{H}), 3.14-1.76(\mathrm{br}$, carborane H), 2.36-2.29 (m, 4H), 1.84-1.75 (m, 4H), 1.59-1.53 (m, 6H), $1.48(\mathrm{~s}, 9 \mathrm{H}), 1.43(\mathrm{~m}, 18 \mathrm{H})$, 1.27-1.17 (m, 2H). ${ }^{13} \mathrm{C}$ NMR (100 MHz, $\left.\mathrm{CDCl}_{3}\right): \delta 174.10,172.82,172.35,172.28,157.64,155.48$, $155.04,82.73,81.59,80.67,73.05,72.18,65.54,65.05,59.75,59.62,54.94,53.04,52.68,40.91,39.28$, $32.43,32.04,31.62,29.13,28.82,28.31,28.07,28.00,22.69,22.08$. HRMS (ESI) $\mathrm{m} / \mathrm{z}$ calcd for $\mathrm{C}_{38} \mathrm{H}_{80} \mathrm{~B}_{20} \mathrm{~N}_{5} \mathrm{O}_{12}(\mathrm{M}-\mathrm{H})^{-} 1018.7670$, found 1018.7641 .

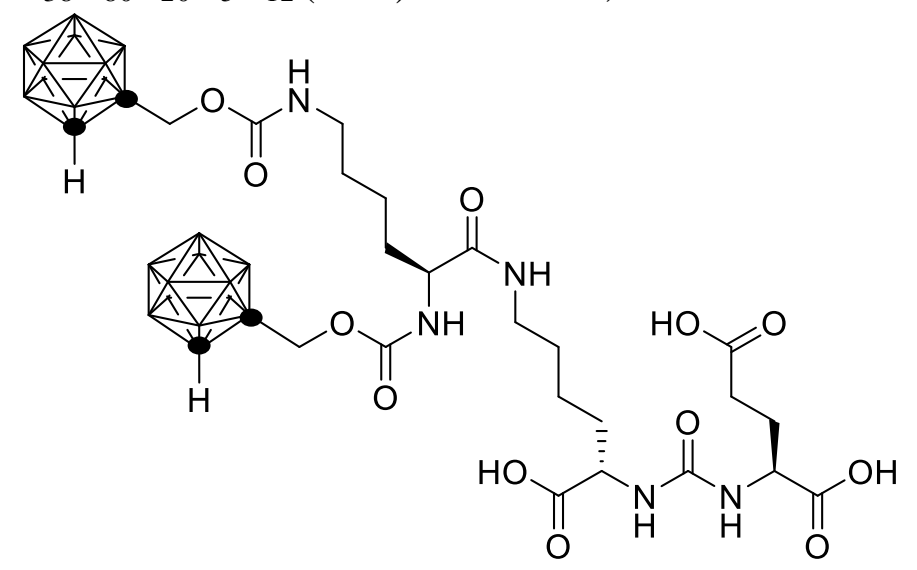

(9S,16S,20S)-1-(1,2-dicarba-closo-dodecarboranyl)-9-((((1,2-dicarba-closo-dodecarboranyl) methoxy) carbonyl)amino)-3,10,18-trioxo-2-oxa-4,11,17,19-tetraazadocosane-16,20,22-tricarboxylic acid (1f).

The title compound was prepared from 9 f, using a similar method described for preparing compound 1a, to generate 1f as a white solid in $100 \%$ yield. ${ }^{1} \mathrm{H}$ NMR $\left(400 \mathrm{MHz}, \mathrm{CD}_{3} \mathrm{OD}\right): \delta 4.61-4.55(\mathrm{~m}, 6 \mathrm{H}), 4.36-$ $4.26(\mathrm{~m}, 2 \mathrm{H}), 4.05-4.02(\mathrm{~m}, 1 \mathrm{H}), 3.33-3.11(\mathrm{~m}, 4 \mathrm{H}), 3.14-1.76(\mathrm{br}$, carborane $\mathrm{H}), 2.46-2.42(\mathrm{~m}, 4 \mathrm{H})$, 1.94-1.85 (m, 4H), 1.56-1.55 (m, 4H), 1.45-1.39 (m, 4H). ${ }^{13} \mathrm{C}$ NMR (100 MHz, CD $\left.{ }_{3} \mathrm{OD}\right): \delta 175.09$, 175.04, 174.54, 173.03, 158.69, 155.70, 155.32, 73.57, 73.27, 64.74, 64.47, 60.67, 60.60, 55.27, 52.54, 52.14, 40.27, 38.64, 33.31, 31.62, 31.40, 29.73, 28.85, 27.52, 22.66, 22.33. HRMS (ESI) $\mathrm{m} / \mathrm{z}$ calcd for $\mathrm{C}_{26} \mathrm{H}_{56} \mathrm{~B}_{20} \mathrm{~N}_{5} \mathrm{O}_{12}(\mathrm{M}-\mathrm{H})^{-} 850.5792$, found 850.5765 .

\section{Procedures for the synthesis of compound $1 \mathrm{~g}$}




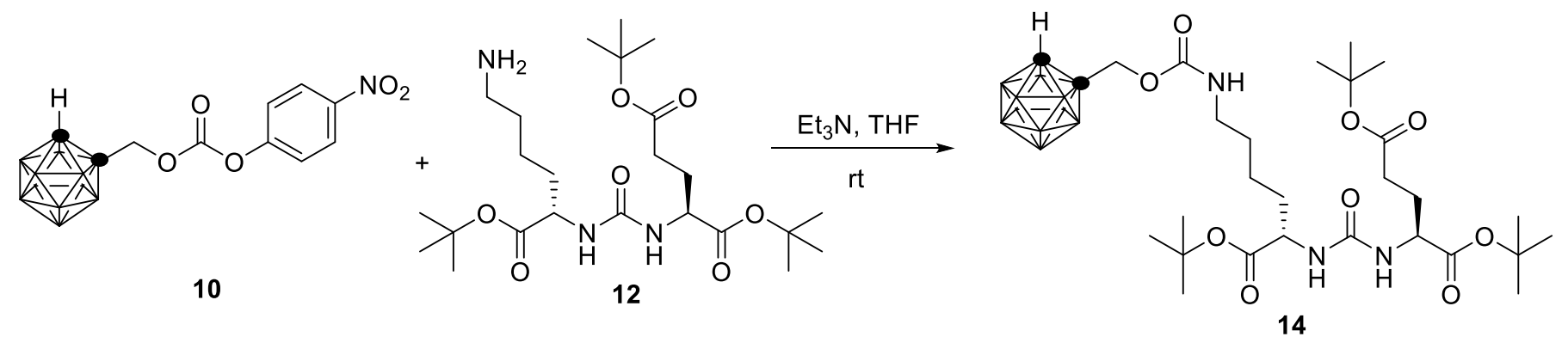

(S)-2-(1-((S)-1-tert-Butylcarboxy-5-((1,2-dicarba-closo-dodecarboranyl)methylcarbamate)pentyl)ureido) di-tert-butyl pentanedioic acid (14).

To a solution of compound $10(680 \mathrm{mg}, 2 \mathrm{mmol})$ in $10 \mathrm{~mL}$ anhydrous toluene was added $\mathrm{Et}_{3} \mathrm{~N}(202 \mathrm{mg}$, $2 \mathrm{mmol})$ and compound 12 (974 $\mathrm{mg}, 2 \mathrm{mmol})$. The reaction mixture was stirred at room temperature for 16 hours. After TLC showed the starting materials were completely consumed, the solvent was removed under reduced pressure. EA was added and the mixture was washed by saturated $\mathrm{Na}_{2} \mathrm{CO}_{3}$ twice. The organic layer was evaporated under reduced pressure and was purified by a flash column chromatography (hexane/ethyl ace tate $=8: 1$ to 4:1) to afford compound 14 as a white solid (936 $\mathrm{mg}, 68 \%$ yield). ${ }^{1} \mathrm{H}$ NMR (400 MHz, $\left.\mathrm{CDCl}_{3}\right): 6.04(\mathrm{~s}, 1 \mathrm{H}), 5.59(\mathrm{~d}, 2 \mathrm{H}, J=8.0 \mathrm{~Hz}), 5.41(\mathrm{~d}, 2 \mathrm{H}, J=7.6 \mathrm{~Hz})$, 4.60-4.46 (m, 2H), 4.38-4.35 (m, 1H), 4.29-4.26 (m, 1H), $4.06(\mathrm{~s}, 1 \mathrm{H}), 3.19-3.14(\mathrm{~m}, 2 \mathrm{H}), 3.14-1.76$ (br, carborane H), 2.35-2.29 (m, 2H), 2.11-2.08 (m, 2H), 1.87-1.73 (m, 2H), 1.60-1.55 (m, 2H), 1.48-1.44 (m, 27H), 1.35-1.30 (m, 2H). ${ }^{13} \mathrm{C}$ NMR (100 MHz, $\left.\mathrm{CDCl}_{3}\right): \delta 173.27,172.34,172.25,157.19,155.21,82.54$, 81.76, 80.67, 73.06, 64.94, 59.47, 53.34, 53.02, 40.91, 32.58, 31.59, 28.93, 28.15, 28.07, 28.02, 22.53. HRMS (ESI) $\mathrm{m} / \mathrm{z}$ calcd for $\mathrm{C}_{28} \mathrm{H}_{56} \mathrm{~B}_{10} \mathrm{~N}_{3} \mathrm{O}_{9}(\mathrm{M}-\mathrm{H})^{-} 688.4953$, found 688.4985 .<smiles>O=C(O)CC[C@H](NC(=O)N[C@@H](CCCCNC(=O)OCC1CC2C3C=CC(C3)[C@H]12)C(=O)O)C(=O)O</smiles>

$(S)-2-(1-((S)-1-C a r b o x y-5-((1,2-$ dicarba-closo-dodecarboranyl) methylcarbamate)pentyl)ureido) pentanedioic acid (1g).

The title compound was prepared from compound 14, using a similar method described for preparing compound 1a, to generate $1 \mathrm{~g}$ as a white solid in $100 \%$ yield. ${ }^{1} \mathrm{H}$ NMR (400 MHz, $\left.\mathrm{CD}_{3} \mathrm{OD}\right): \delta 4.58-4.55$ $(\mathrm{m}, 3 \mathrm{H}), 4.34-4.27(\mathrm{~m}, 2 \mathrm{H}), 3.13(\mathrm{t}, 2 \mathrm{H}, J=6.4 \mathrm{~Hz}), 3.14-1.76(\mathrm{br}$, carborane $\mathrm{H}), 2.45-2.42(\mathrm{~m}, 2 \mathrm{H})$, 2.19-2.12 (m, 2H), 1.94-1.85 (m, 2H), 1.46-1.44 (m, 4H). ${ }^{13} \mathrm{C}$ NMR (100 MHz, CD $\left.{ }_{3} \mathrm{OD}\right): \delta 175.15$, $175.10,174.52$, 158.71, 155.67, 73.55, 64.47, 60.63, 52.59, 52.12, 40.36, 31.75, 29.73, 28.85, 27.50, 22.40. HRMS (ESI) $\mathrm{m} / \mathrm{z}$ calcd for $\mathrm{C}_{16} \mathrm{H}_{32} \mathrm{~B}_{10} \mathrm{~N}_{3} \mathrm{O}_{9}(\mathrm{M}-\mathrm{H})^{-} 520.3075$, found 520.3117 .

\section{Procedures for the synthesis of compound $1 \mathrm{~h}$}<smiles>CC(C)(C)OC(=O)CC[C@H](NC(=O)N[C@@H](CCCCNC(=O)CCCCCNC(=O)OCC1[CH][C@@H]2C3C=CC(C3)C12)C(=O)OC(C)(C)C)C(=O)OC(C)(C)C</smiles> 
(S)-2-(1-((S)-1-tert-Butylcarboxy-5-((1,2-dicarba-closo-dodecarboranyl)methyl-(6-amino-6-oxohexyl) carbamate)pentyl)ureido) di-tert-butyl pentanedioic acid (16).

The title compound was prepared from compound $\mathbf{1 0}$ and compound 15, using a similar method described for preparing compound 14. It was purified by a flash column chromatography (hexane/ethyl acetate $=1: 1$ to pure ethyl acetate) to afford compound $\mathbf{1 6}$ as a white solid in $65 \%$ yield. ${ }^{1} \mathrm{H} \mathrm{NMR}$ (400 $\left.\mathrm{MHz} \mathrm{CDCl}_{3}\right): \delta 6.24(\mathrm{~s}, 1 \mathrm{H}), 5.48-5.43(\mathrm{~m}, 3 \mathrm{H}), 4.55(\mathrm{~s}, 2 \mathrm{H}), 4.35-4.29(\mathrm{~m}, 2 \mathrm{H}), 4.03(\mathrm{~s}, 1 \mathrm{H}), 3.32-3.20$ (m, 4H), 3.14-1.76 (br, carborane H), 2.37-2.31 (m, 2H), 2.24-2.20 (m, 2H), 2.12-2.06 (m, 2H), 1.88$1.83(\mathrm{~m}, 2 \mathrm{H}), 1.70-1.66(\mathrm{~m}, 2 \mathrm{H}), 1.57-1.52(\mathrm{~m}, 4 \mathrm{H}), 1.48-1.46(\mathrm{~m}, 27 \mathrm{H}), 1.40-1.36(\mathrm{~m}, 4 \mathrm{H}) .{ }^{13} \mathrm{C} \mathrm{NMR}$ $\left(100 \mathrm{MHz}, \mathrm{CDCl}_{3}\right): \delta 173.24,172.75,172.42,172.37,157.20,155.14,82.27,81.77,80.72,73.11,65.05$, 59.63, 53.24, 53.09, 40.98, 38.84, 36.15, 32.50, 31.63, 29.11, 28.68, 28.22, 28.09, 28.03, 26.04, 24.96, 22.36. HRMS (ESI) $\mathrm{m} / \mathrm{z}$ calcd for $\mathrm{C}_{34} \mathrm{H}_{67} \mathrm{~B}_{10} \mathrm{~N}_{4} \mathrm{O}_{10}(\mathrm{M}-\mathrm{H})^{-} 801.5793$, found 801.5811.<smiles>O=C(O)CC[C@@H]1NC(=O)N[C@H](C(=O)O)CCCCNC(=O)CCCCCNC(=O)OCC(C2C3C4CC5C4C2C53)OC1=O</smiles>

(S)-2-(1-((S)-1-Carboxy-5-((1,2-dicarba-closo-dodecarboranyl)methyl-(6-amino-6-oxohexyl)carbamate) pentyl)ureido) pentanedioic acid (1h).

The title compound was prepared from compound 16, using a similar method described for preparing compound 1a, to generate $\mathbf{1 h}$ as a white solid in $100 \%$ yield. ${ }^{1} \mathrm{H}$ NMR (400 MHz, $\mathrm{CD}_{3} \mathrm{OD}$ ): $\delta$ 4.58-4.54 $(\mathrm{m}, 3 \mathrm{H}), 4.34-4.28(\mathrm{~m}, 2 \mathrm{H}), 3.19-3.12(\mathrm{~m}, 4 \mathrm{H}), 3.14-1.76(\mathrm{br}$, carborane $\mathrm{H}), 2.44-2.42(\mathrm{~m}, 2 \mathrm{H}), 2.22-$ $2.16(\mathrm{~m}, 4 \mathrm{H}), 1.92-1.85(\mathrm{~m}, 2 \mathrm{H}), 1.65-1.51(\mathrm{~m}, 6 \mathrm{H}), 1.45-1.35(\mathrm{~m}, 4 \mathrm{H}) .{ }^{13} \mathrm{C}$ NMR $\left(100 \mathrm{MHz}, \mathrm{CD}_{3} \mathrm{OD}\right)$ : $\delta 175.15,175.09,174.80,174.52,158.72,155.67,73.60,64.44,60.66,52.62,52.15,40.43,38.79,35.61$, 31.81, 29.75, 29.00, 28.53, 27.51, 25.95, 25.29, 22.58. HRMS (ESI) m/z calcd for $\mathrm{C}_{22} \mathrm{H}_{43} \mathrm{~B}_{10} \mathrm{~N}_{4} \mathrm{O}_{10}(\mathrm{M}-$ H) ${ }^{-} 633.3915$, found 633.3910 . 

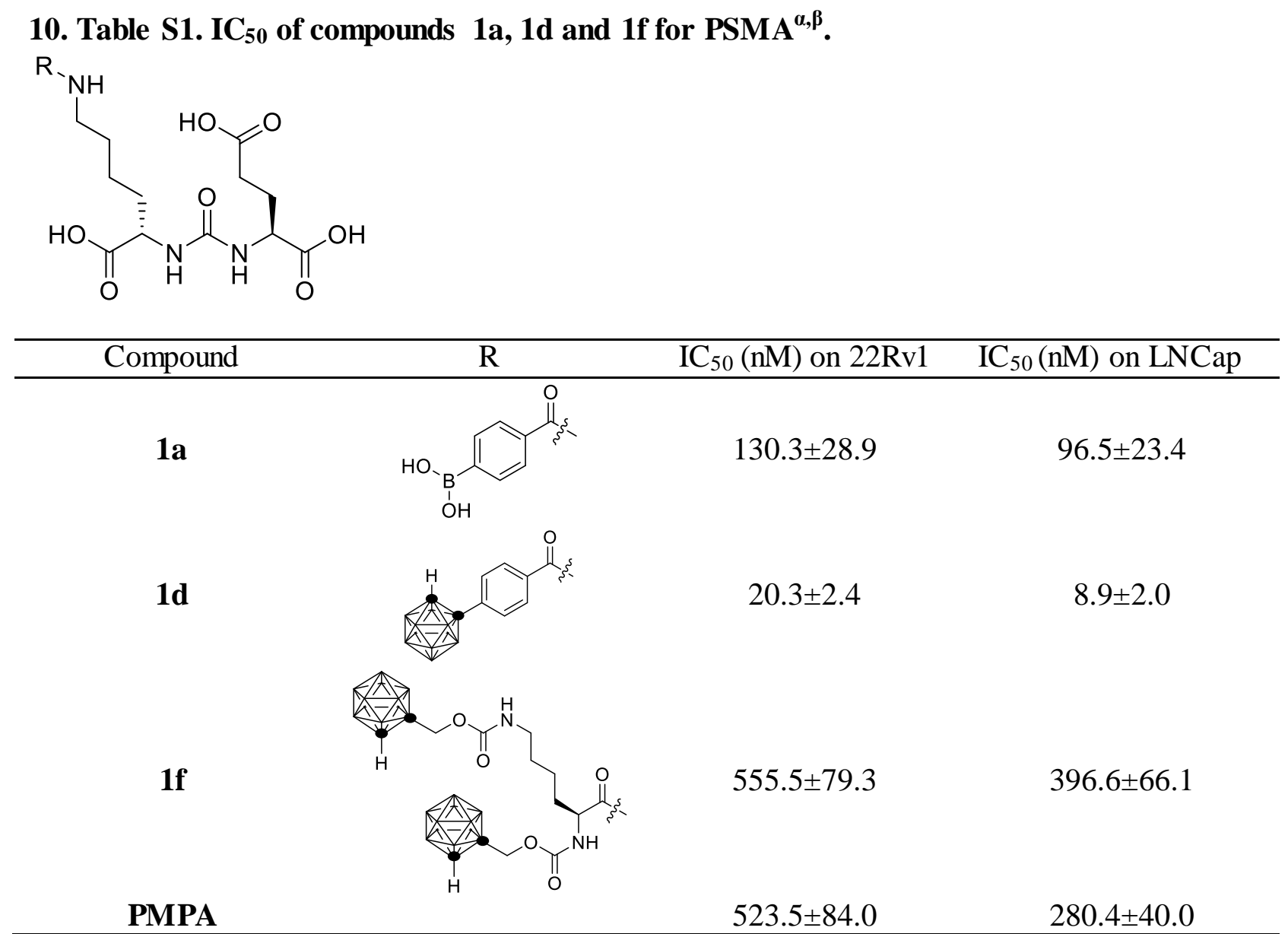

${ }^{\alpha}$ Competitive binding compound is ${ }^{68} \mathrm{Ga}$-PSMA-11. ${ }^{\beta}$ Cells were plated $48 \mathrm{~h}$ before testing (triplet). Various concentration (0.01-100000 $\mathrm{nM}$ ) of compounds with $10 \mu \mathrm{Ci}$ of ${ }^{68} \mathrm{Ga}$-PSMA-11 were added to cells and incubated for $1 \mathrm{~h}$. Cells were washed and lysed. A gamma counter was used to read the bound fraction to the lysed cells.

\section{Table S2. Serum protein binding}

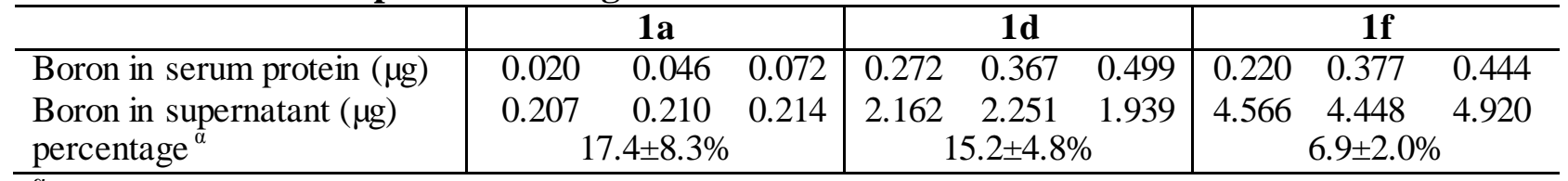

${ }^{\alpha}$ boron in plasma protein/totalboron in serum

12. Table S3. Cell toxicity test

\begin{tabular}{ccccccc}
\hline Compound & Concentration & \multicolumn{2}{c}{ Luminescent output (triplet) } & Average \pm sdv & Viability(\%) \\
\hline blank & - & 387090 & 381061 & 408994 & $39238 \pm 14700$ & $100.0 \pm 3.7$ \\
\hline \multirow{6}{*}{ 1a } & $0.01 \mathrm{nM}$ & 446835 & 421817 & 431825 & $433493 \pm 12592$ & $110.5 \pm 3.2$ \\
& $0.1 \mathrm{nM}$ & 403565 & 407489 & 398212 & $403089 \pm 4657$ & $102.7 \pm 1.2$ \\
& $1 \mathrm{nM}$ & 398079 & 381461 & 386596 & $388712 \pm 8509$ & $99.1 \pm 2.2$ \\
& $10 \mathrm{nM}$ & 442438 & 416581 & 437392 & $432137 \pm 13706$ & $110.1 \pm 3.5$ \\
& $100 \mathrm{nM}$ & 442137 & 391710 & 414235 & $416027 \pm 25261$ & $106.0 \pm 6.4$ \\
& $1 \mu \mathrm{M}$ & 378508 & 409720 & 416765 & $401664 \pm 20361$ & $102.4 \pm 5.2$ \\
& $10 \mu \mathrm{M}$ & 441594 & 402777 & 469303 & $437892 \pm 33417$ & $111.6 \pm 8.5$ \\
& $100 \mu \mathrm{M}$ & 469477 & 403043 & 418832 & $430450 \pm 34708$ & $109.7 \pm 8.8$ \\
\hline
\end{tabular}




\begin{tabular}{ccccccc}
\hline & $0.01 \mathrm{nM}$ & 383065 & 368995 & 368995 & $373685 \pm 8123$ & $95.2 \pm 2.1$ \\
& $0.1 \mathrm{nM}$ & 364097 & 345835 & 324661 & $344864 \pm 19736$ & $87.9 \pm 5.0$ \\
$1 \mathbf{d}$ & 352811 & 360499 & 329159 & $347490 \pm 16333$ & $88.6 \pm 4.2$ \\
& $10 \mathrm{nM}$ & 420714 & 477534 & 436648 & $444965 \pm 29309$ & $113.4 \pm 7.5$ \\
& $100 \mathrm{nM}$ & 457951 & 378799 & 352746 & $396499 \pm 54790$ & $101.0 \pm 14.0$ \\
& $1 \mu \mathrm{M}$ & 342686 & 391341 & 366108 & $366711 \pm 24333$ & $93.5 \pm 6.2$ \\
& $10 \mu \mathrm{M}$ & 421953 & 390080 & 399240 & $403758 \pm 16410$ & $102.9 \pm 4.2$ \\
& $100 \mu \mathrm{M}$ & 389610 & 429276 & 423865 & $414250 \pm 21510$ & $105.6 \pm 5.5$ \\
\hline \multirow{4}{*}{$\mathbf{1 f}$} & $0.01 \mathrm{nM}$ & 382016 & 412152 & 374767 & $389645 \pm 19826$ & $99.3 \pm 5.1$ \\
& $0.1 \mathrm{nM}$ & 332074 & 307073 & 313974 & $317707 \pm 12912$ & $81.0 \pm 3.3$ \\
& $1 \mathrm{nM}$ & 359067 & 337808 & 301658 & $332844 \pm 29024$ & $84.8 \pm 7.4$ \\
& $10 \mathrm{nM}$ & 434212 & 393382 & 364768 & $397454 \pm 34901$ & $101.3 \pm 8.9$ \\
& $100 \mathrm{nM}$ & 343830 & 360836 & 309942 & $338203 \pm 25909$ & $86.2 \pm 6.6$ \\
& $1 \mu \mathrm{M}$ & 380909 & 387275 & 308546 & $358910 \pm 43733$ & $91.5 \pm 11.1$ \\
& $10 \mu \mathrm{M}$ & 351628 & 369105 & 365434 & $362056 \pm 9215$ & $92.3 \pm 2.3$ \\
& $100 \mu \mathrm{M}$ & 362195 & 422872 & 380552 & $388539 \pm 31117$ & $99.0 \pm 7.9$ \\
\hline
\end{tabular}

13. Figure S1. Cell toxicity analysis for compound $1 \mathrm{a}, 1 \mathrm{~d}$ and $1 \mathrm{f}$. Cell Toxicity Assay

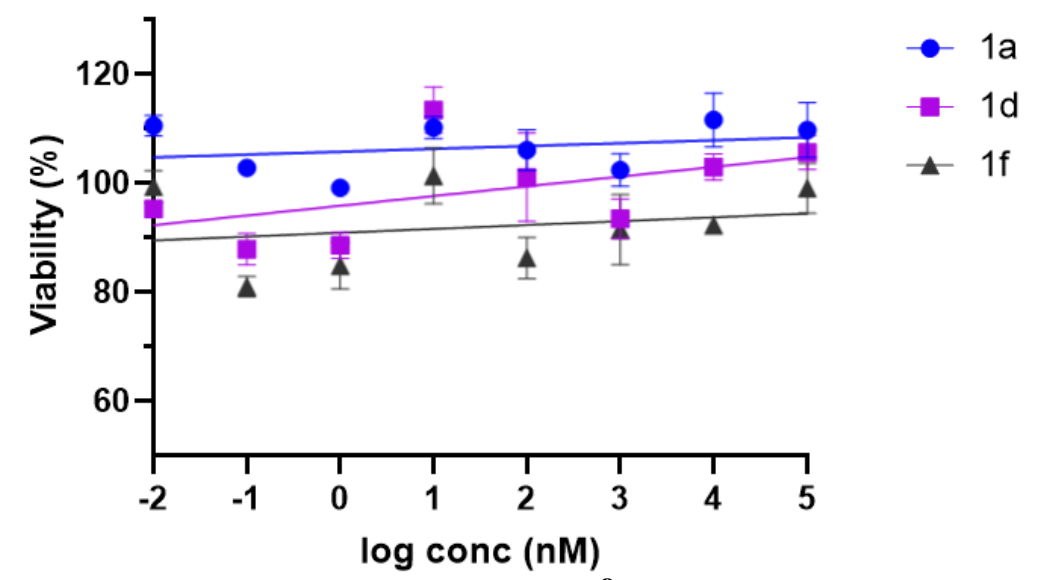

14. Table S4. Acute toxicity test ${ }^{\alpha, \beta}$

\begin{tabular}{lll|lll}
\hline Compound & Dose/mouse & survival rate & Compound & Dose/mouse & survival rate \\
\hline $\mathbf{1 a}$ & $30 \mathrm{mg}$ & $100 \%$ & $\mathbf{1 d}$ & $5 \mathrm{mg}$ & $100 \%$ \\
$\mathbf{1 d}$ & $15 \mathrm{mg}$ & $50 \%$ & $\mathbf{1 f}$ & $15 \mathrm{mg}$ & $50 \%$ \\
1d & $7.5 \mathrm{mg}$ & $50 \%$ & $\mathbf{1 f}$ & $7.5 \mathrm{mg}$ & $100 \%$ \\
\hline
\end{tabular}

${ }^{\alpha}$ Compounds were dosed to athymic male mice through intraperitoneal injection. The checkpoint is at 4 hour post injection. ${ }^{\beta}$ Two mice in each testing group.

15. Table S5. Region of interest analysis of \%ID/cc on tumor for the micro PET/CT images

\begin{tabular}{ccccccccccc}
\hline & \multicolumn{2}{c}{ vehicle } & \multicolumn{2}{c}{ BPA } & \multicolumn{2}{c}{ 1a } & \multicolumn{2}{c}{ 1d } & \multicolumn{2}{c}{ 1f } \\
\cline { 2 - 10 } & mean & $\max$ & mean & $\max$ & $\operatorname{mean}$ & $\max$ & $\operatorname{mean}$ & $\max$ & $\operatorname{mean}$ & $\max$ \\
\hline Mouse 1 & 2.116 & 4.909 & 1.972 & 5.151 & 0.029 & 1.178 & 0.111 & 1.581 & 0.680 & 2.423
\end{tabular}


$\begin{array}{lllllllllll}\text { Mouse } 2 & 1.772 & 4.818 & 1.694 & 4.836 & 0.202 & 1.239 & 0.115 & 2.327 & 0.443 & 2.384\end{array}$

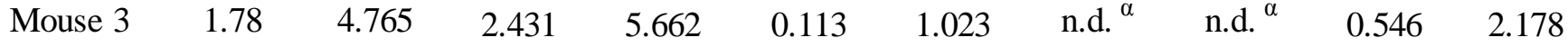

$\begin{array}{lllllllllll}\text { Mouse } 4 & 1.705 & 4.316 & 1.487 & 5.696 & 0.131 & 1.312 & 0.125 & 1.893 & 0.589 & 2.097\end{array}$

$\%$ ID/gram

$1.843 \pm 4.702 \pm 1.896 \pm 5.336 \pm 0.119 \pm 1.188 \pm 0.117 \pm 1.934 \pm 0.564 \pm 2.271 \pm$ $\begin{array}{llllllllll}0.185 & 0.264 & 0.408 & 0.416 & 0.071 & 0.123 & 0.007 & 0.375 & 0.098 & 0.158\end{array}$

${ }^{\alpha}$ n.d. not detected. Mouse died before imaging.

16. Table S6. Region of interest analysis of SUV on tumor for the micro PET/CT images

\begin{tabular}{ccccccccccc}
\hline & \multicolumn{2}{c}{ vehicle } & \multicolumn{2}{c}{ BPA } & \multicolumn{2}{c}{ 1a } & \multicolumn{2}{c}{ 1d } & \multicolumn{1}{c}{ 1f } \\
\cline { 2 - 10 } & mean & $\max$ & mean & $\max$ & $\operatorname{mean}$ & $\max$ & $\operatorname{mean}$ & $\max$ & $\operatorname{mean}$ & $\max$ \\
\hline Mouse 1 & 0.324 & 0.751 & 0.394 & 1.030 & 0.006 & 0.247 & 0.022 & 0.316 & 0.136 & 0.485 \\
Mouse 2 & 0.399 & 1.084 & 0.339 & 0.967 & 0.040 & 0.245 & 0.023 & 0.465 & 0.089 & 0.477 \\
Mouse 3 & 0.356 & 0.953 & 0.486 & 1.132 & 0.024 & 0.215 & n.d. $^{\alpha}$ & n.d. $^{\alpha}$ & 0.107 & 0.426 \\
Mouse 4 & 0.344 & 0.872 & 0.297 & 1.139 & 0.020 & 0.205 & 0.025 & 0.376 & 0.118 & 0.419 \\
& $0.356 \pm$ & $0.915 \pm$ & $0.379 \pm$ & $1.067 \pm$ & $0.023 \pm$ & 0.228 & $0.023 \pm$ & $0.386 \pm$ & $0.112 \pm$ & $0.452 \pm$ \\
\% ID/gram & 0.032 & 0.140 & 0.082 & 0.083 & 0.014 & \pm 0.022 & 0.001 & 0.075 & 0.020 & 0.034
\end{tabular}

${ }^{\alpha}$ n.d. not detected. Mouse died before imaging.

17. Table S7. ${ }^{68}$ Ga-PSMA-11 biodistribution analysis data ${ }^{\alpha}$

\begin{tabular}{lrrrr|rrrr}
\hline & \multicolumn{5}{c}{ Vehicle_1h } & \multicolumn{4}{c}{ BPA_1h } \\
\hline blood & 0.039 & 0.035 & 0.037 & 0.038 & 0.512 & 0.507 & 1.133 & 0.894 \\
brain & 0.008 & 0.014 & 0.011 & 0.017 & 0.044 & 0.041 & 0.064 & 0.047 \\
bone & 0.085 & 0.107 & 0.068 & 0.08 & 0.462 & 0.335 & 0.4 & 0.366 \\
heart & 0.372 & 0.225 & 0.121 & 0.249 & 0.728 & 1.048 & 0.604 & 0.559 \\
kidney & 12.268 & 50.111 & 54.349 & 78.894 & 23.211 & 19.334 & 60.303 & 31.879 \\
liver & 0.104 & 0.141 & 0.117 & 0.157 & 0.499 & 0.425 & 0.551 & 0.513 \\
lung & 0.542 & 0.65 & 0.702 & 0.733 & 1.793 & 1.837 & 1.444 & 1.259 \\
muscle & 0.097 & 0.153 & 0.065 & 0.141 & 0.383 & 0.318 & 0.353 & 0.366 \\
pancreas & 0.286 & 0.436 & 0.233 & 0.568 & 1.487 & 0.875 & 0.829 & 0.737 \\
salivary & 0.41 & 0.584 & 0.528 & 0.794 & 2.066 & 1.606 & 0.989 & 1.103 \\
skin & 0.252 & 0.47 & 0.371 & 0.636 & 1.112 & 1.411 & 1.002 & 1.174 \\
spleen & 4.485 & 7.428 & 5.07 & 9.35 & 10.833 & 16.524 & 6.708 & 10.989 \\
tumor & 2.045 & 2.669 & 2.354 & 1.881 & 4.268 & 3.867 & 4.316 & 5.461 \\
\hline & \multicolumn{9}{c}{ BPA_4h } & & & $1 \mathrm{a} \_1 \mathrm{~h}$ & & \\
\hline blood & 0.594 & 0.217 & 0.107 & 0.168 & 1.198 & 0.767 & 1.544 & 1.258 \\
brain & 0.028 & 0.042 & 0.167 & 0.076 & 0.081 & 0.029 & 0.111 & 0.065 \\
bone & 0.178 & 0.173 & 0.248 & 0.227 & 0.365 & 0.25 & 0.645 & 0.459 \\
heart & 0.302 & 0.585 & 0.379 & 0.456 & 1.37 & 0.398 & 1.256 & 0.872 \\
kidney & 22.751 & 173.753 & 242.434 & 241.164 & 2.741 & 3.251 & 4.498 & 4.127 \\
liver & 0.34 & 0.304 & 0.214 & 0.474 & 1.314 & 0.303 & 0.91 & 0.549 \\
lung & 1.23 & 1.214 & 0.73 & 1.5 & 5.5 & 0.686 & 1.76 & 0.954 \\
muscle & 0.181 & 0.161 & 0.203 & 0.735 & 0.416 & 0.446 & 0.628 & 0.453 \\
pancreas & 1.619 & 0.536 & 0.662 & 0.942 & 3.821 & 0.211 & 2.286 & 0.733 \\
salivary & 0.959 & 0.597 & 0.648 & 0.721 & 0.402 & 0.338 & 0.94 & 0.872 \\
skin & 0.787 & 0.633 & 0.601 & 0.646 & 0.699 & 0.502 & 1.478 & 1.172 \\
spleen & 5.461 & 6.047 & 8.734 & 12.074 & 2.195 & 0.214 & 1.134 & 0.418
\end{tabular}




\begin{tabular}{|c|c|c|c|c|c|c|c|c|}
\hline tumor & 3.857 & 4.628 & 4.795 & 4.605 & 0.462 & 0.429 & 0.846 & 0.605 \\
\hline & \multicolumn{4}{|c|}{ 1a_4h } & \multicolumn{4}{|c|}{$1 \mathrm{~d} \_1 \mathrm{~h}$} \\
\hline blood & 0.013 & 0.015 & 0.032 & 0.037 & 1.053 & 4.034 & 2.662 & 0.999 \\
\hline brain & 0.005 & 0.014 & 0.033 & 0.025 & 0.052 & 0.153 & 0.087 & 0.103 \\
\hline bone & 0.023 & 0.016 & 0.044 & 0.035 & 0.665 & 1.061 & 0.915 & 2.597 \\
\hline heart & 0.025 & 0.041 & 0.023 & 0.048 & 0.829 & 1.775 & 1.595 & 0.744 \\
\hline kidney & 0.193 & 0.314 & 0.054 & 0.25 & 6.096 & 17.551 & 11.704 & 5.52 \\
\hline liver & 0.083 & 0.062 & 0.078 & 0.204 & 0.842 & 1.938 & 0.936 & 0.534 \\
\hline lung & 0.05 & 0.014 & 0.054 & 0.063 & 2.56 & 2.84 & 1.774 & 0.843 \\
\hline muscle & 0.016 & 0.008 & 0.044 & 0.04 & 1.04 & 1.038 & 0.668 & 1.295 \\
\hline pancreas & 0.069 & 0.026 & 0.048 & 0.072 & 3.532 & 3.603 & 0.931 & 1.519 \\
\hline salivary & 0.023 & 0.014 & 0.033 & 0.06 & 1.259 & 1.651 & 1.269 & 0.401 \\
\hline skin & 0.057 & 0.029 & 0.045 & 0.078 & 0.656 & 4.03 & 1.834 & 0.935 \\
\hline spleen & 0.062 & 0.068 & 0.049 & 0.057 & 1.085 & 1.692 & 0.635 & 0.497 \\
\hline tumor & 0.072 & 0.04 & 0.054 & 0.042 & 0.537 & 1.634 & 1.019 & 0.493 \\
\hline \multicolumn{5}{|c|}{ 1d_4h } & \multicolumn{4}{|c|}{ 1f_1h } \\
\hline blood & 0.017 & 0.015 & 0.036 & \multirow{13}{*}{$\begin{array}{c}\text { Mouse } \\
\text { died }\end{array}$} & 3.832 & 2.679 & 1.828 & 4.42 \\
\hline brain & 0.026 & 0.018 & 0.017 & & 0.156 & 0.222 & 0.08 & 0.186 \\
\hline bone & 0.02 & 0.017 & 0.029 & & 1.239 & 1.404 & 0.546 & 1.609 \\
\hline heart & 0.046 & 0.035 & 0.017 & & 2.407 & 2.035 & 1.101 & 2.974 \\
\hline kidney & 0.177 & 0.208 & 0.729 & & 4.643 & 13.032 & 1.607 & 17.631 \\
\hline liver & 0.055 & 0.047 & 0.111 & & 1.495 & 1.862 & 0.677 & 2.382 \\
\hline lung & 0.057 & 0.035 & 0.043 & & 3.594 & 2.924 & 1.327 & 4.891 \\
\hline muscle & 0.018 & 0.026 & 0.014 & & 1.157 & 0.86 & 0.469 & 1.501 \\
\hline pancreas & 0.025 & 0.031 & 0.04 & & 5.094 & 2.428 & 1.123 & 2.773 \\
\hline salivary & 0.028 & 0.029 & 0.017 & & 1.867 & 1.805 & 0.675 & 1.969 \\
\hline skin & 0.078 & 0.034 & 0.027 & & 3.444 & 3.201 & 1.232 & 4.236 \\
\hline spleen & 0.066 & 0.036 & 0.049 & & 1.918 & 2.135 & 0.701 & 1.988 \\
\hline tumor & 0.062 & 0.1 & 0.124 & & 0.6 & 1.51 & 0.329 & 1.85 \\
\hline \multicolumn{5}{|c|}{ 1f_4h } & & & & \\
\hline blood & 1.684 & 1.068 & 1.775 & 0.358 & & & & \\
\hline brain & 0.12 & 0.052 & 0.067 & 0.043 & & & & \\
\hline bone & 0.395 & 0.33 & 0.369 & 0.202 & & & & \\
\hline heart & 0.565 & 0.437 & 0.668 & 0.216 & & & & \\
\hline kidney & 29.615 & 29.886 & 17.722 & 11.068 & & & & \\
\hline liver & 1.359 & 2.277 & 1.235 & 0.491 & & & & \\
\hline lung & 0.928 & 0.808 & 0.843 & 0.305 & & & & \\
\hline muscle & 0.349 & 0.263 & 0.299 & 0.211 & & & & \\
\hline pancreas & 0.658 & 0.818 & 0.797 & 0.337 & & & & \\
\hline salivary & 0.621 & 0.528 & 0.399 & 0.163 & & & & \\
\hline skin & 0.866 & 0.958 & 0.997 & 0.367 & & & & \\
\hline spleen & 0.618 & 0.531 & 0.508 & 0.4 & & & & \\
\hline tumor & 0.499 & 0.494 & 0.558 & 0.458 & & & & \\
\hline
\end{tabular}

${ }^{\alpha}$ value unit is ID\%/gram tissue

18. Table S8. In vivo boron biodistribution analysis data ( $\mu \mathrm{g} / \mathrm{gram}$ tissue)

\begin{tabular}{|c|c|c|c|c|c|c|c|c|}
\hline & \multicolumn{4}{|c|}{ Vehicle_1h } & \multicolumn{4}{|c|}{ BPA_1h } \\
\hline blood & 0.06 & -0.17 & -0.17 & -0.04 & 3.4 & 1.2 & 1.91 & 2.1 \\
\hline brain & -0.04 & -0.26 & -0.26 & -0.15 & 2.47 & 0.85 & 0.67 & 1.25 \\
\hline bone & 0.14 & -0.03 & -0.03 & 0.2 & 4.96 & 1.61 & 1.45 & 2.43 \\
\hline heart & -0.26 & -1.16 & -1.16 & -0.36 & 3.84 & 1.22 & 1.19 & 2.02 \\
\hline
\end{tabular}




\begin{tabular}{|c|c|c|c|c|c|c|c|c|}
\hline kidney & 0.02 & -0.21 & -0.21 & -0.02 & 7.77 & 2.5 & 1.92 & 3.18 \\
\hline liver & -0.16 & -0.24 & -0.24 & -0.05 & 4.07 & 1.23 & 0.96 & 1.99 \\
\hline lung & -0.26 & -0.5 & -0.5 & -0.08 & 3.87 & 0.85 & 4.81 & 5.38 \\
\hline muscle & -0.24 & -0.45 & -0.45 & -0.09 & 4.83 & 1.65 & 0.96 & 2.22 \\
\hline pancreas & -0.53 & -0.5 & -0.5 & -1.16 & 61.58 & 12.85 & 10.02 & 25.97 \\
\hline salivary & -0.32 & -0.37 & -0.37 & -0.5 & 4.86 & 1.28 & 1.35 & 2.06 \\
\hline skin & -0.22 & -0.31 & -0.31 & -0.11 & 6.64 & 1.13 & 1.67 & 1.88 \\
\hline spleen & -0.43 & -0.51 & -0.51 & -1.19 & 8.98 & 1.33 & 1.17 & 4.07 \\
\hline tumor & -0.12 & -0.21 & -0.21 & -0.21 & 7.68 & 3.06 & 1.6 & 4.35 \\
\hline \multicolumn{5}{|c|}{ BPA_4h } & \multicolumn{4}{|c|}{ 1a_1h } \\
\hline blood & 5.3 & 1.44 & 0.93 & 5.27 & 10.7 & 10.49 & 5.18 & 4.72 \\
\hline brain & 3.05 & 0.96 & 0.52 & 3.54 & 0.91 & 0.87 & 0.7 & 0.6 \\
\hline bone & 4.76 & 1.97 & 1.7 & 7.04 & 4.7 & 5.82 & 3.16 & 3.05 \\
\hline heart & 3.43 & 1.92 & 1.12 & 6.95 & 8.58 & 5.05 & 3.53 & 3.23 \\
\hline kidney & 6.22 & 4.92 & 1.81 & 14.63 & 21.76 & 25.28 & 12.87 & 16.75 \\
\hline liver & 3.22 & 1.35 & 0.95 & 7.59 & 12.14 & 9.33 & 8.32 & 8.69 \\
\hline lung & 3.91 & 2.15 & 1.21 & 7.01 & 24.1 & 6.73 & 4.31 & 3.77 \\
\hline muscle & 4.76 & 1.57 & 1.55 & 10.27 & 3.22 & 6.97 & 2.46 & 2.49 \\
\hline pancreas & 11 & 8.67 & 6.74 & 51.37 & 19.79 & 3.93 & 9.89 & 8.17 \\
\hline salivary & 4.06 & 1.69 & 0.86 & 5.78 & 3.75 & 3.9 & 3.24 & 3.29 \\
\hline skin & 4.23 & 1.19 & 1.18 & 4.23 & 3.64 & 4.69 & 4.55 & 3.76 \\
\hline spleen & 4.32 & 2.25 & 1.32 & 10.63 & 14.19 & 4.39 & 4.44 & 3.9 \\
\hline \multirow[t]{2}{*}{ tumor } & 11.38 & 3.91 & 3.42 & 9.7 & 3.87 & 4.26 & 5.32 & 2.84 \\
\hline & \multicolumn{4}{|c|}{ 1a_4h } & \multicolumn{4}{|c|}{ 1d_1h } \\
\hline blood & 1.6 & 0.99 & 0.91 & 3.32 & 15.23 & 36.4 & 20.17 & 18.07 \\
\hline brain & 0.88 & 0.73 & 0.76 & 1.02 & 0.25 & 0.65 & 0.48 & 0.48 \\
\hline bone & 1.75 & 1.47 & 2.9 & 3.38 & 2.88 & 5.57 & 5.08 & 7.47 \\
\hline heart & 0.88 & 0.89 & 0.97 & 1.58 & 5.66 & 8.79 & 10.51 & 8.64 \\
\hline kidney & 7.11 & 4 & 3.35 & 11.65 & 11.37 & 23.26 & 14.82 & 16.29 \\
\hline liver & 5.37 & 3.09 & 3.21 & 7.5 & 184.35 & 371.48 & 256.67 & 208.6 \\
\hline lung & 1.53 & 0.8 & 1.03 & 2.07 & 15.2 & 20.6 & 16.01 & 13.77 \\
\hline muscle & 1.38 & 0.53 & 1.48 & 1.87 & 3.84 & 4.66 & 5.08 & 3.89 \\
\hline pancreas & 2.3 & 1.5 & 0.62 & 3.1 & 17.77 & 24.24 & 14.36 & 20.24 \\
\hline salivary & 1.11 & 0.55 & 1.37 & 1.36 & 3.06 & 6.23 & 4.02 & 3.28 \\
\hline skin & 1.41 & 0.58 & 0.71 & 1.76 & 3 & 13.14 & 6.02 & 6.91 \\
\hline spleen & 2.21 & 1.45 & 0.61 & 2.93 & 7.49 & 15.39 & 7.24 & 7.37 \\
\hline \multirow[t]{2}{*}{ tumor } & 1.82 & 0.93 & 1.29 & 2.25 & 4.9 & 8.62 & 3.41 & 2.69 \\
\hline & \multicolumn{4}{|c|}{ 1d_4h } & \multicolumn{4}{|c|}{ 1f_1h } \\
\hline blood & 18.7 & 17.03 & 12.28 & 20.36 & 24.74 & 16.02 & 15.85 & 12.82 \\
\hline brain & 0.97 & 0.63 & 0.41 & 0.45 & 0.56 & 0.39 & 0.56 & 0.47 \\
\hline bone & 4.87 & 2.98 & 2.06 & 3.19 & 3.22 & 3.35 & 3.76 & 4.43 \\
\hline heart & 10.17 & 8.31 & 4.77 & 8.15 & 8.88 & 4.11 & 6.68 & 10.1 \\
\hline kidney & 12.94 & 16 & 12.97 & 13.67 & 20.3 & 20.94 & 19.76 & 18.93 \\
\hline liver & 64.29 & 205.83 & 310.49 & 198.95 & 107.29 & 107.92 & 123.22 & 99.01 \\
\hline lung & 11.7 & 12.69 & 8.86 & 14.73 & 15.5 & 7.85 & 14.39 & 27.62 \\
\hline muscle & 3.38 & 1.47 & 1.67 & 2.26 & 4.55 & 2.24 & 4.72 & 8.9 \\
\hline pancreas & 20.11 & 3.21 & 4.64 & 5.53 & 671.01 & 85.56 & 208.01 & 195.21 \\
\hline salivary & 3.63 & 3.65 & 2.54 & 3.8 & 2.82 & 2.53 & 2.17 & 4.94 \\
\hline skin & 5.06 & 3.57 & 3.27 & 4.66 & 3 & 3.11 & 18.51 & 9.65 \\
\hline spleen & 7.77 & 6.18 & 3.82 & 4.45 & 72.66 & 27.61 & 67.05 & 39 \\
\hline tumor & 5.2 & 4.41 & 3.54 & 3.51 & 2.25 & 1.88 & 1.25 & 7.74 \\
\hline
\end{tabular}




\begin{tabular}{|c|c|c|c|c|c|}
\hline & \multicolumn{4}{|c|}{ 1f_4h } & \\
\hline blood & 74.93 & 79.93 & 143.35 & 15.08 & \\
\hline brain & 1.43 & 0.92 & 1.9 & 0.55 & \\
\hline bone & 4.34 & 3.78 & 5.22 & 3.32 & \\
\hline heart & 12.23 & 11.59 & 9.93 & 6.24 & \\
\hline kidney & 29.99 & 24.88 & 17.98 & 19.56 & \\
\hline liver & 214.31 & 413.58 & 131.96 & 149.75 & \\
\hline lung & 31.56 & 20.51 & 25.49 & 12.06 & \\
\hline muscle & 3.84 & 7.59 & 5.69 & 3.42 & \\
\hline pancreas & 248.53 & 336.14 & 250.16 & 116.96 & \\
\hline salivary & 5.95 & 4.47 & 2.61 & 2.16 & \\
\hline skin & 5.15 & 2.85 & 10.01 & 9.89 & \\
\hline spleen & 59.93 & 51.86 & 29.11 & 30.53 & \\
\hline tumor & 9.36 & 1.36 & 1.96 & 0.84 & \\
\hline
\end{tabular}

19. Table S9. In vivo boron biodistribution analysis data (ID\%/gram tissue)

\begin{tabular}{|c|c|c|c|c|c|c|c|c|}
\hline & \multicolumn{4}{|c|}{ BPA_1h } & \multicolumn{4}{|c|}{ BPA_4h } \\
\hline blood & 1.32 & 0.47 & 0.74 & 0.81 & 2.05 & 0.56 & 0.36 & 2.04 \\
\hline brain & 0.96 & 0.33 & 0.26 & 0.48 & 1.18 & 0.37 & 0.2 & 1.37 \\
\hline bone & 1.92 & 0.62 & 0.56 & 0.94 & 1.84 & 0.76 & 0.66 & 2.73 \\
\hline heart & 1.49 & 0.47 & 0.46 & 0.78 & 1.33 & 0.74 & 0.43 & 2.69 \\
\hline kidney & 3.01 & 0.97 & 0.74 & 1.23 & 2.41 & 1.91 & 0.7 & 5.67 \\
\hline liver & 1.58 & 0.48 & 0.37 & 0.77 & 1.25 & 0.52 & 0.37 & 2.94 \\
\hline lung & 1.5 & 0.33 & 1.86 & 2.09 & 1.52 & 0.83 & 0.47 & 2.72 \\
\hline muscle & 1.87 & 0.64 & 0.37 & 0.86 & 1.84 & 0.61 & 0.6 & 3.98 \\
\hline pancreas & 23.87 & 4.98 & 3.88 & 10.07 & 4.26 & 3.36 & 2.61 & 19.91 \\
\hline salivary & 1.88 & 0.5 & 0.52 & 0.8 & 1.57 & 0.66 & 0.33 & 2.24 \\
\hline skin & 2.57 & 0.44 & 0.65 & 0.73 & 1.64 & 0.46 & 0.46 & 1.64 \\
\hline spleen & 3.48 & 0.52 & 0.45 & 1.58 & 1.67 & 0.87 & 0.51 & 4.12 \\
\hline tumor & 2.98 & 1.19 & 0.62 & 1.69 & 4.41 & 1.52 & 1.33 & 3.76 \\
\hline \multicolumn{5}{|c|}{ 1a_1h } & \multicolumn{4}{|c|}{ 1a_4h } \\
\hline blood & 1.54 & 1.51 & 0.75 & 0.68 & 0.23 & 0.14 & 0.13 & 0.48 \\
\hline brain & 0.13 & 0.13 & 0.1 & 0.09 & 0.13 & 0.11 & 0.11 & 0.15 \\
\hline bone & 0.68 & 0.84 & 0.46 & 0.44 & 0.25 & 0.21 & 0.42 & 0.49 \\
\hline heart & 1.24 & 0.73 & 0.51 & 0.47 & 0.13 & 0.13 & 0.14 & 0.23 \\
\hline kidney & 3.14 & 3.64 & 1.85 & 2.41 & 1.02 & 0.58 & 0.48 & 1.68 \\
\hline liver & 1.75 & 1.34 & 1.2 & 1.25 & 0.77 & 0.45 & 0.46 & 1.08 \\
\hline lung & 3.47 & 0.97 & 0.62 & 0.54 & 0.22 & 0.12 & 0.15 & 0.3 \\
\hline muscle & 0.46 & 1 & 0.35 & 0.36 & 0.2 & 0.08 & 0.21 & 0.27 \\
\hline pancreas & 2.85 & 0.57 & 1.43 & 1.18 & 0.33 & 0.22 & 0.09 & 0.45 \\
\hline salivary & 0.54 & 0.56 & 0.47 & 0.47 & 0.16 & 0.08 & 0.2 & 0.2 \\
\hline skin & 0.52 & 0.68 & 0.66 & 0.54 & 0.2 & 0.08 & 0.1 & 0.25 \\
\hline spleen & 2.04 & 0.63 & 0.64 & 0.56 & 0.32 & 0.21 & 0.09 & 0.42 \\
\hline \multirow[t]{2}{*}{ tumor } & 0.56 & 0.61 & 0.77 & 0.41 & 0.26 & 0.13 & 0.19 & 0.32 \\
\hline & \multicolumn{4}{|c|}{ 1d_1h } & \multicolumn{4}{|c|}{ 1d_4h } \\
\hline blood & 1.6 & 3.82 & 2.12 & 1.9 & 1.96 & 1.79 & 1.29 & 2.14 \\
\hline brain & 0.03 & 0.07 & 0.05 & 0.05 & 0.1 & 0.07 & 0.04 & 0.05 \\
\hline bone & 0.3 & 0.59 & 0.53 & 0.78 & 0.51 & 0.31 & 0.22 & 0.34 \\
\hline heart & 0.59 & 0.92 & 1.1 & 0.91 & 1.07 & 0.87 & 0.5 & 0.86 \\
\hline kidney & 1.19 & 2.44 & 1.56 & 1.71 & 1.36 & 1.68 & 1.36 & 1.44 \\
\hline \multirow[t]{2}{*}{ liver } & 19.36 & 39.02 & 26.96 & 21.91 & 6.75 & 21.62 & 32.61 & 20.9 \\
\hline & \multicolumn{8}{|c|}{ S16 } \\
\hline
\end{tabular}




\begin{tabular}{|c|c|c|c|c|c|c|c|c|}
\hline lung & 1.6 & 2.16 & 1.68 & 1.45 & 1.23 & 1.33 & 0.93 & 1.55 \\
\hline muscle & 0.4 & 0.49 & 0.53 & 0.41 & 0.36 & 0.15 & 0.18 & 0.24 \\
\hline pancreas & 1.87 & 2.55 & 1.51 & 2.13 & 2.11 & 0.34 & 0.49 & 0.58 \\
\hline salivary & 0.32 & 0.65 & 0.42 & 0.34 & 0.38 & 0.38 & 0.27 & 0.4 \\
\hline skin & 0.32 & 1.38 & 0.63 & 0.73 & 0.53 & 0.38 & 0.34 & 0.49 \\
\hline spleen & 0.79 & 1.62 & 0.76 & 0.77 & 0.82 & 0.65 & 0.4 & 0.47 \\
\hline tumor & 0.28 & 0.91 & 0.36 & 0.28 & 0.55 & 0.46 & 0.37 & 0.37 \\
\hline \multicolumn{5}{|c|}{ 1f_1h } & \multicolumn{4}{|c|}{ 1f_4h } \\
\hline blood & 1.3 & 0.84 & 0.83 & 0.67 & 3.94 & 4.2 & 7.54 & 0.79 \\
\hline brain & 0.03 & 0.02 & 0.03 & 0.02 & 0.08 & 0.05 & 0.1 & 0.03 \\
\hline bone & 0.17 & 0.18 & 0.2 & 0.23 & 0.23 & 0.2 & 0.27 & 0.17 \\
\hline heart & 0.47 & 0.22 & 0.35 & 0.53 & 0.64 & 0.61 & 0.52 & 0.33 \\
\hline kidney & 1.07 & 1.1 & 1.04 & 1 & 1.58 & 1.31 & 0.95 & 1.03 \\
\hline liver & 5.64 & 5.67 & 6.48 & 5.21 & 11.27 & 21.74 & 6.94 & 7.87 \\
\hline lung & 0.81 & 0.41 & 0.76 & 1.45 & 1.66 & 1.08 & 1.34 & 0.63 \\
\hline muscle & 0.24 & 0.12 & 0.25 & 0.47 & 0.2 & 0.4 & 0.3 & 0.18 \\
\hline pancreas & 35.28 & 4.5 & 10.94 & 10.26 & 13.07 & 17.67 & 13.15 & 6.15 \\
\hline salivary & 0.15 & 0.13 & 0.11 & 0.26 & 0.31 & 0.24 & 0.14 & 0.11 \\
\hline skin & 0.16 & 0.16 & 0.97 & 0.51 & 0.27 & 0.15 & 0.53 & 0.52 \\
\hline spleen & 3.82 & 1.45 & 3.53 & 2.05 & 3.15 & 2.73 & 1.53 & 1.61 \\
\hline tumor & 0.12 & 0.1 & 0.07 & 0.41 & 0.49 & 0.07 & 0.1 & 0.04 \\
\hline
\end{tabular}

20. Figure S2. In vivo boron biodistribution analysis data (ID\%/gram tissue)

Boron Biodistribution (ID\%/gram)

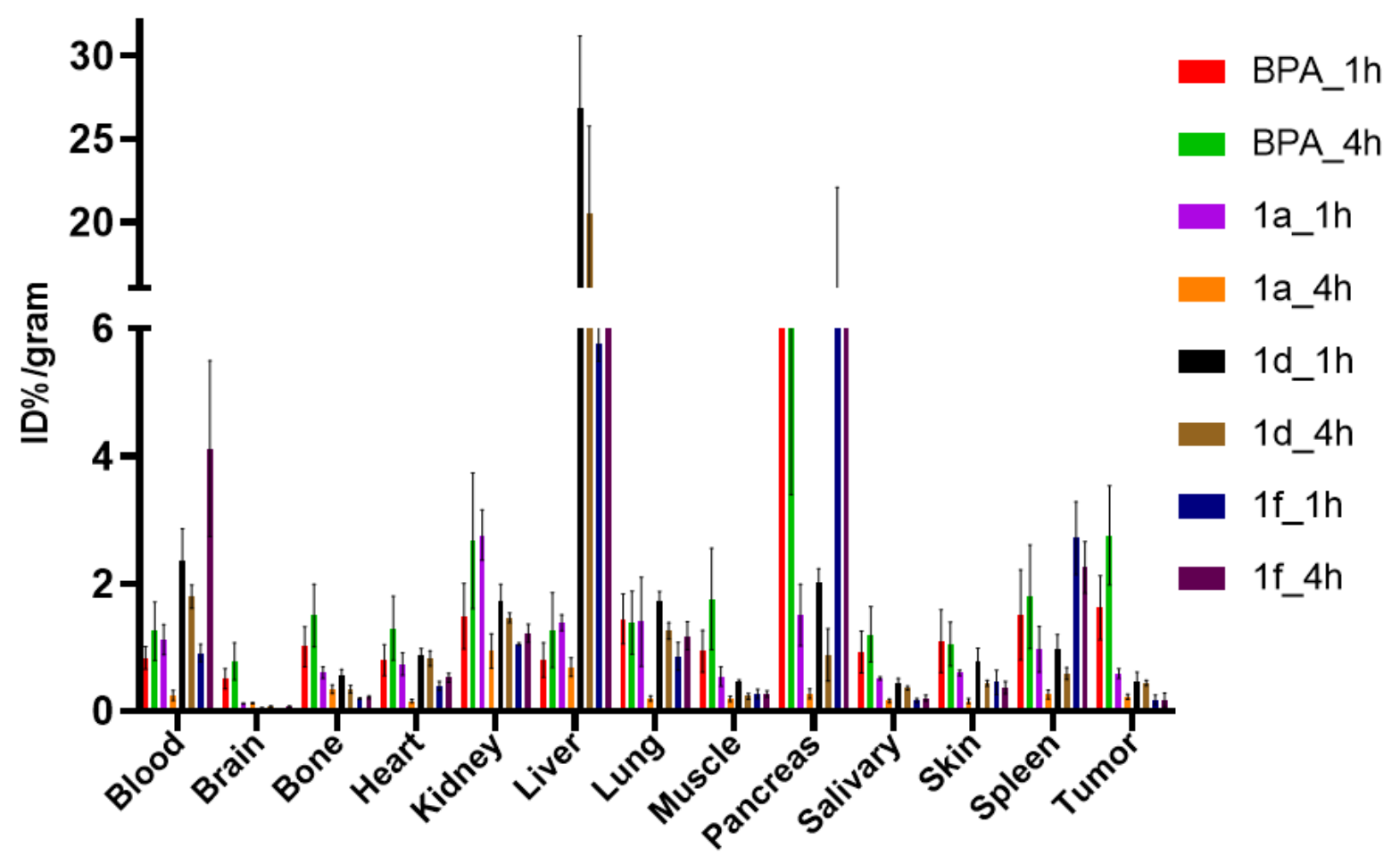

Tissue

\section{Reference}

1) Youn, S.; Kim, K. I.; Ptacek, J.; Ok, K.; Novakova, Z.; Kim, Y. H.; Koo, J. H.; Barinka, C.; Byun, Y. Carborane-Containing Urea-Based Inhibitors of Glutamate Carboxypeptidase II: Synthesis and Structural Characterization. Bioorganic Med. Chem. Lett. 2015, 25 (22), 5232-5236. 
22. ${ }^{1} \mathrm{H}$ and ${ }^{13} \mathrm{C}$ NMR spectra data (4-((6-(tert-Butoxy)-5-(3-((S)-1,5-di-tert-butoxy-1,5-dioxopentan-2-yl)ureido)-6-oxohexyl) carbamoyl)phenyl)boronic acid (13a)
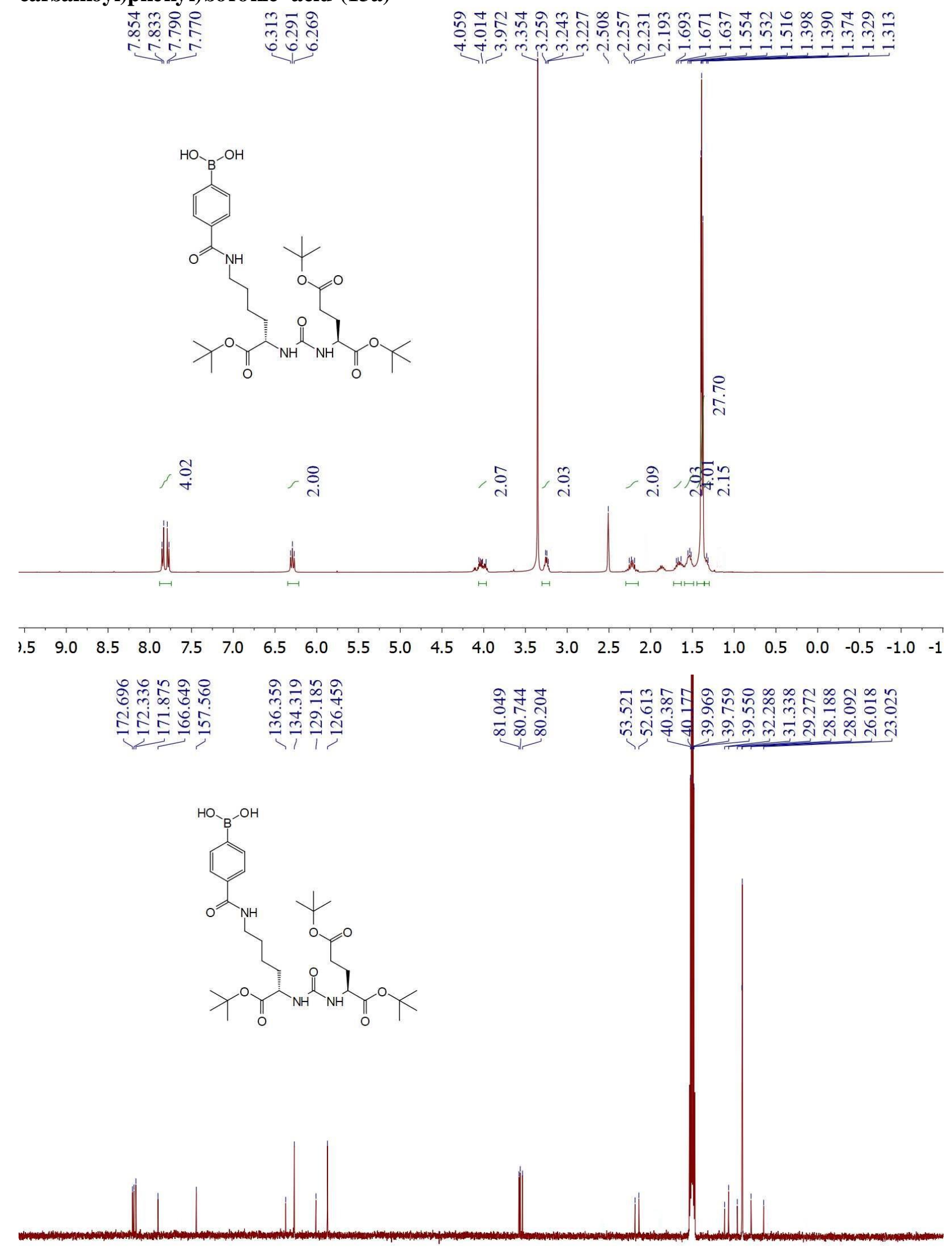
((5-(4-Boronobenzamido)-1-carboxy pentyl)carbamoyl)- $L$-glutamic acid (1a)
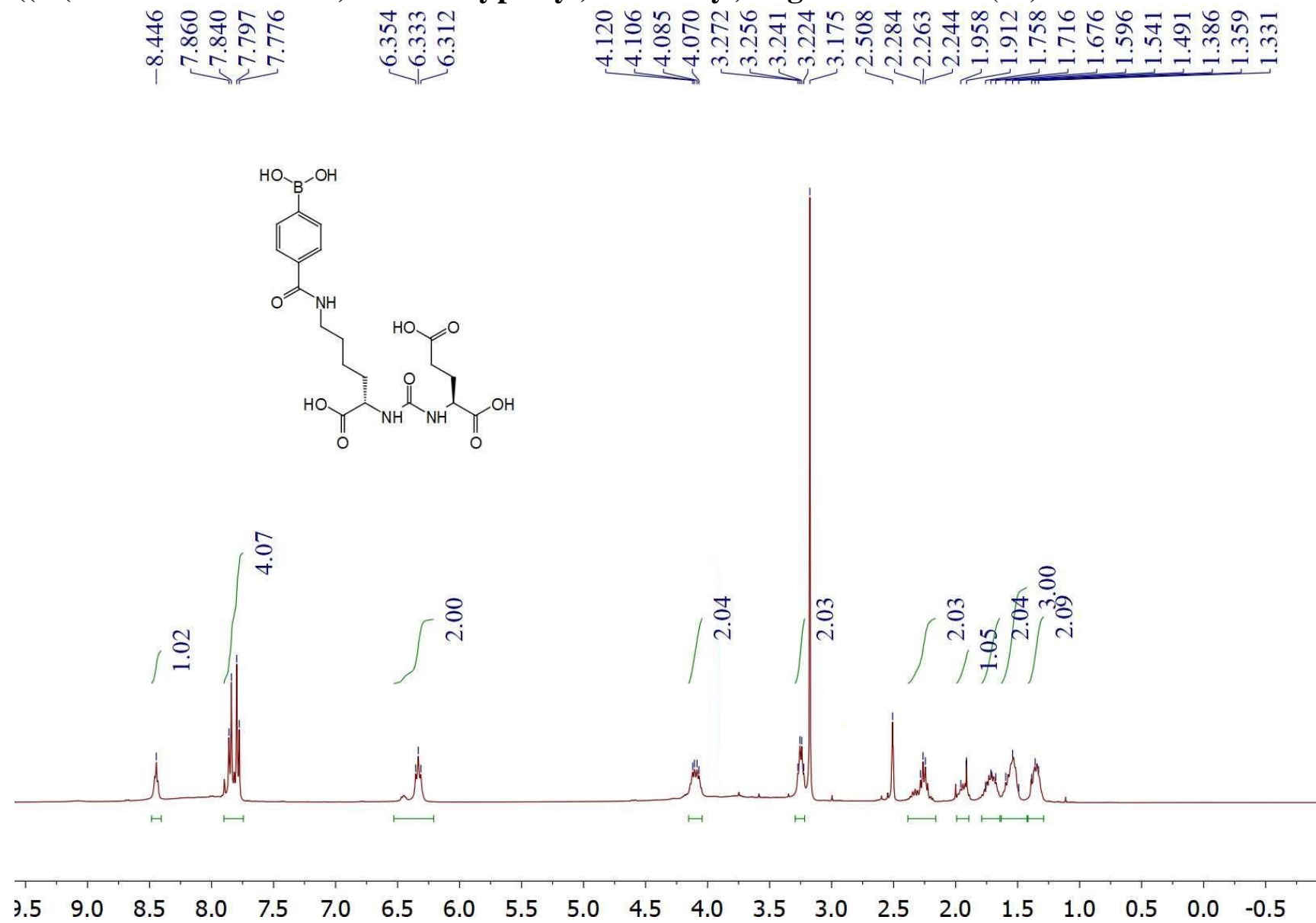

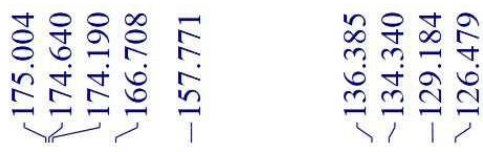
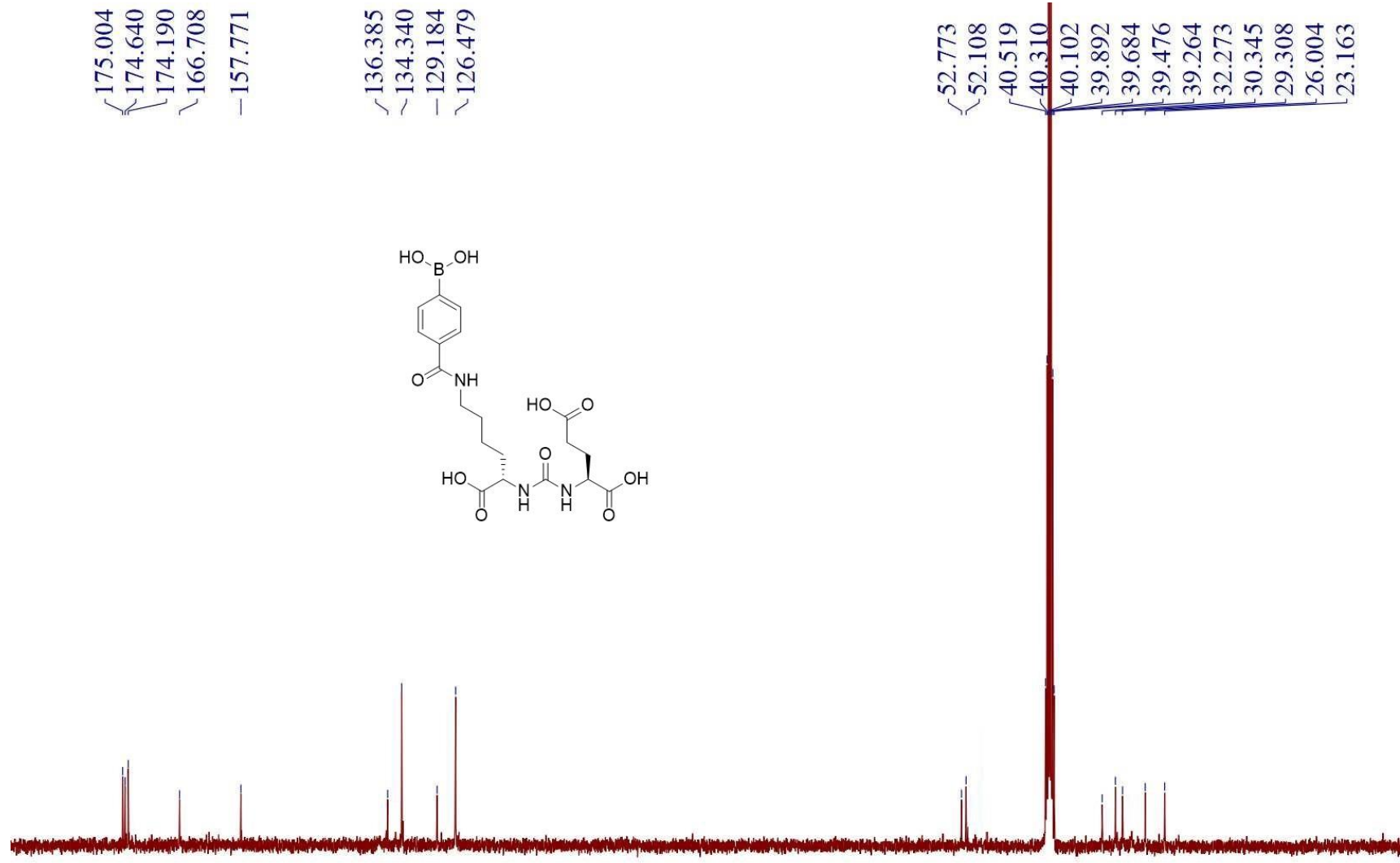
Di-tert-butyl ((1-(tert-butoxy)-1-oxo-6-(4-(4,4,5,5-tetramethyl-1,3,2-dioxaborolan-2-yl)benzamido) hexan-2-yl)carbamoyl)- $L$-glutamate (13b)

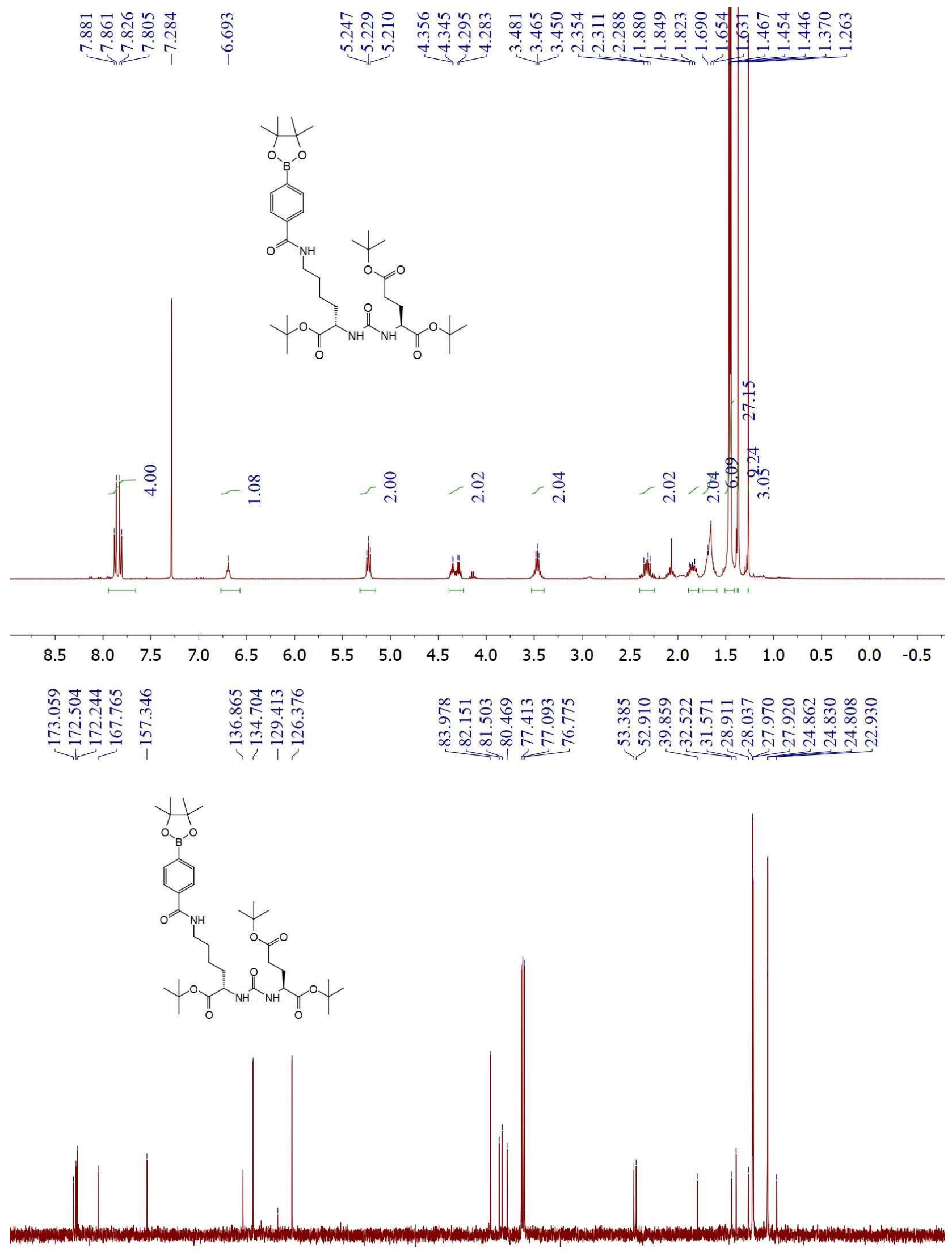

$\begin{array}{llllllllllllllllllll}180 & 170 & 160 & 150 & 140 & 130 & 120 & 110 & 100 & 90 & 80 & 70 & 60 & 50 & 40 & 30 & 20 & 10 & 0 & -10\end{array}$


((1-carboxy-5-(4-(4,4,5,5-tetramethyl-1,3,2-dioxaborolan-2-yl) benzamido) pentyl)carbamoyl)- $L$ glutamic acid (1b)
규뉴

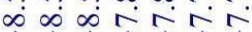

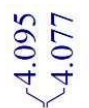

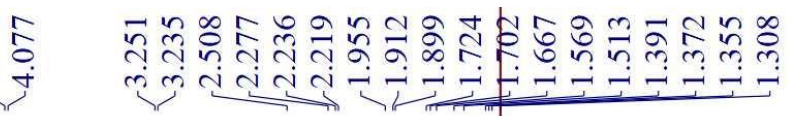

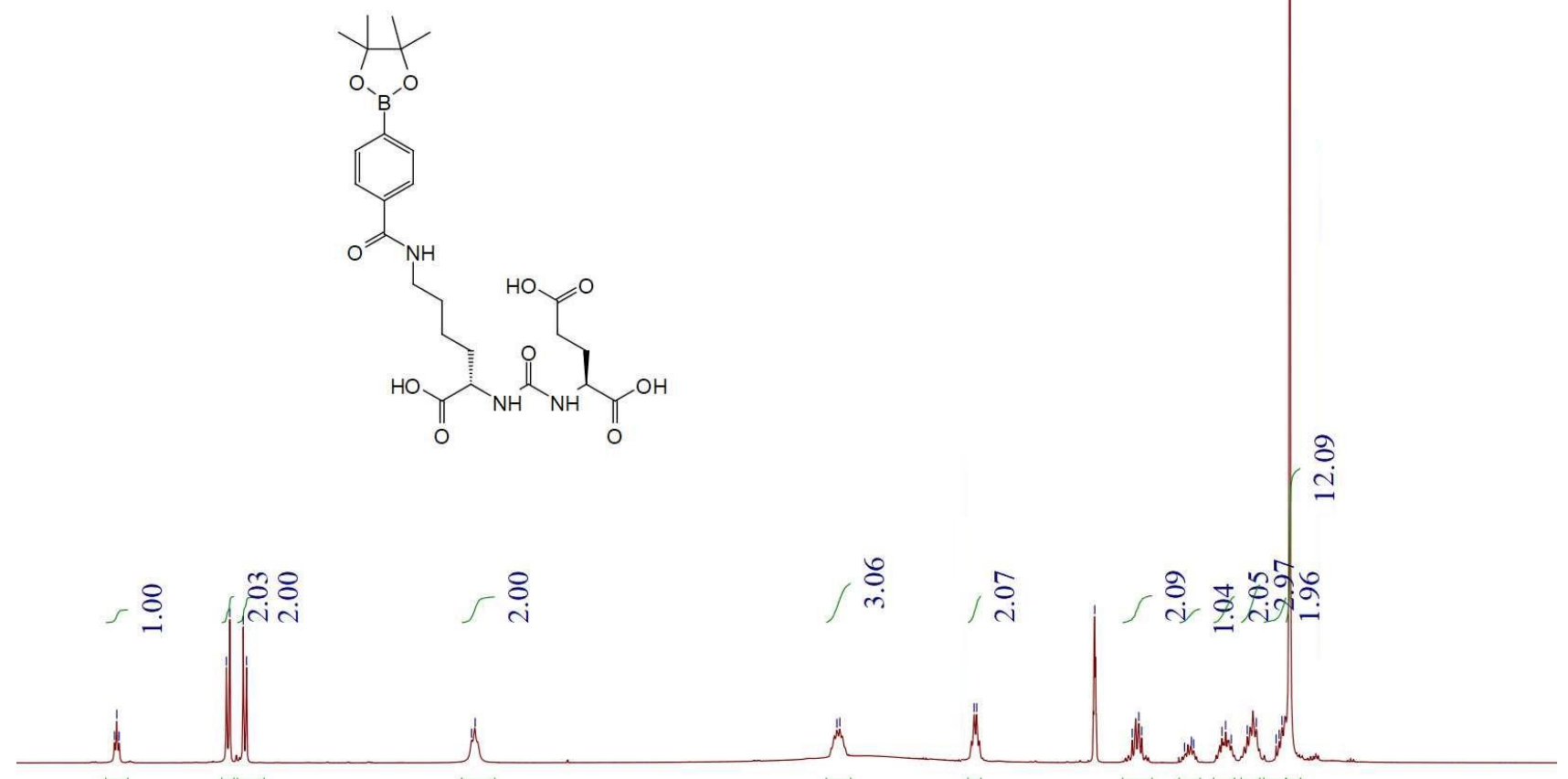

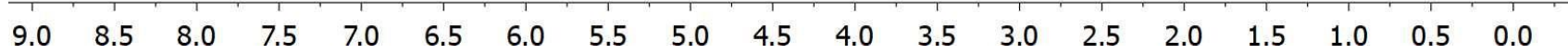

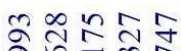

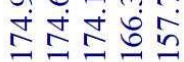

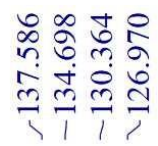

$\infty$
$\substack{\infty \\ \infty \\ \infty \\ \infty}$
1

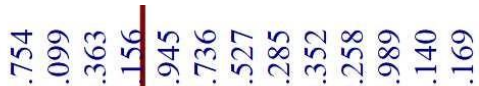

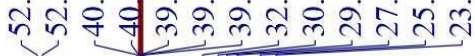

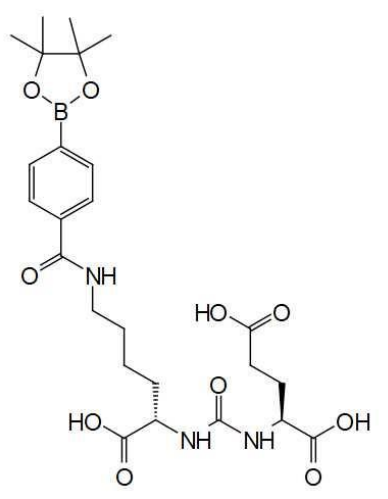


Di-tert-butyl (((S)-1-(tert-butoxy)-6-(((1,2-dicarba-closo-dodecarboranyl)carbonyl)amino)-1oxohexan-2-yl)carbamoyl)-L-glutamate (13c)
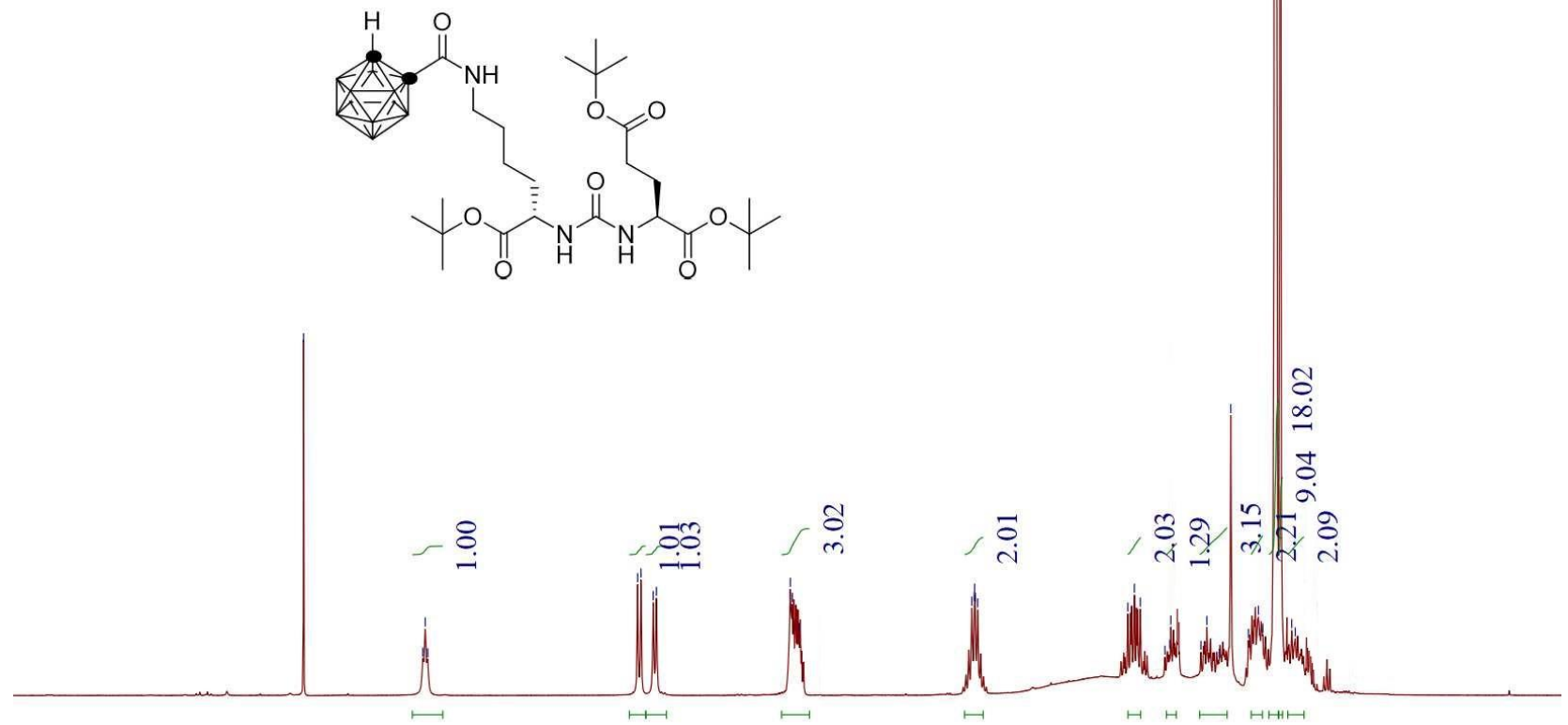

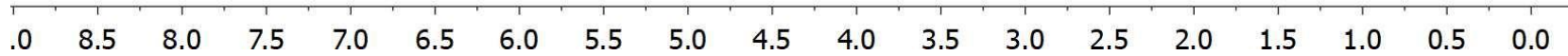

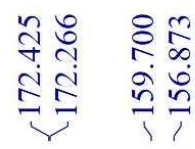

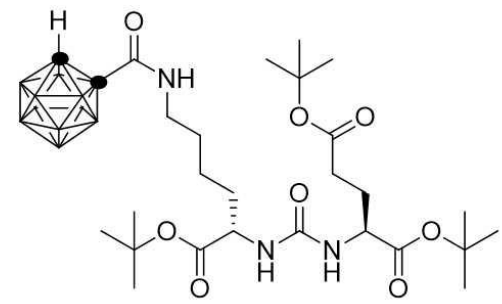




\section{4-(1,2-Dicarba-closo-dodecarboranyl) benzoic acid (2d)}

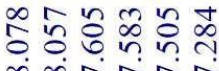

$\infty \infty \pi N$
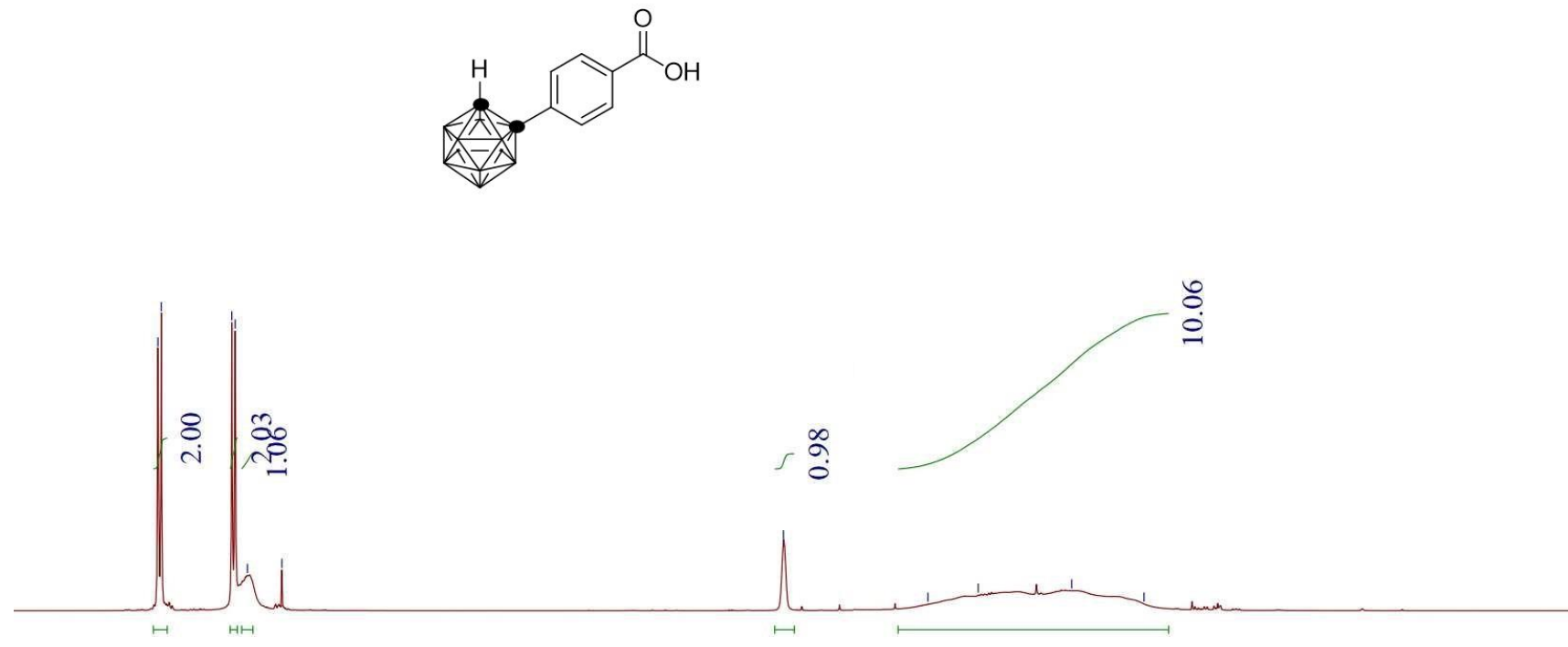

$\begin{array}{llllllllllllllllllll}.0 & 8.5 & 8.0 & 7.5 & 7.0 & 6.5 & 6.0 & 5.5 & 5.0 & 4.5 & 4.0 & 3.5 & 3.0 & 2.5 & 2.0 & 1.5 & 1.0 & 0.5 & 0.0 & -0.5\end{array}$

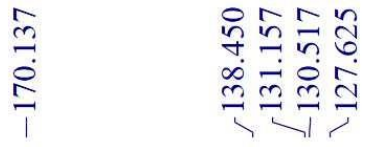

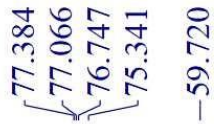
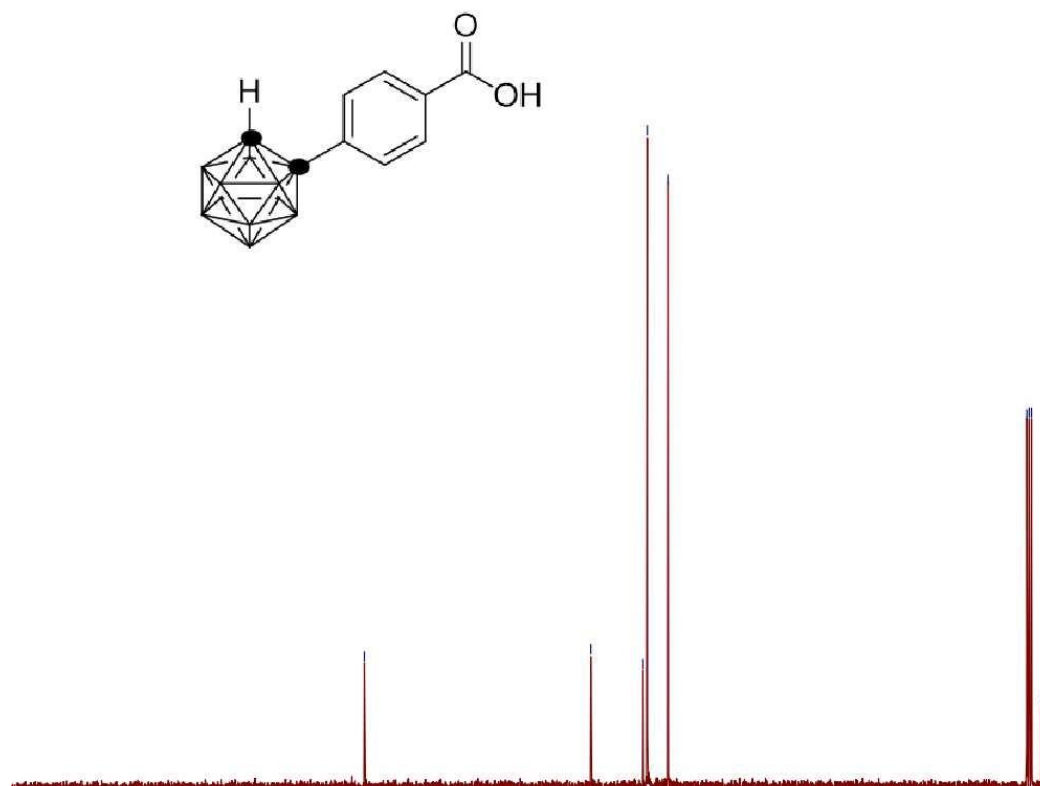

ureido) di-tert-butyl pentanedioic acid (13d)
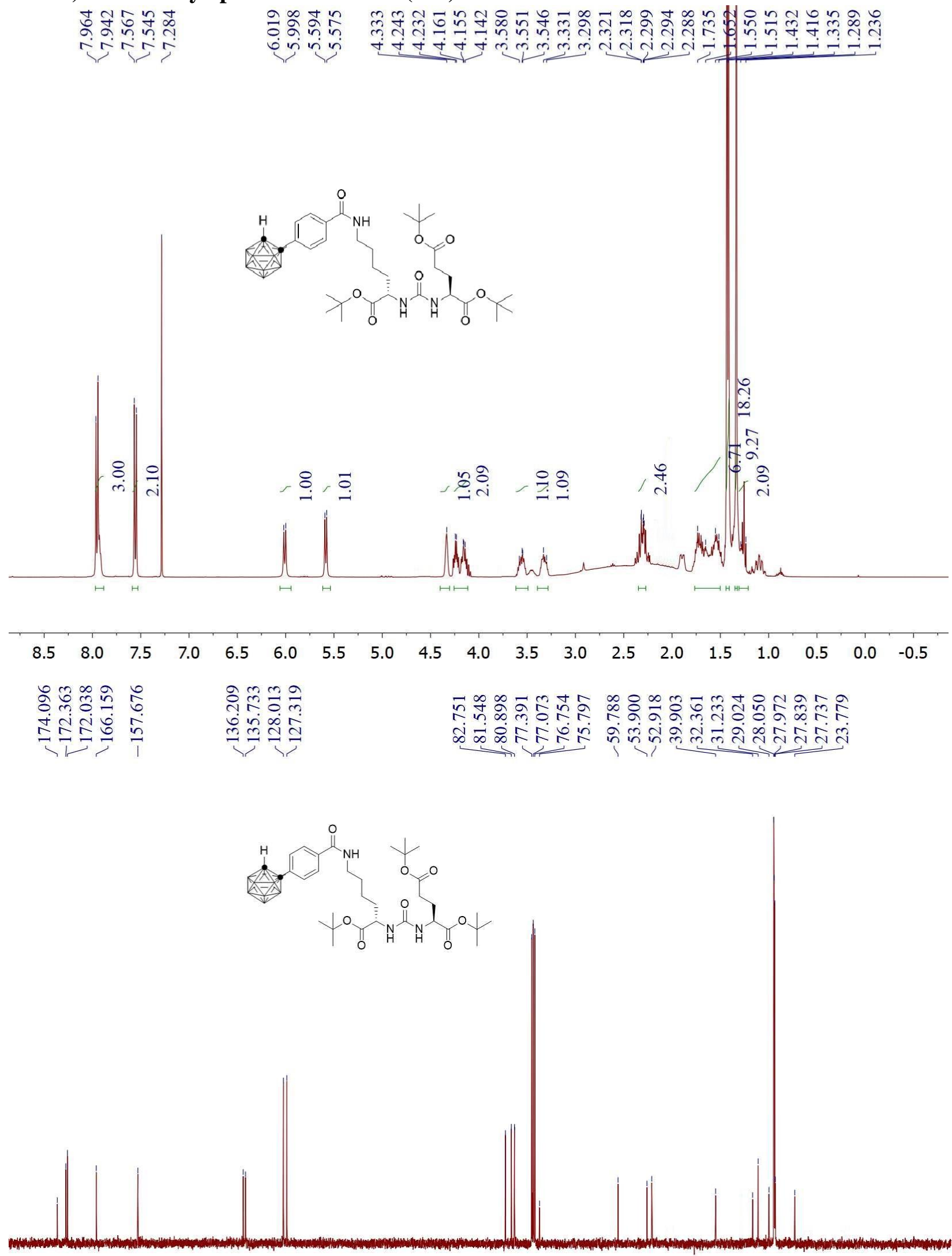

pentanedioic acid (1d)

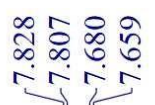

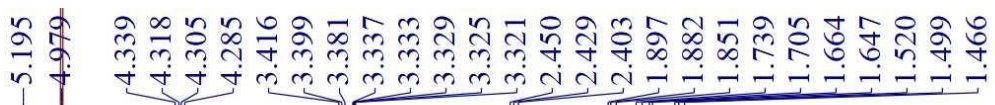<smiles>O=C(O)CC[C@H](NC(=O)N[C@@H](CCCCNC(=O)c1ccc(C2C3C=CC2C3)cc1)C(=O)O)C(=O)O</smiles>
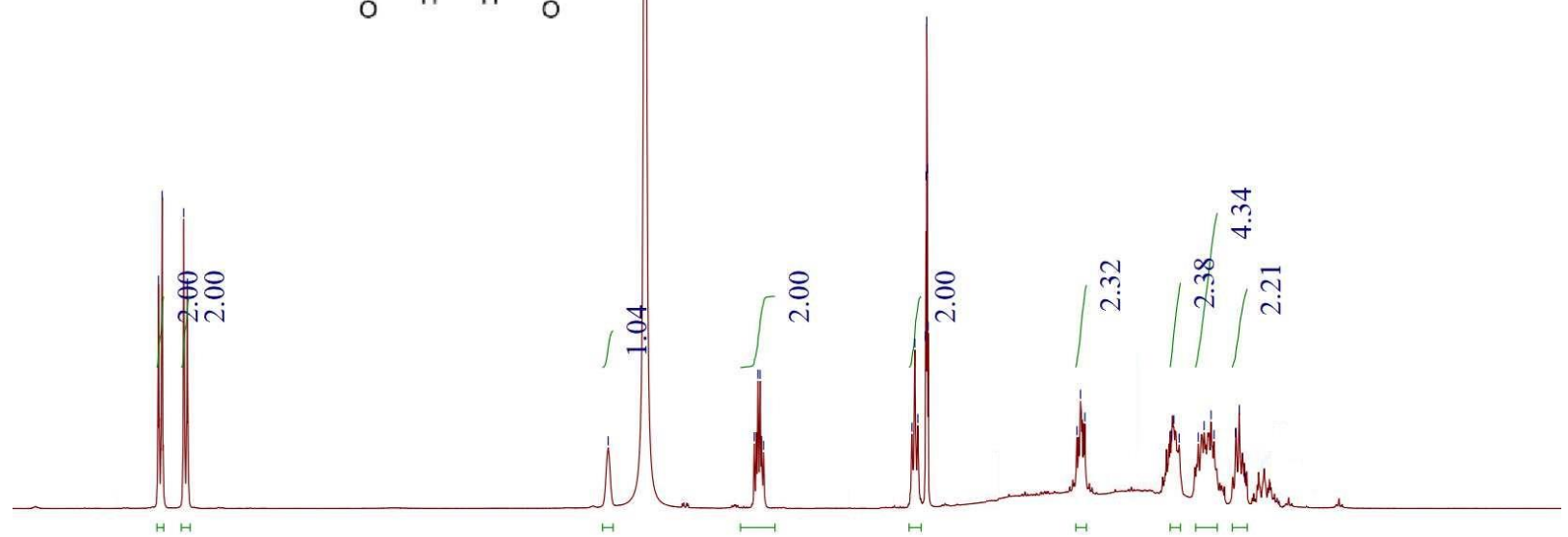

\begin{tabular}{|c|c|c|c|c|c|c|}
\hline 8.5 & 8.0 & 7.5 & 7.0 & 6.5 & 6.0 & 5.5 \\
\hline & & $\begin{array}{l}\hat{\sigma} \\
\vdots \\
\tilde{2}\end{array}$ & 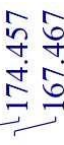 & 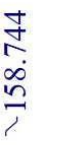 & $\begin{array}{l}0 \\
\infty \\
0 \\
0 \\
0 \\
\end{array}$ & 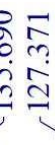 \\
\hline
\end{tabular}
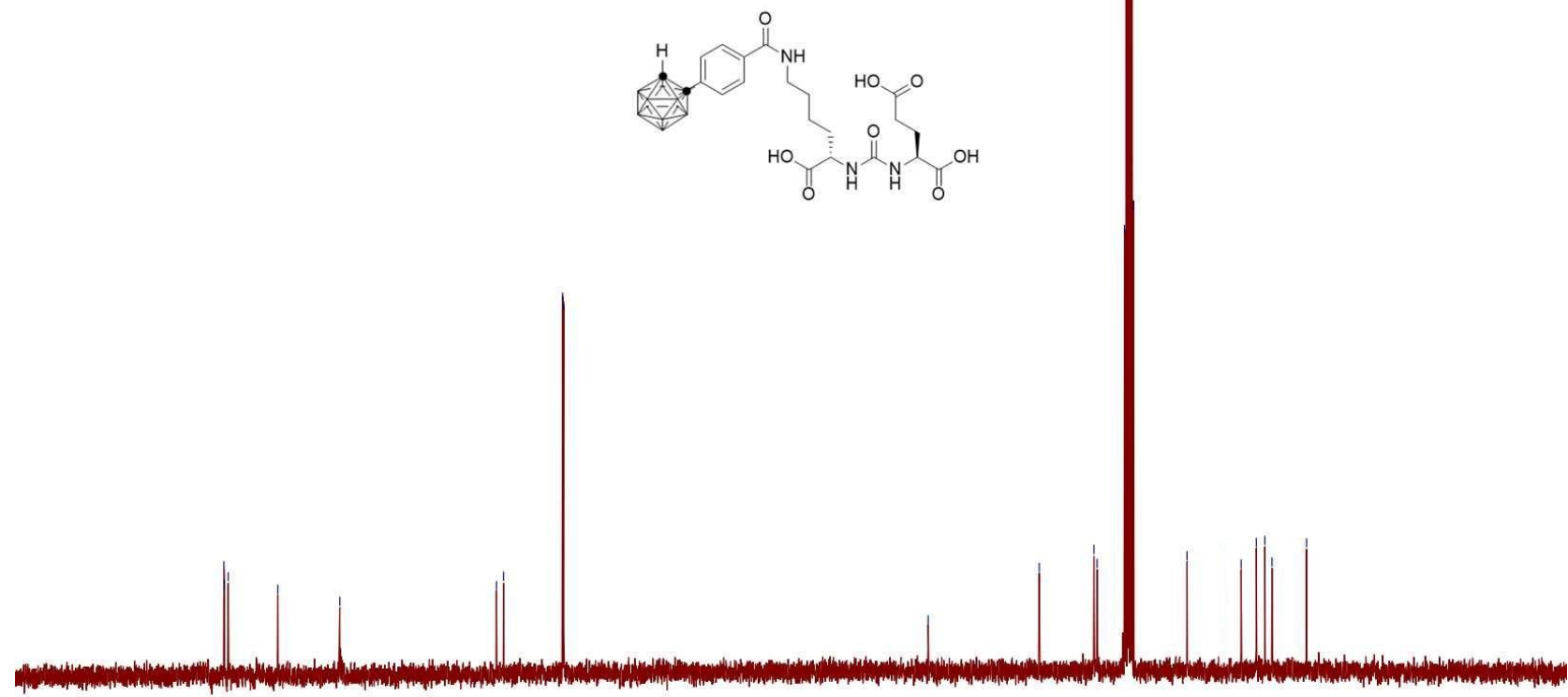


\section{Benzyl 4-(4-ethynylphenyl)butanoate (7)}

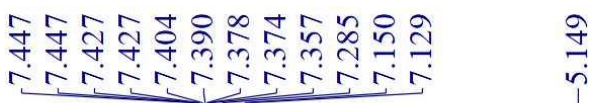
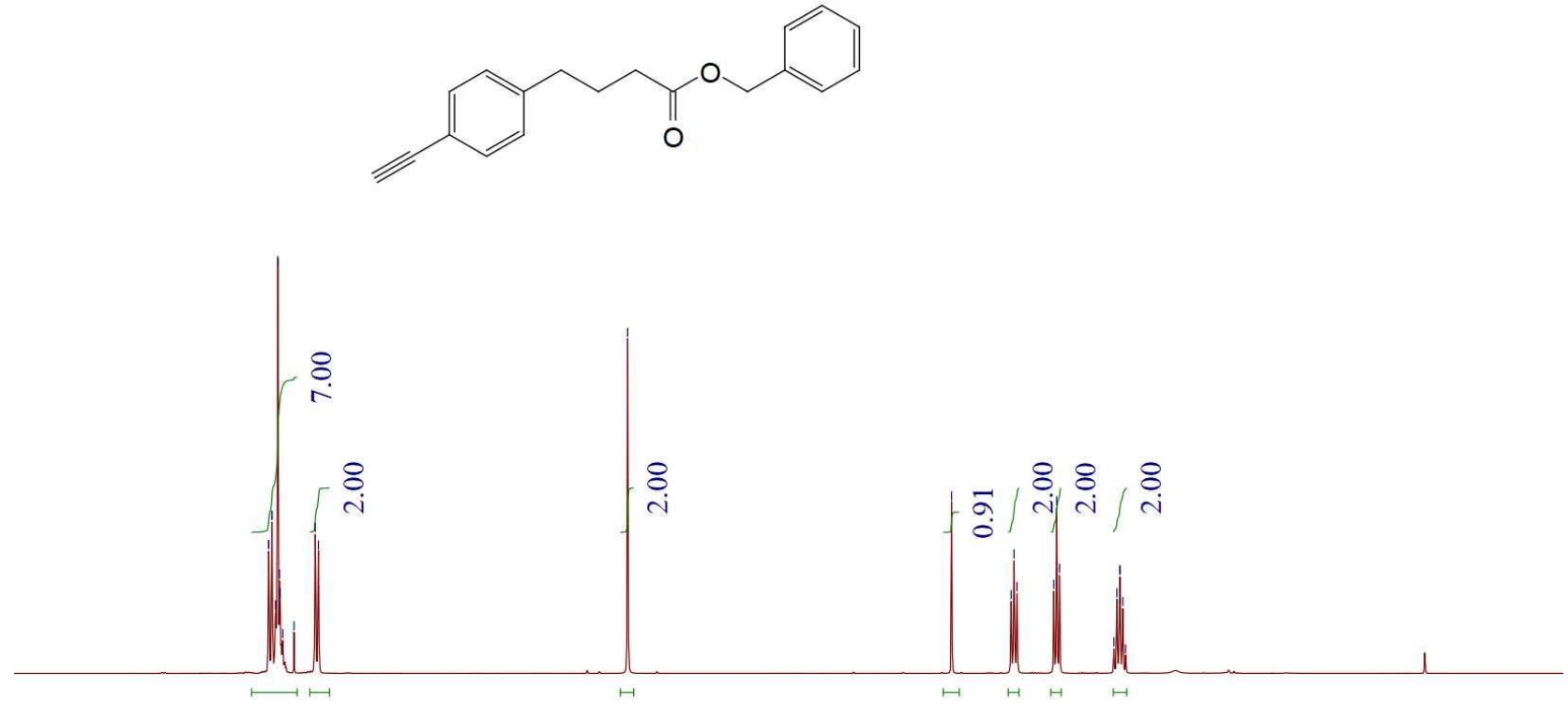

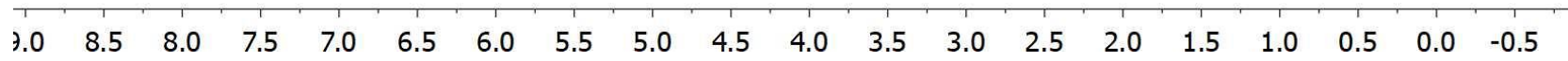

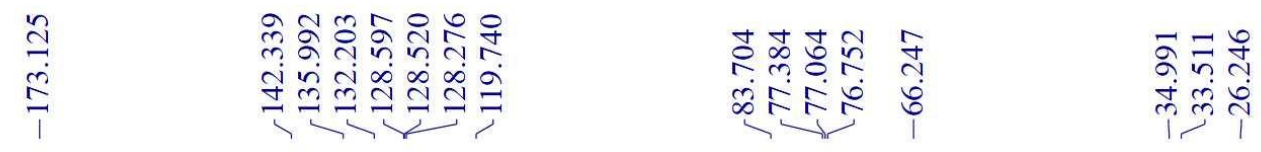

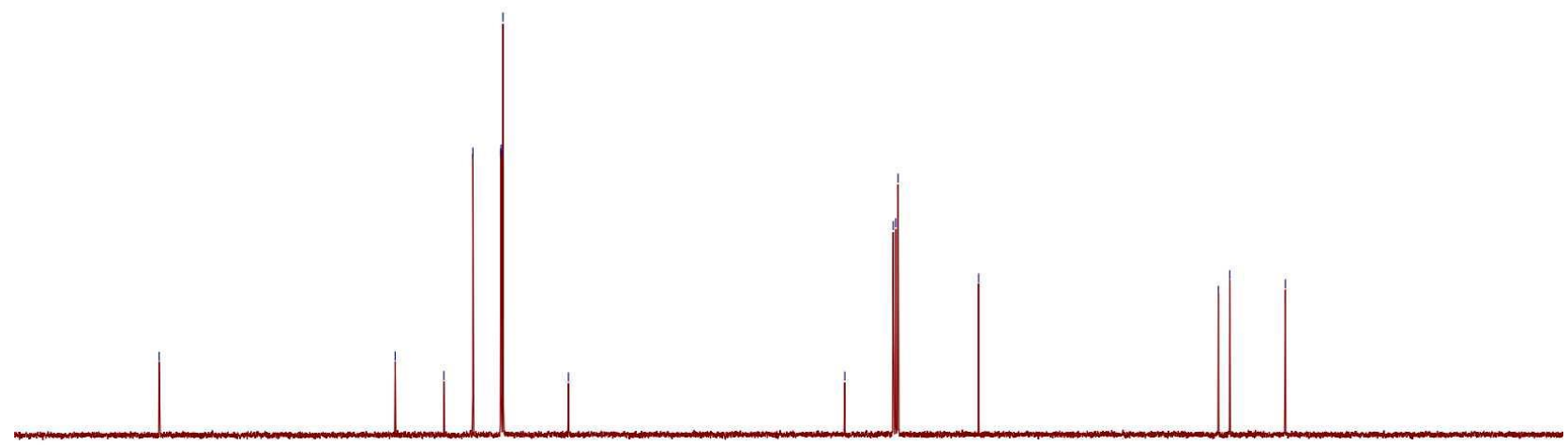




\section{4-(4-(1,2-Dicarba-closo-dodecarboranyl)phenyl)butanoic acid (2e)}

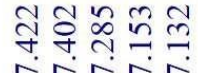

nू
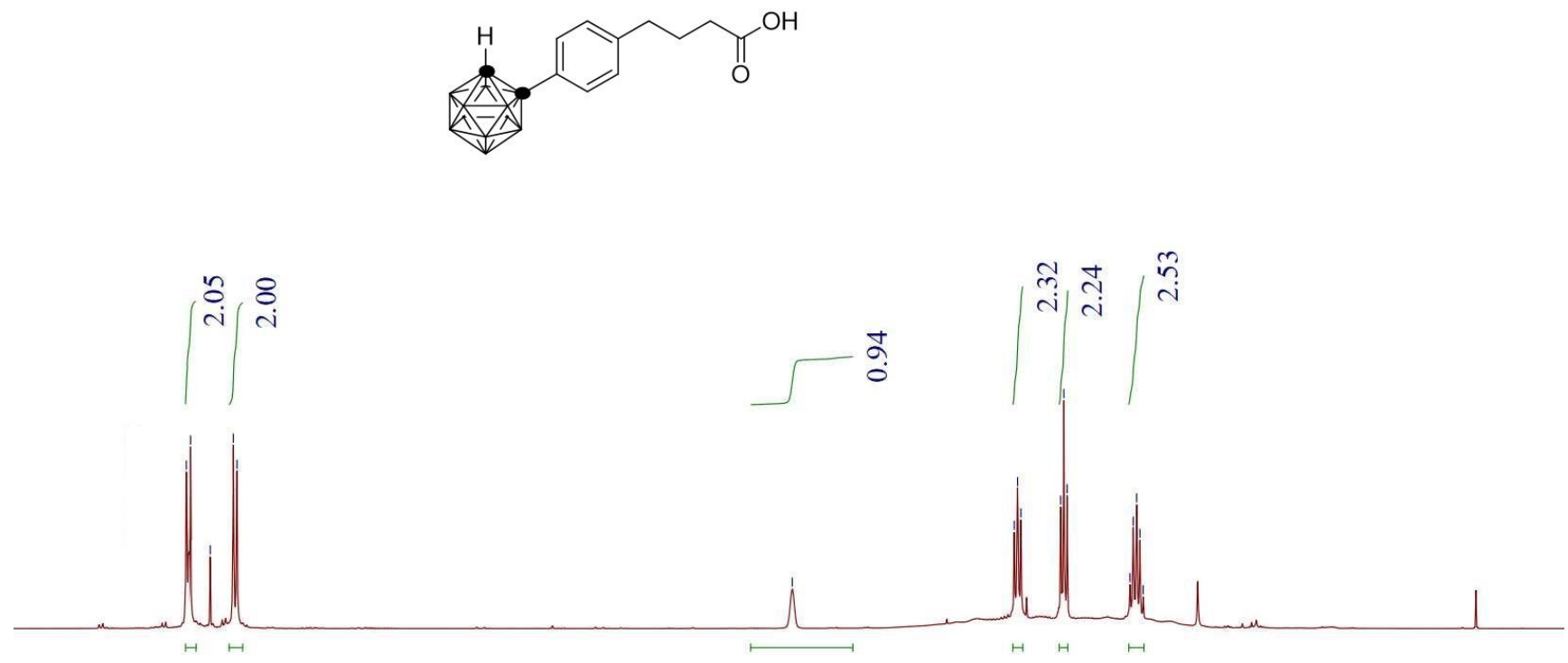

\begin{tabular}{|c|c|c|c|c|c|c|c|c|c|c|c|c|c|c|}
\hline 8.0 & 7.5 & 7.0 & 6.5 & 6.0 & 5.5 & 5.0 & 4.5 & 4.0 & 3.5 & 2.5 & 2.0 & $\begin{array}{ll}1.5 & 1.0\end{array}$ & 0.5 & 0.0 \\
\hline & $f$ & & 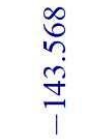 & 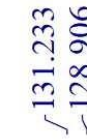 & & & & & 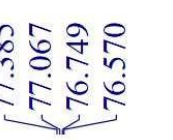 & $\begin{array}{l}\text { fo } \\
\text { m. } \\
\text { ì } \\
1\end{array}$ & & 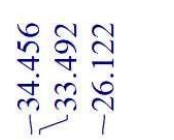 & & \\
\hline
\end{tabular}
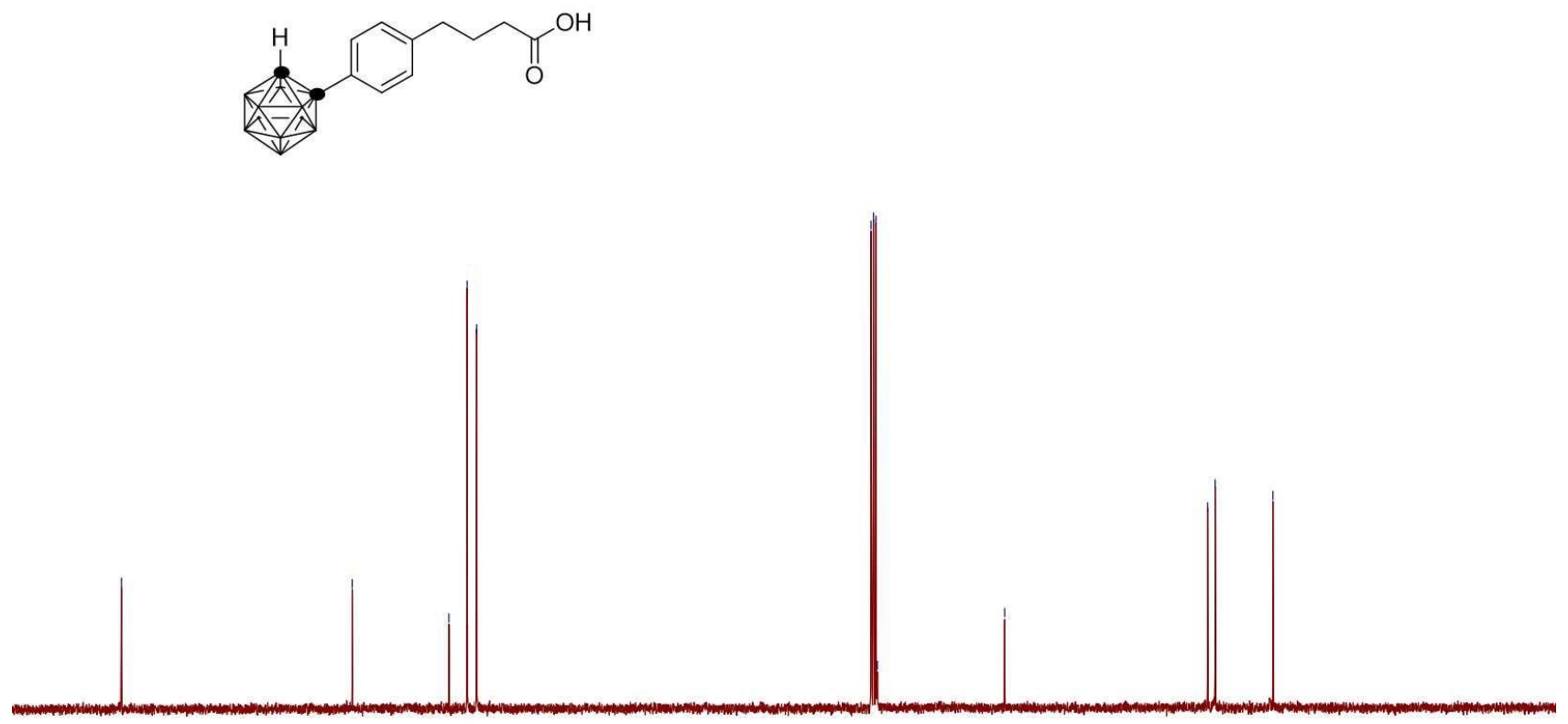

$\begin{array}{lllllllllll}1 & 180 & 170 & 160 & 150 & 140 & 130 & 120 & 110 & 100 & 90\end{array}$ 
Di-tert-butyl (((S)-1-(-butoxy)-6-(4-(4-(1,2-dicarba-closo-dodecarboranyl)phenyl)butanamido) -1oxohexan-2-yl)carbamoyl)-L-glutamate (13e)

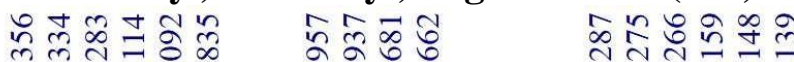

Niño inin

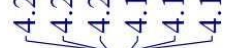

은드 0 은

भंm
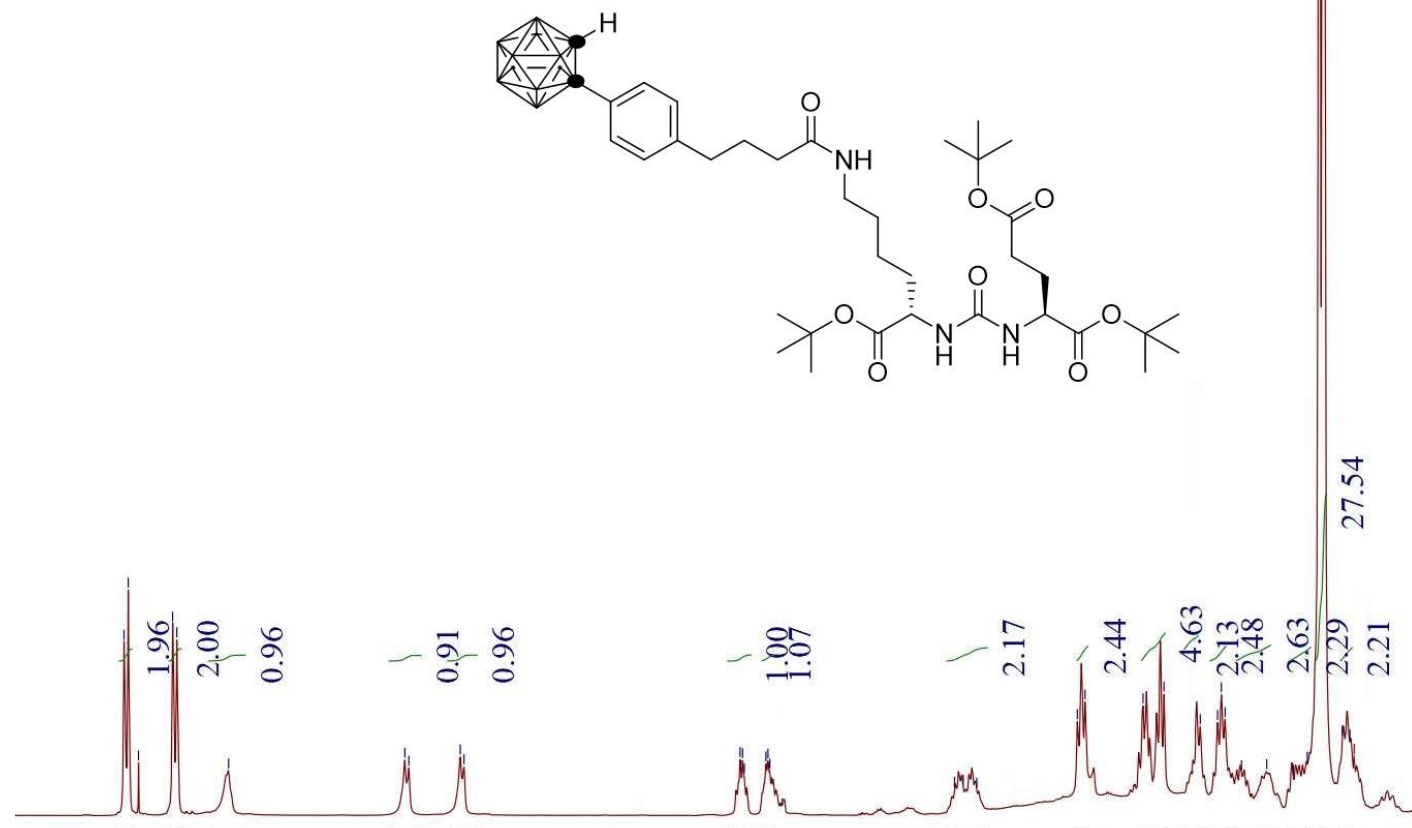

\begin{tabular}{|c|c|c|c|c|c|c|c|c|c|c|c|c|c|c|c|}
\hline 7.5 & 7.0 & 6.5 & 6.0 & 5.5 & 5.0 & 4.5 & 4.0 & 3.5 & 3.0 & 2.5 & 2.0 & 1.5 & 1.0 & 0.5 & 0 \\
\hline $\begin{array}{l}\infty \\
\stackrel{\infty}{+} \\
\stackrel{n}{=}\end{array}$ & 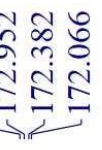 & $\begin{array}{l}\frac{2}{d} \\
\text { in } \\
\frac{1}{1}\end{array}$ & $\begin{array}{l}\stackrel{3}{5} \\
\stackrel{\dot{m}}{+}\end{array}$ & $\frac{m}{0}$ & & & & $\begin{array}{ll}m & \infty \\
2 & \infty \\
n & n \\
\infty & \infty \\
\infty & \infty \\
\end{array}$ & 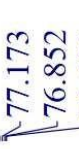 & $\begin{array}{l}\exists: \\
30 \\
0 \\
0\end{array}$ & 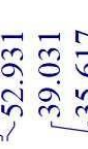 & $\begin{array}{ll}m & m \\
0 & 8 \\
\dot{y} & \sim \\
m & m\end{array}$ & 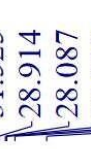 & 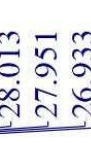 & 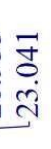 \\
\hline
\end{tabular}
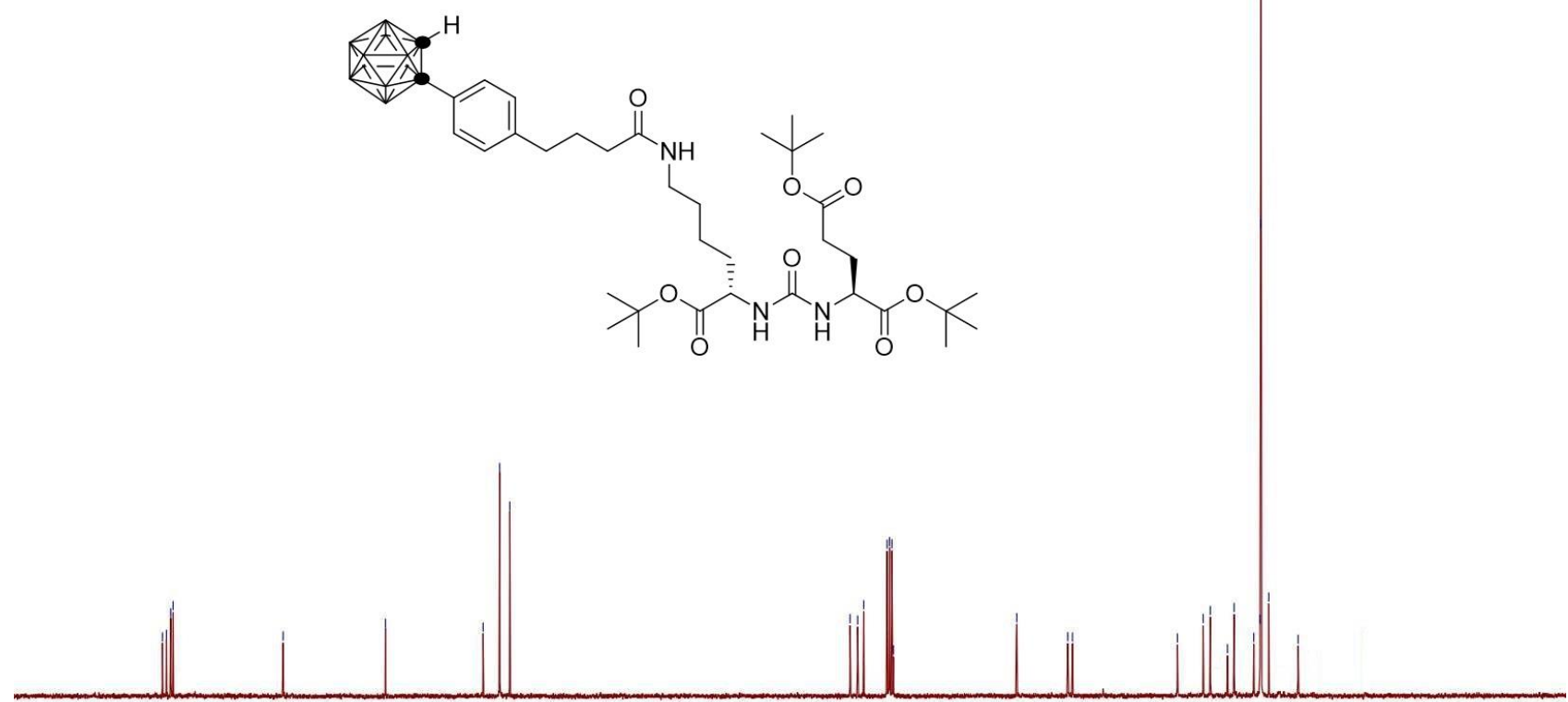

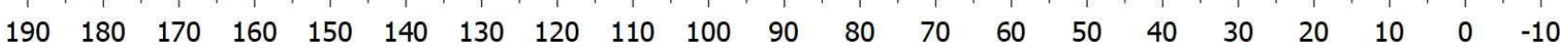


(((S)-1-carboxy-5-(4-(4-(1,2-dicarba-closo-dodecarbo ranyl)phenyl) butanamido)pentyl) carbamoyl)-L-glutamic acid (1e)

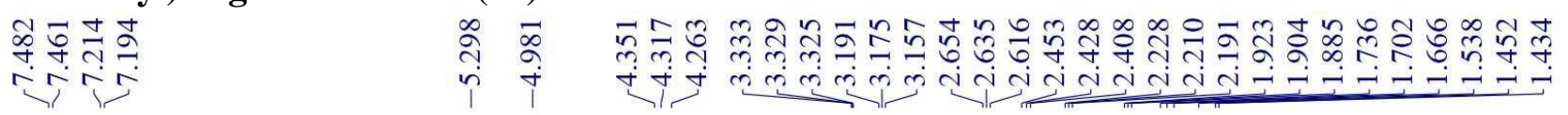
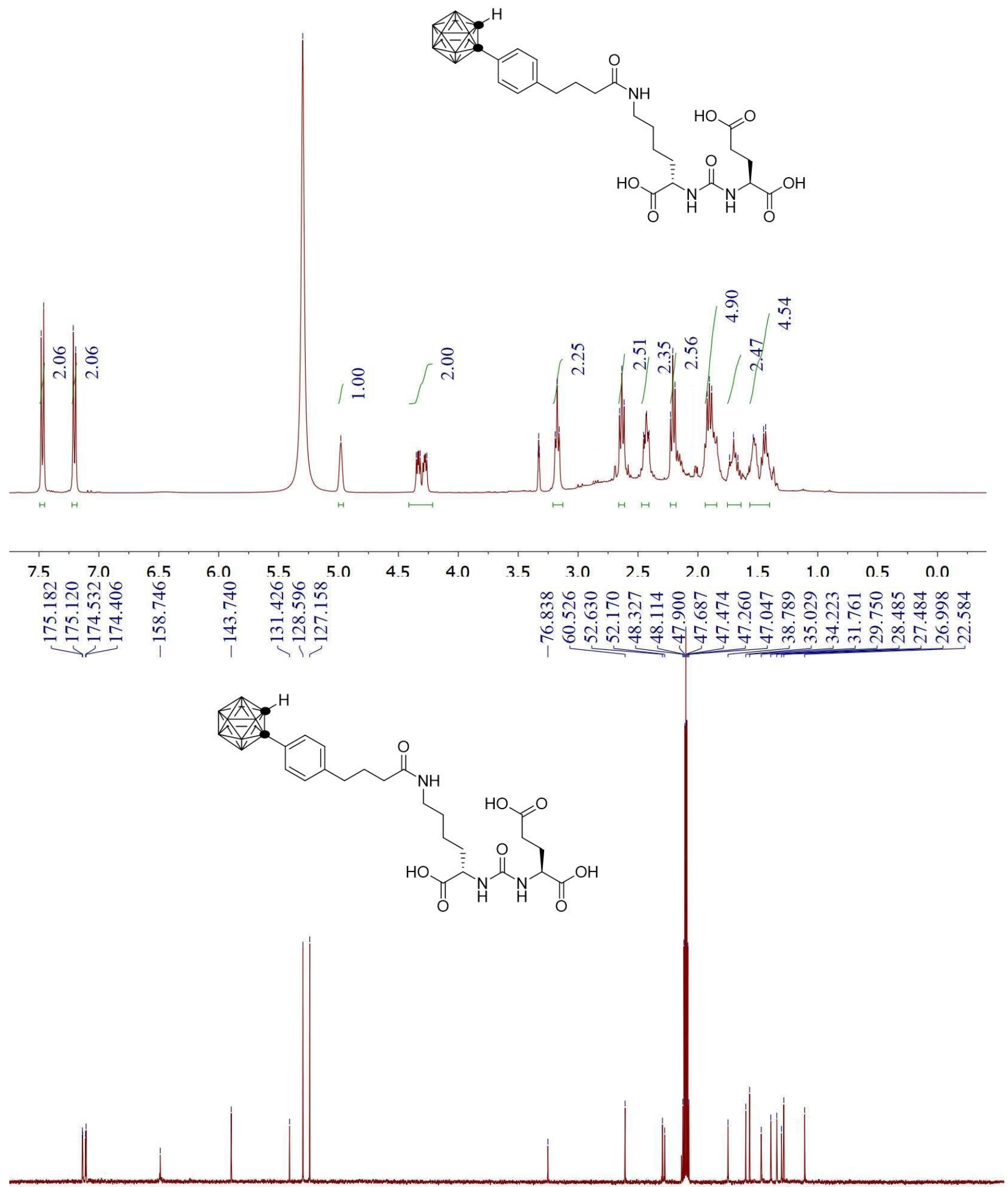
1,2-Dicarba-closo-dodecarboranyl (4-nitrophenyl) carbonate (10)

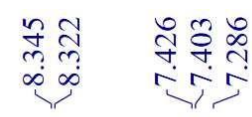

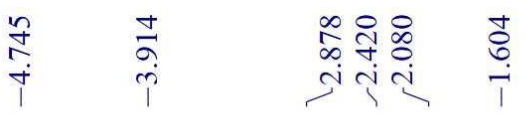
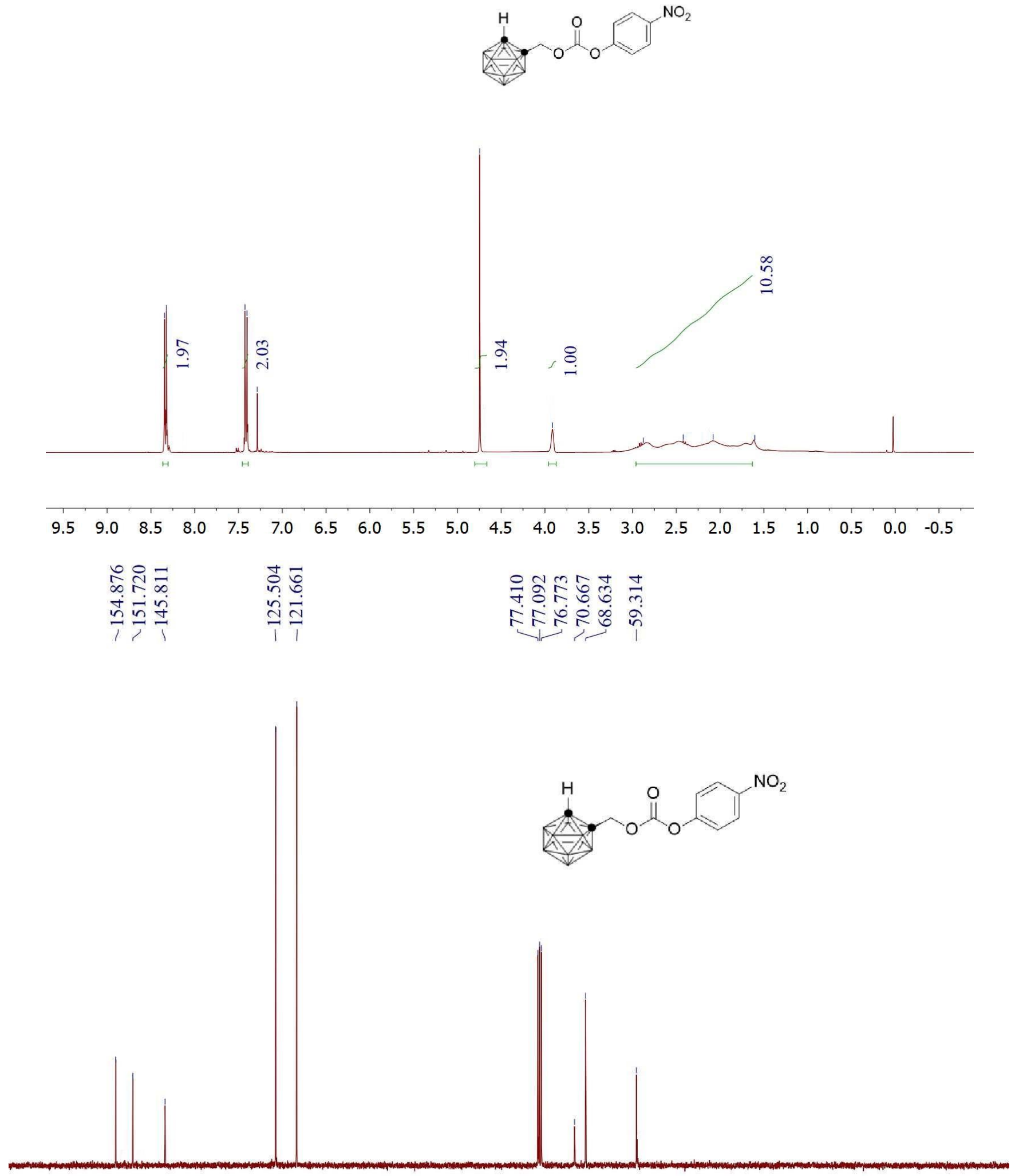

$\begin{array}{llllllllll}170 & 160 & 150 & 140 & 130 & 120 & 110 & 100 & 90 & 80\end{array}$


$N^{2}, N^{6}$-Bis((-(1,2-dicarba-closo-dodecarboranyl)methoxy)carbonyl)-L-lysine (2f)

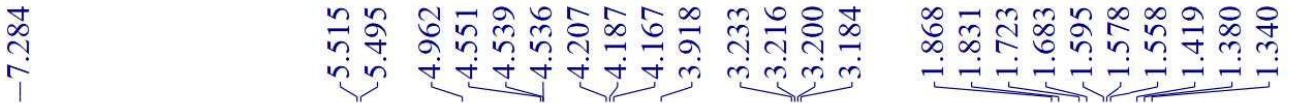
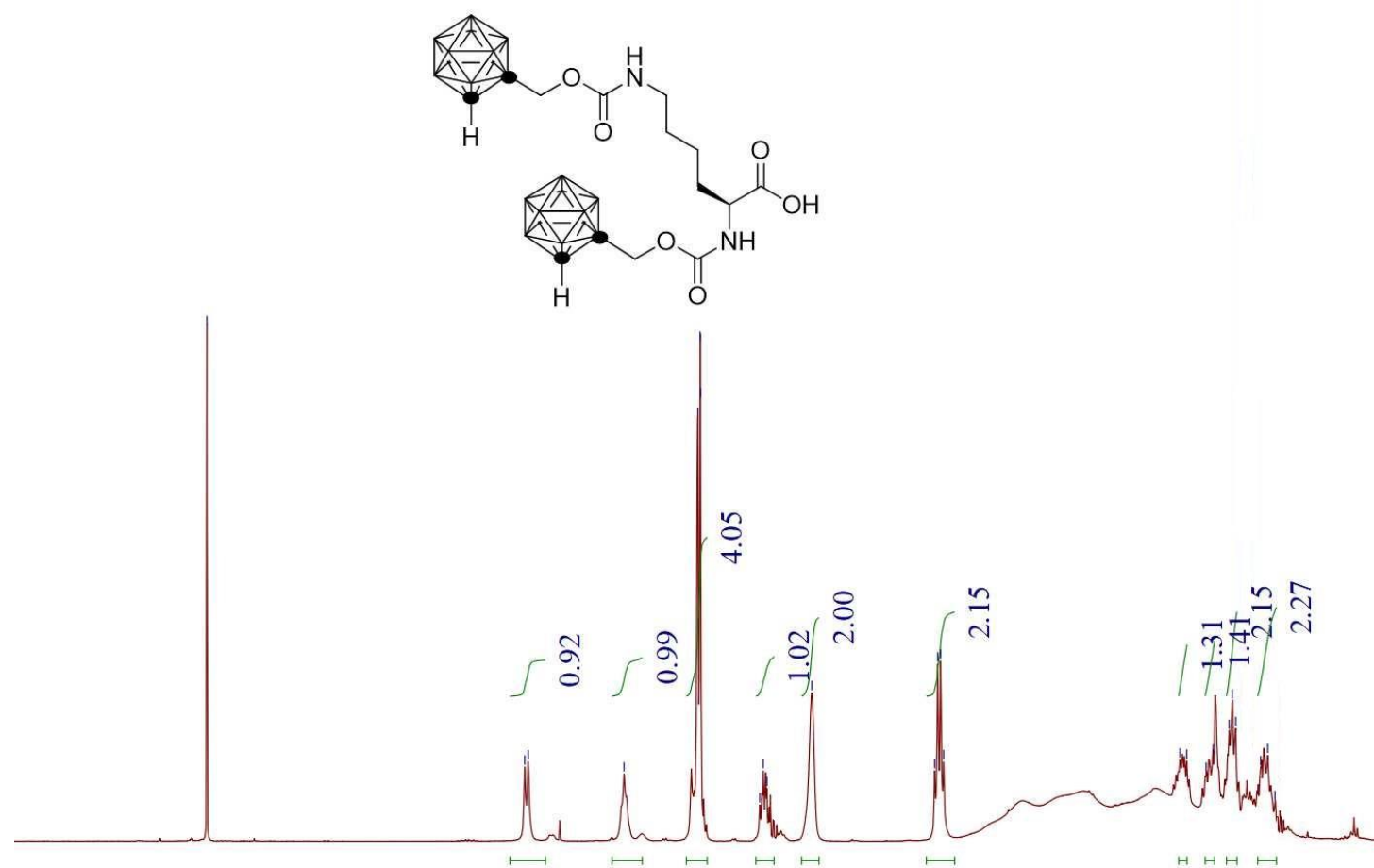

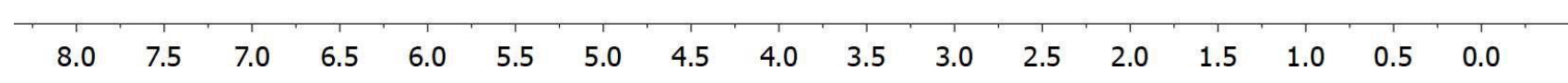

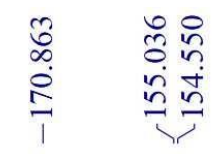

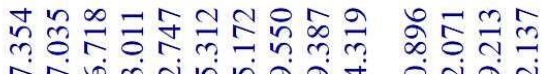

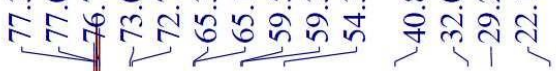

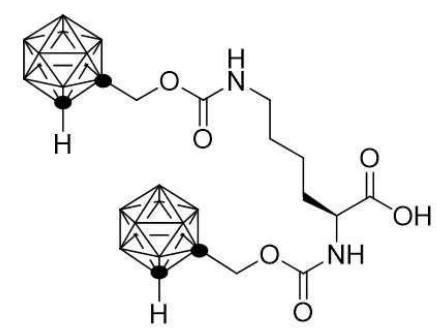




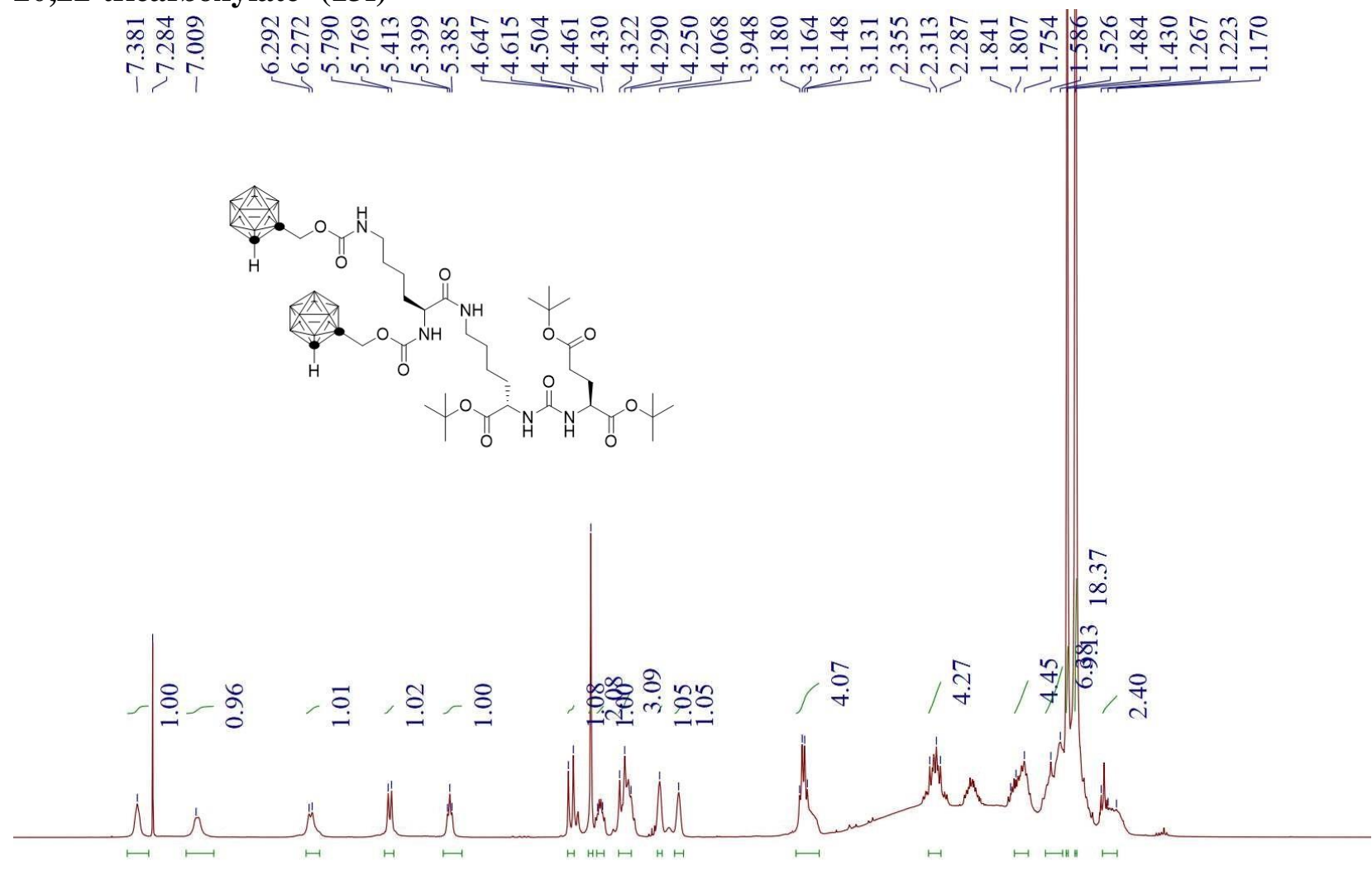

\begin{tabular}{|c|c|c|c|c|c|c|c|c|c|c|c|c|c|c|c|}
\hline 8.0 & 7.5 & 7.0 & 6.5 & 6.0 & 5.5 & 5.0 & 4.5 & 4.0 & 3.5 & 3.0 & 2.5 & 2.0 & 1.5 & 1.0 & 0.5 \\
\hline
\end{tabular}

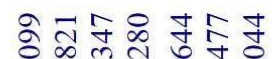

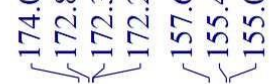
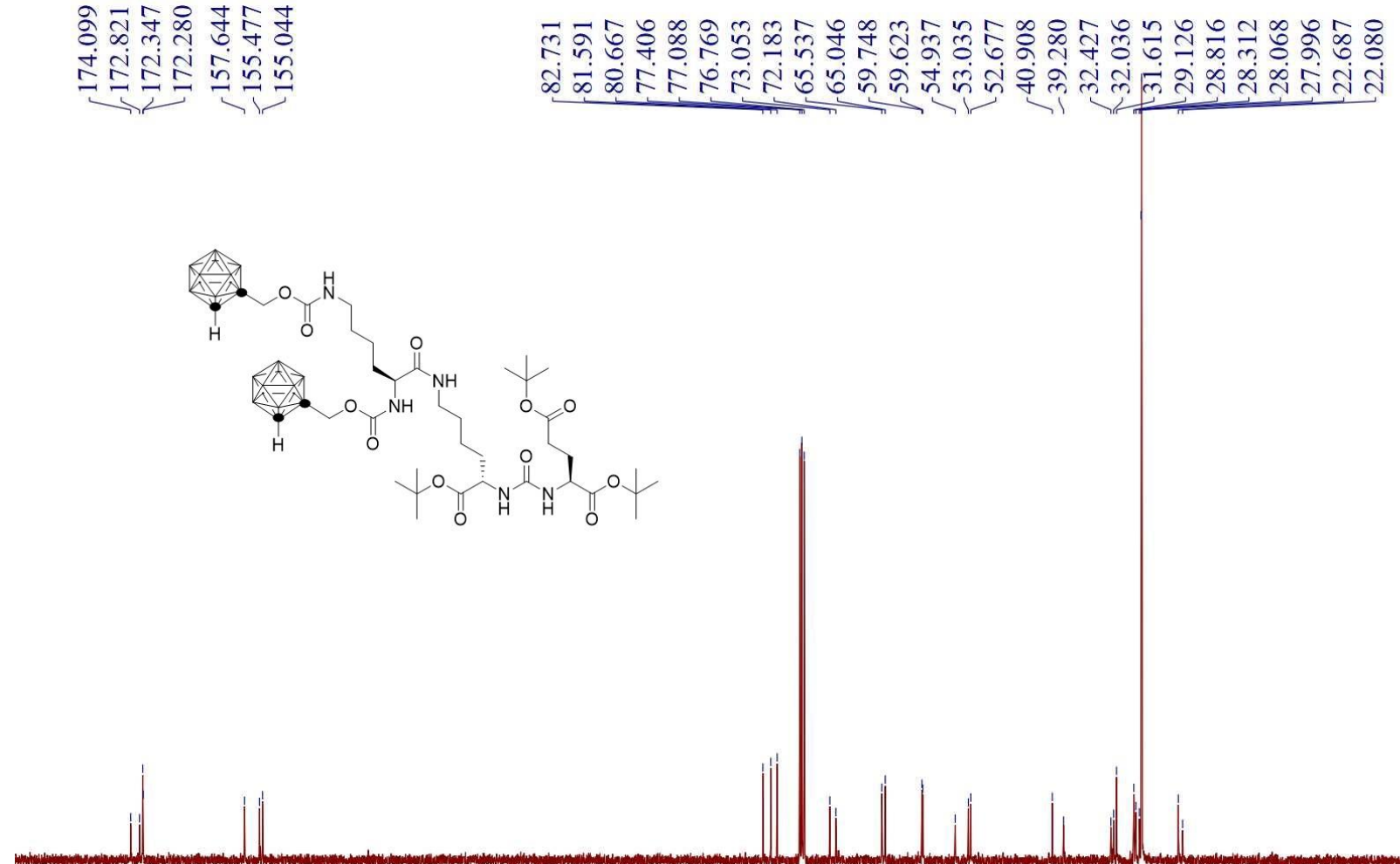
(9S,16S,20S)-1-(1,2-dicarba-closo-dodecarboranyl)-9-((((1,2-dicarba-closo-dodecarboranyl) methoxy)carbonyl)amino)-3,10,18-trioxo-2-oxa-4,11,17,19-tetraazadocosane-16,20,22-tricarboxylic acid (1f)

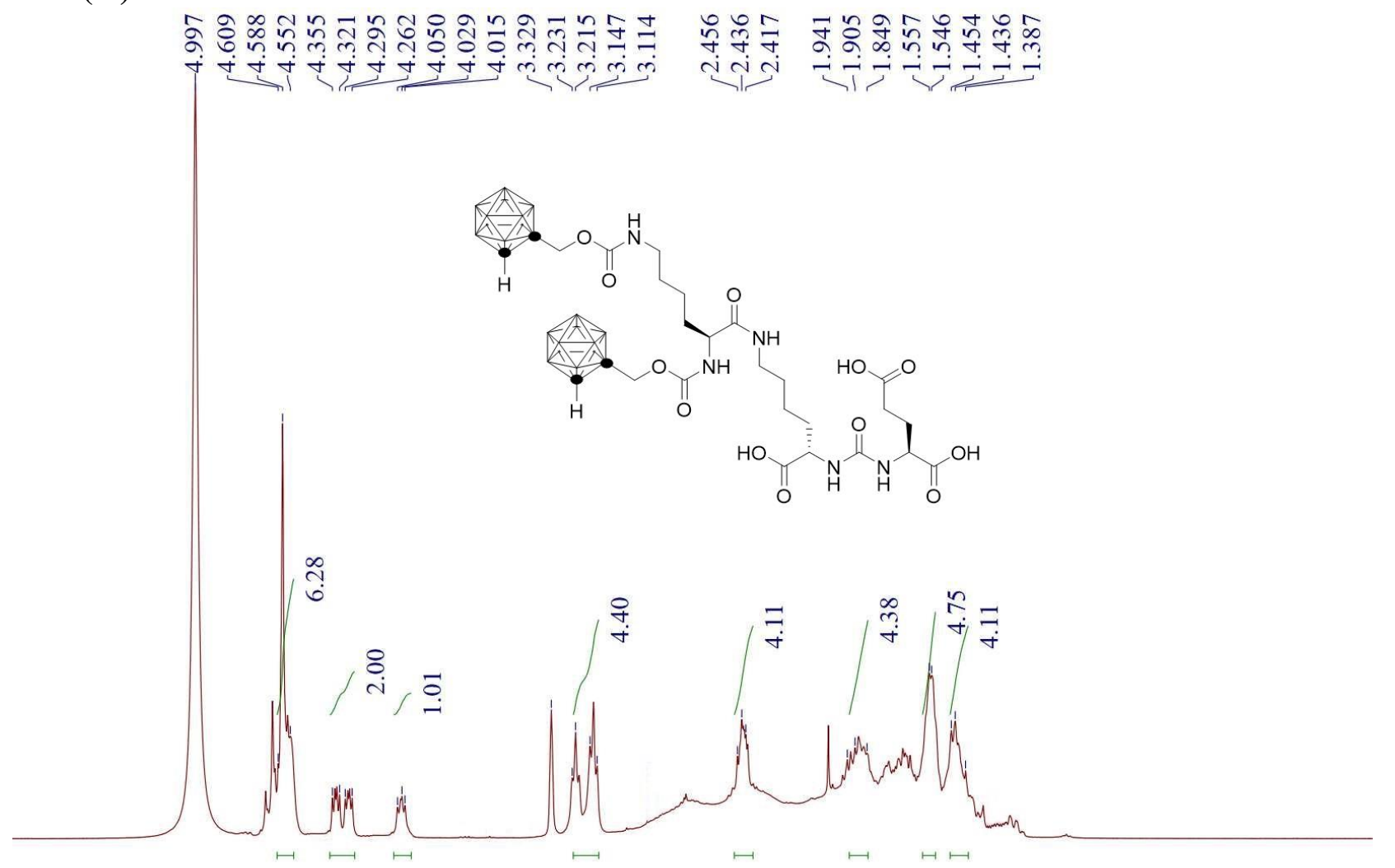

$\begin{array}{lllllllllllllllll}5.6 & 5.2 & 4.8 & 4.4 & 4.0 & 3.6 & 3.2 & 2.8 & 2.4 & 2.0 & 1.6 & 1.2 & 0.8 & 0.4 & 0.0 & -0.4\end{array}$

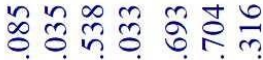

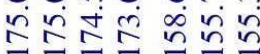

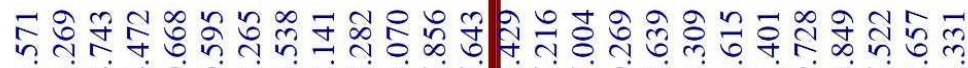

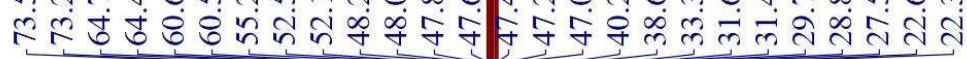
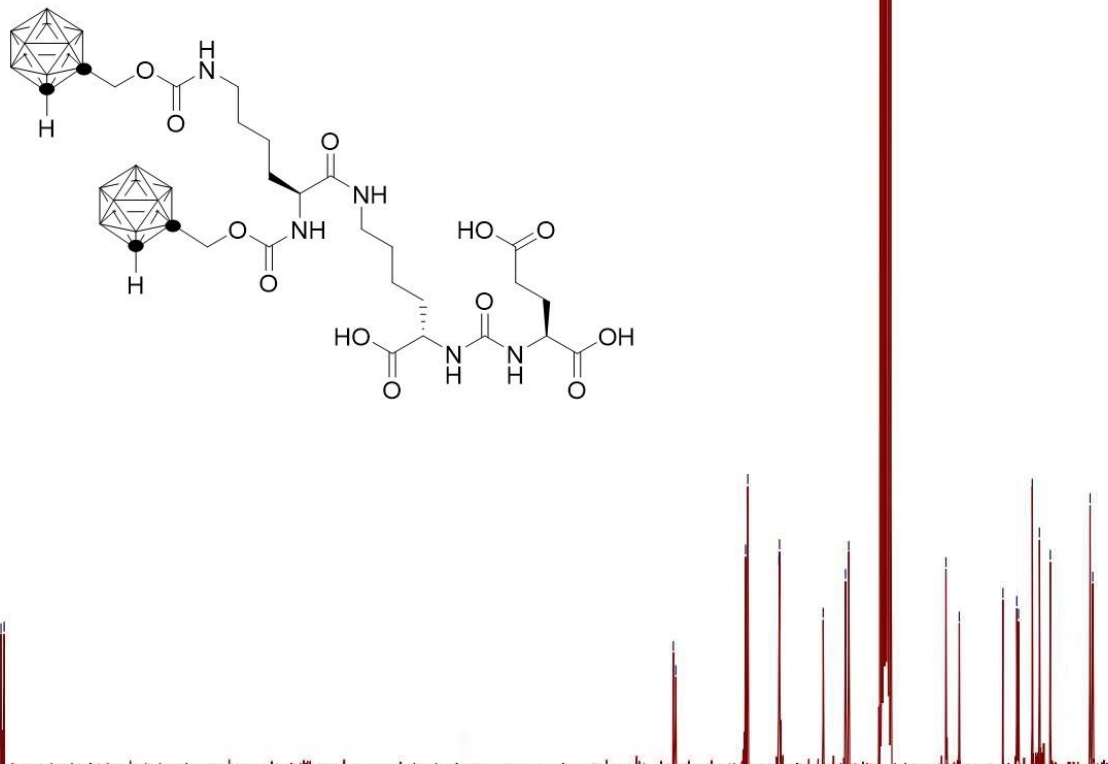
(S)-2-(1-((S)-1-tert-B utylcarboxy-5-((1,2-dicarba-closo-dodecarbo ranyl)methylcarbamate) pentyl) ureido) di-tert-butyl pentanedioic acid (14)

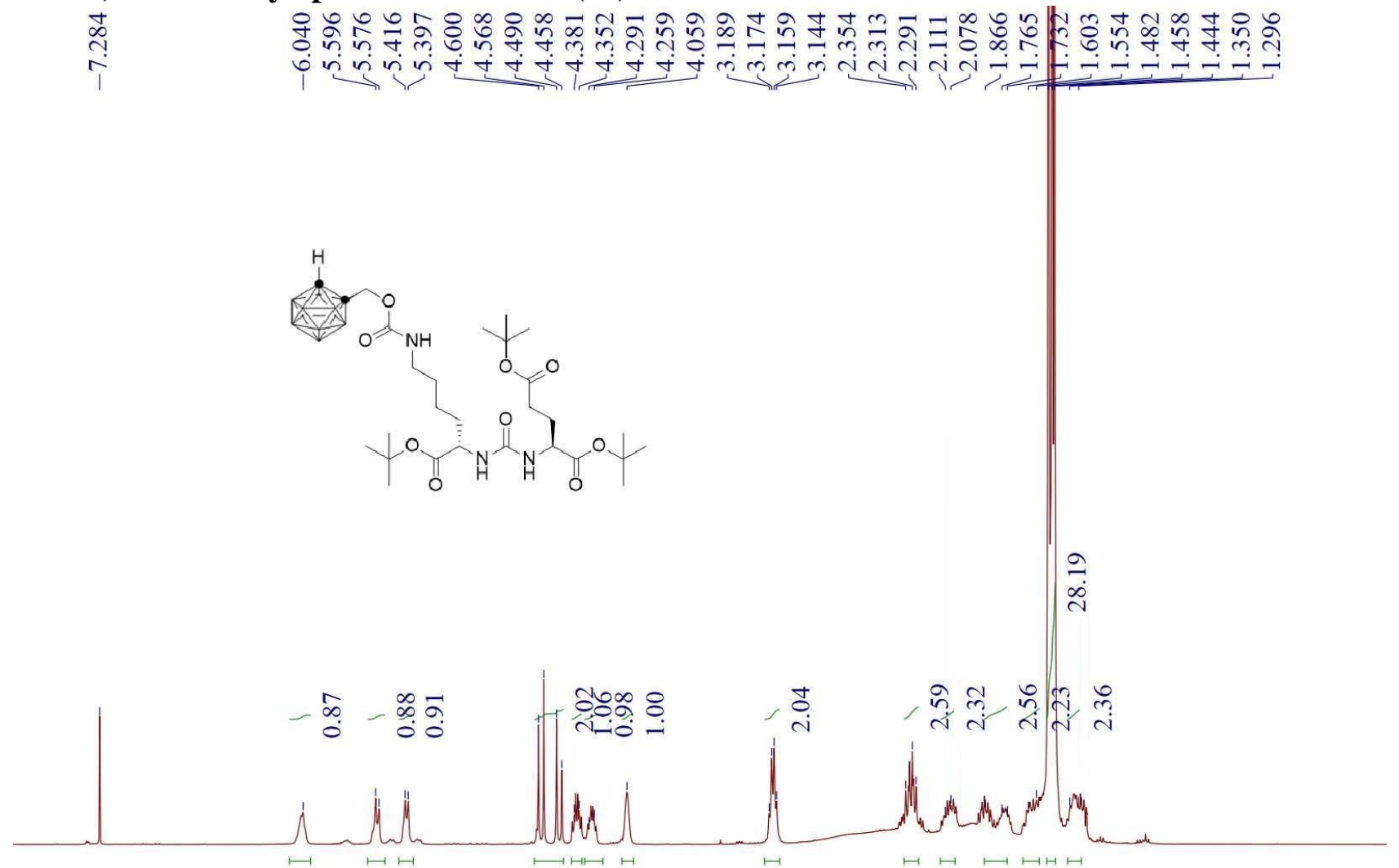

\begin{tabular}{|c|c|c|c|c|c|c|c|c|c|c|c|c|c|c|c|c|}
\hline 7.5 & 7.0 & 6.5 & 6.0 & 5.5 & 5.0 & 4.5 & 4.0 & 3.5 & 3.0 & 2.5 & 2.0 & 1.5 & 1.0 & 0.5 & 0.0 & -0.5 \\
\hline & 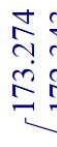 & & 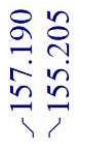 & & & & & 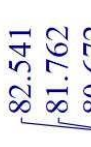 & 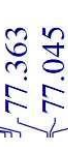 & 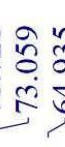 & $\begin{array}{l}n \\
m \\
n \\
n \\
n\end{array}$ & $\begin{array}{l}0 \\
2 \\
0 \\
0 \\
0 \\
0\end{array}$ & 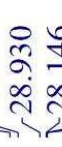 & 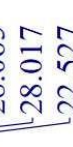 & & \\
\hline
\end{tabular}

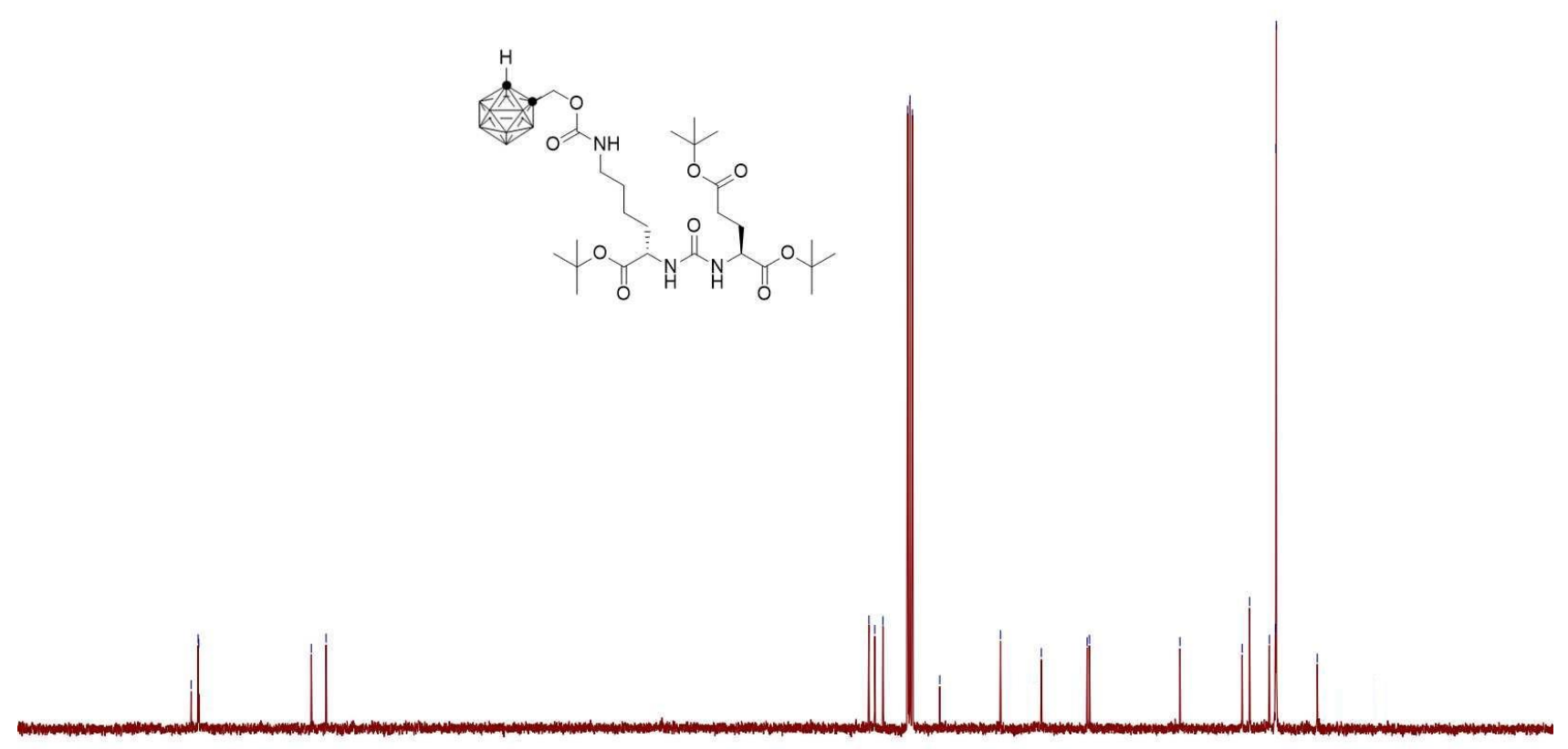

$\begin{array}{llllllllllllllllllll}190 & 180 & 170 & 160 & 150 & 140 & 130 & 120 & 110 & 100 & 90 & 80 & 70 & 60 & 50 & 40 & 30 & 20 & 10 & 0\end{array}$


(S)-2-(1-((S)-1-Carboxy-5-((1,2-dicarba-closo-dodecarboranyl) methylcarbamate)pentyl)ureido) pentanedioic acid (1g)

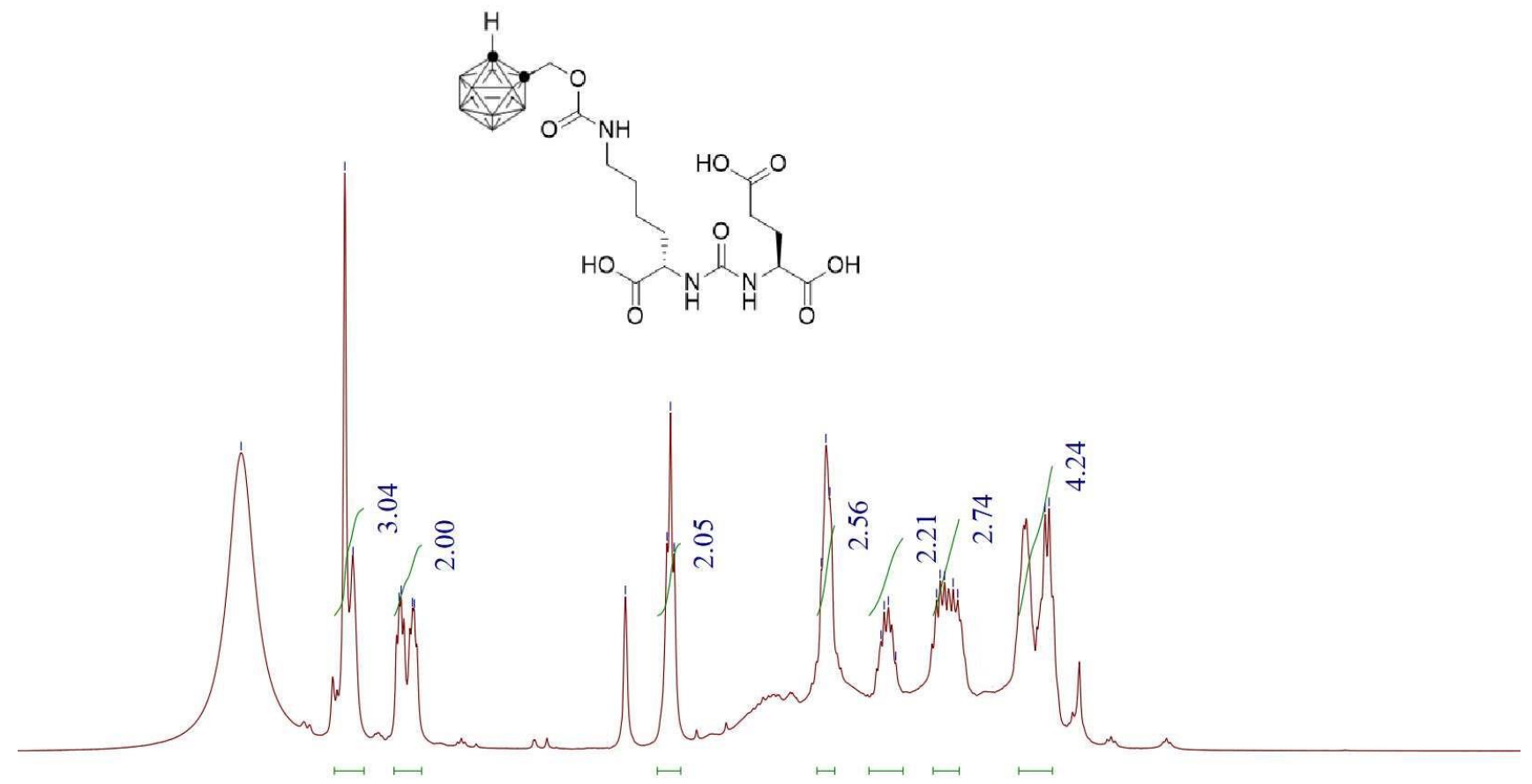

\begin{tabular}{|c|c|c|c|c|c|c|c|c|c|c|c|c|c|c|c|c|}
\hline 5.8 & 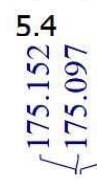 & $\begin{array}{l}5.0 \\
\stackrel{n}{\Xi} \\
\stackrel{ \pm}{ \pm}\end{array}$ & $\begin{array}{rl} & 4.6 \\
= & 0 \\
\geqslant & 6 \\
\infty & i \\
\curvearrowleft & \frac{n}{1} \\
1 & 1\end{array}$ & 4.2 & 3.8 & 3.4 & 3.0 & 2.6 & 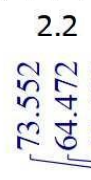 & 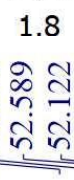 & $\begin{array}{l}1.4 \\
\infty \\
\infty \\
\infty \\
\infty \\
\infty \\
+5 \\
+5 \\
\end{array}$ & 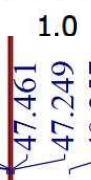 & 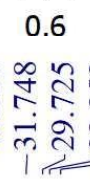 & 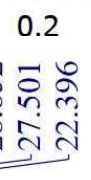 & -0.2 & $-0 . \epsilon$ \\
\hline
\end{tabular}

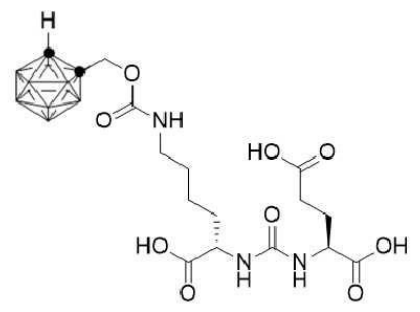


(S)-2-(1-((S)-1-tert-B utylcarboxy-5-((1,2-dicarba-closo-dodecarbo rany l)methyl-(6-amino-6oxohexyl)carbamate)pentyl)ureido) di-tert-butyl pentanedioic acid (16)

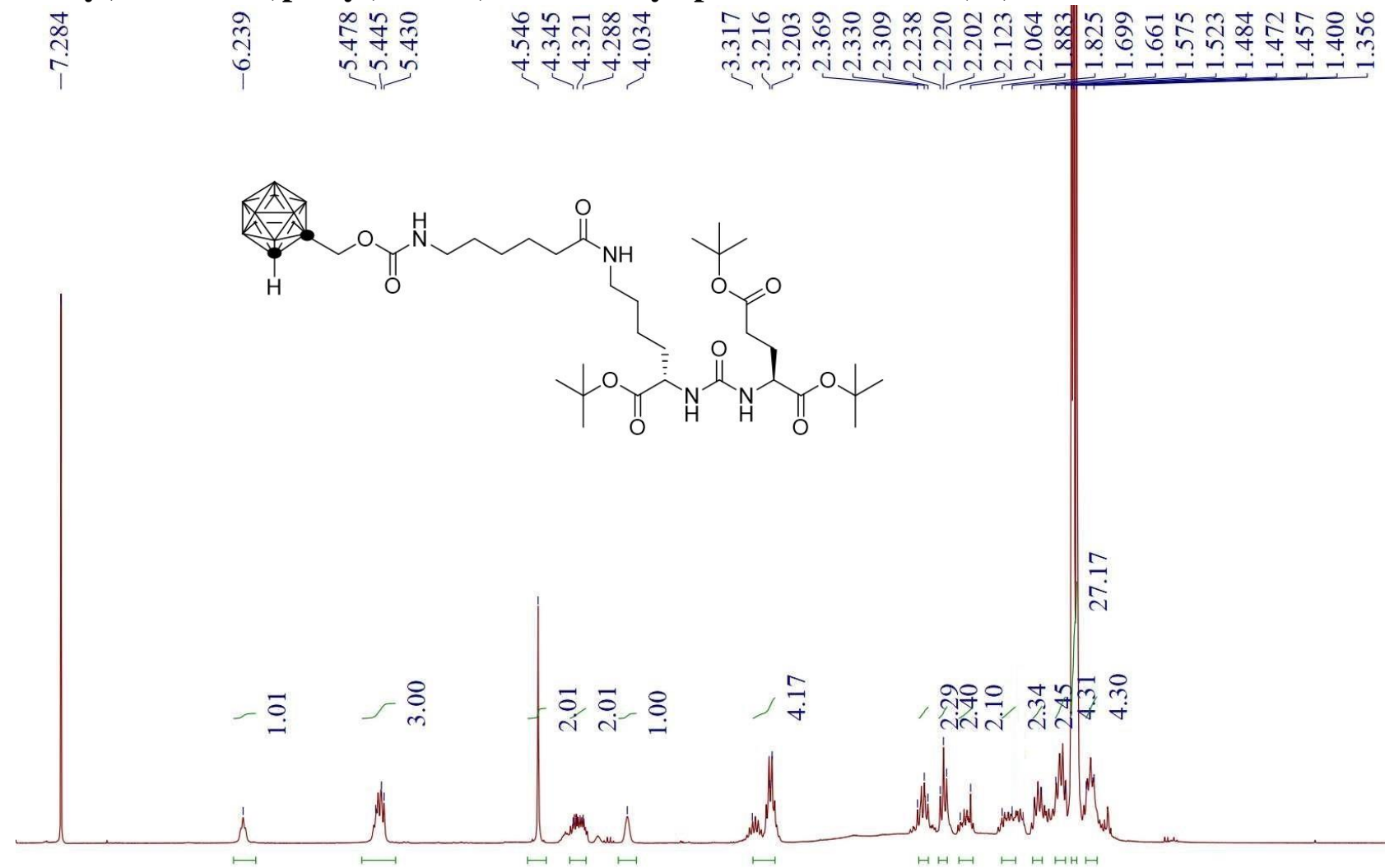

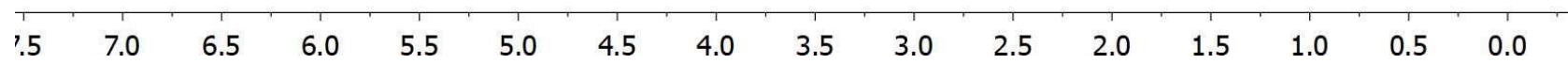
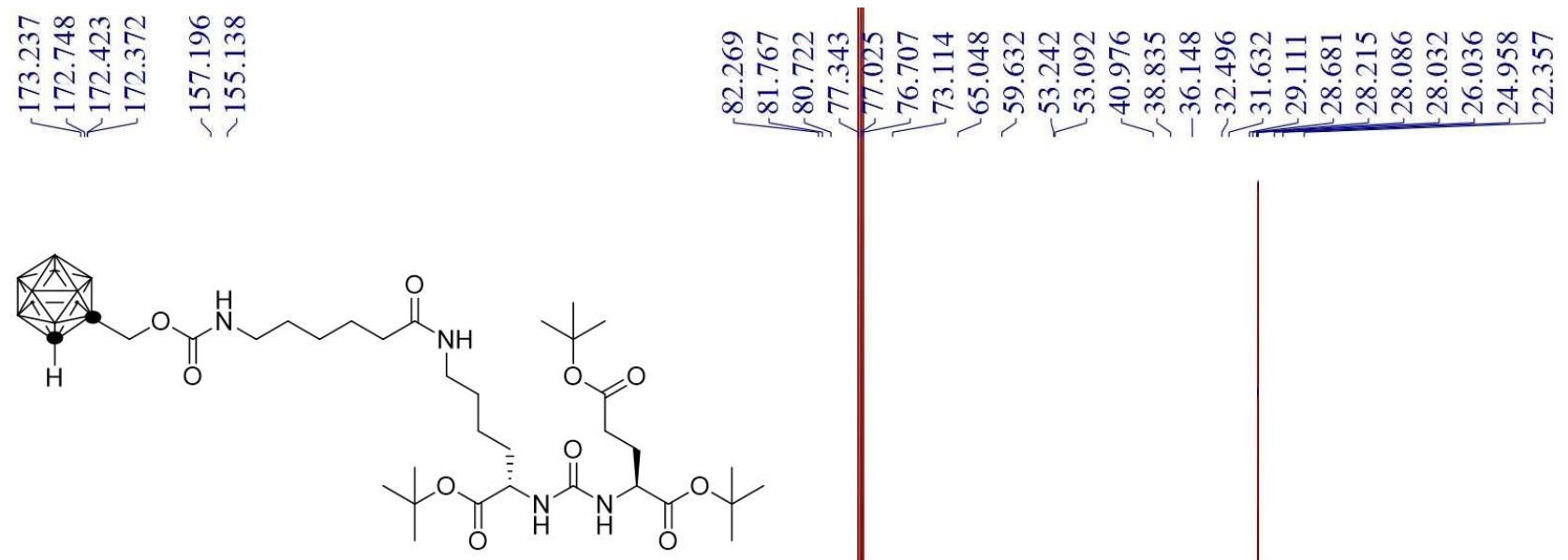

$\begin{array}{llllllllllllllllllll}180 & 170 & 160 & 150 & 140 & 130 & 120 & 110 & 100 & 90 & 80 & 70 & 60 & 50 & 40 & 30 & 20 & 10 & 0 & -11\end{array}$


(S)-2-(1-((S)-1-Carboxy-5-((1,2-dicarba-closo-dodecarboranyl)methyl-(6-amino-6-oxohexyl) carbamate)pentyl)ureido) pentanedioic acid (1h)
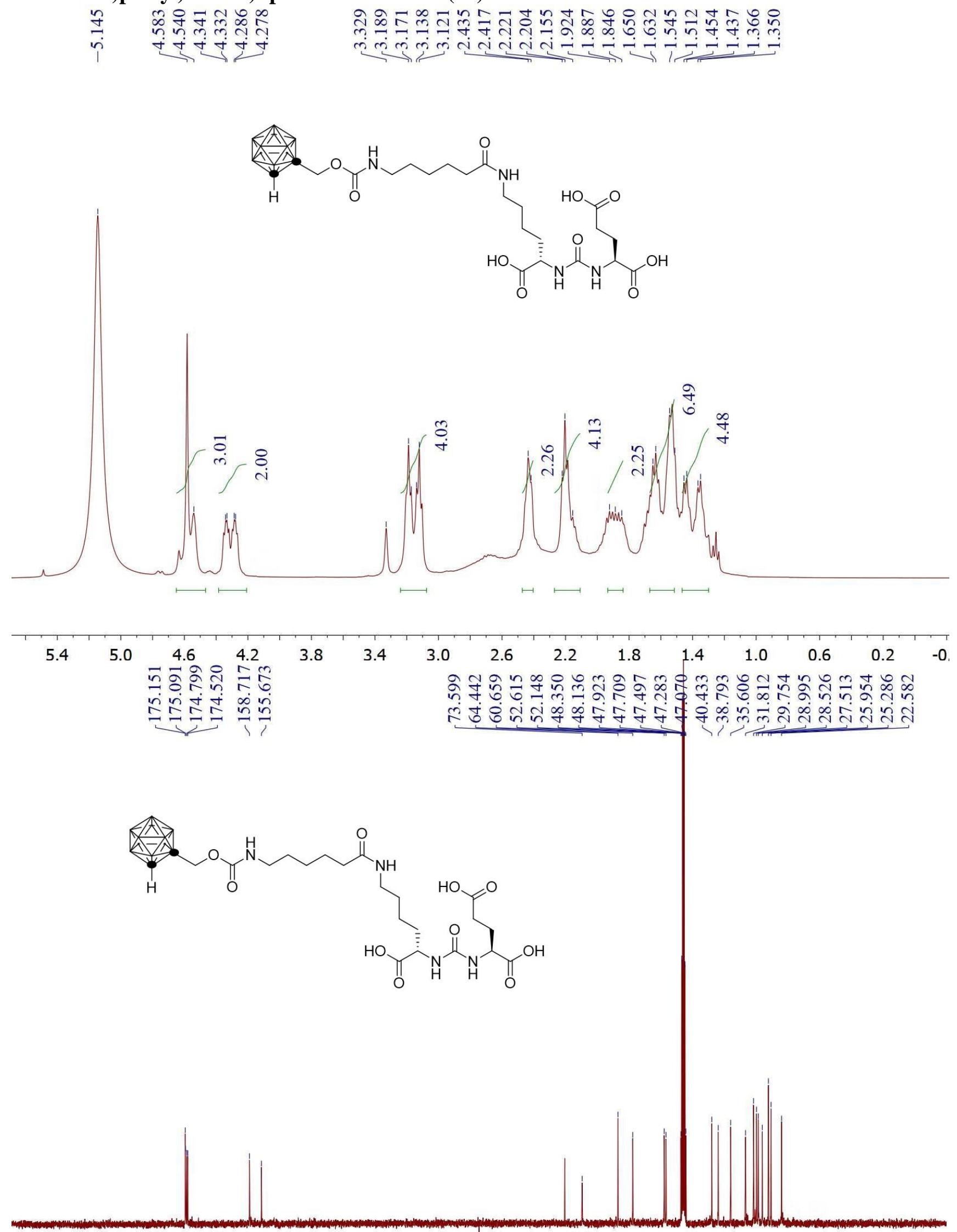